\title{
Investigation and simulation of the Planetary Combination Hybrid Electric Vehicle
}

\author{
Csaba Toth-Nagy \\ West Virginia University
}

Follow this and additional works at: https://researchrepository.wvu.edu/etd

\section{Recommended Citation}

Toth-Nagy, Csaba, "Investigation and simulation of the Planetary Combination Hybrid Electric Vehicle" (2000). Graduate Theses, Dissertations, and Problem Reports. 1143.

https://researchrepository.wvu.edu/etd/1143

This Thesis is protected by copyright and/or related rights. It has been brought to you by the The Research Repository @ WVU with permission from the rights-holder(s). You are free to use this Thesis in any way that is permitted by the copyright and related rights legislation that applies to your use. For other uses you must obtain permission from the rights-holder(s) directly, unless additional rights are indicated by a Creative Commons license in the record and/ or on the work itself. This Thesis has been accepted for inclusion in WVU Graduate Theses, Dissertations, and Problem Reports collection by an authorized administrator of The Research Repository @ WVU. For more information, please contact researchrepository@mail.wvu.edu. 


\title{
Investigation and Simulation of the Planetary Combination Hybrid Electric Vehicle
}

Csaba Tóth-Nagy

\author{
Thesis submitted to the \\ College of Engineering and Mineral Resources \\ at West Virginia University \\ in partial fulfillment of the requirements \\ for the degree of \\ Master of Science \\ in \\ Mechanical Engineering \\ Christopher M. Atkinson, Ph.D., Chair \\ Nigel N. Clark, Ph.D. \\ Victor H. Mucino, Ph.D. \\ Department of Mechanical and Aerospace Engineering \\ Morgantown, West Virginia \\ 2000
}

Keywords: Hybrid, HEV, Simulation, Planetary, PC-Hybrid

Copyright 2000 Csaba Tóth-Nagy 


\begin{abstract}
Investigation and Simulation of the Planetary Combination Hybrid Electric Vehicle
\end{abstract}

\title{
Csaba Tóth-Nagy
}

The purpose of this study was the detailed examination of a Planetary Combination Hybrid Electric Vehicle design (PC-Hybrid). The PC-Hybrid unites all the advantages of the existing hybrid electric vehicle powertrain concepts, such as series, parallel and combination, while eliminating the disadvantages of each.

The PC-Hybrid powertrain is built up of an internal combustion engine, and two electric motor/alternators connected together via a planetary gear set. Several different powertrain configuration layouts were investigated as possible setups of the PC-Hybrid and the two most promising ones were chosen for further investigation and simulation. A control strategy has been developed for the optimal operation PC-Hybrid configurations. A computer program was written to simulate the fuel economy of the PC-Hybrid.

A Hybrid Vehicle Simulator, HVSim (developed at WVU), was used as the basis of the computer simulation and was used to compare the fuel consumption of the PC-Hybrid design to a baseline conventional vehicle setup as well as to the currently existing hybrid electric vehicle configurations. The program uses a backward-looking simulation model that calculates the speed and torque required of the engine, the motor and the alternator for a given driving cycle. Once the engine, motor and alternator speed and torque are calculated, HVSim uses efficiency maps of the engine and motor to define their efficiency. Using the instantaneous efficiency HVSim defines the power loss in each component and calculates the fuel consumption of the simulated vehicle.

The simulation results show that the fuel economy of the PC-Hybrid is better than that of a comparable Series HEV on the FTP City cycle and better than that of a comparable Parallel HEV on the Highway FET cycle while maintaining similar performance to the stock conventional vehicle. In addition the exhaust gas emissions may be reduced, compared to conventional vehicle or a parallel $\mathrm{HEV}$, due to the reduced requirement for transient engine operation. 


\section{Table of Contents}

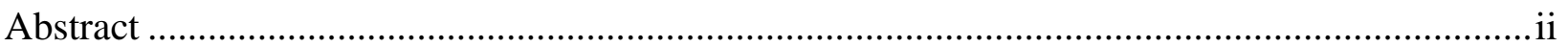

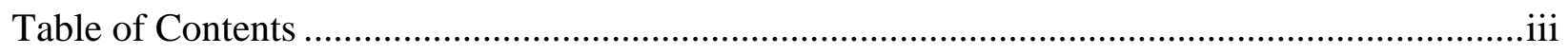

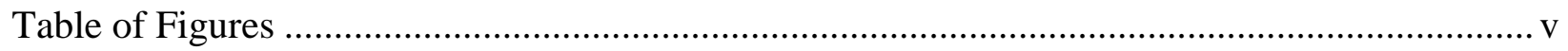

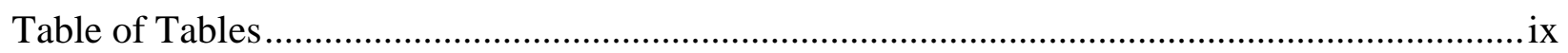

Table of Pictures...........................................................................................................

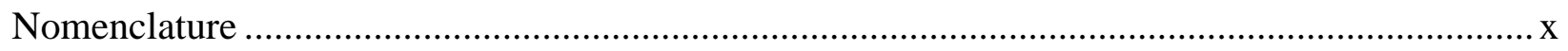

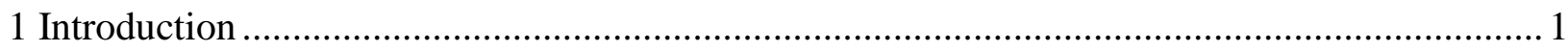

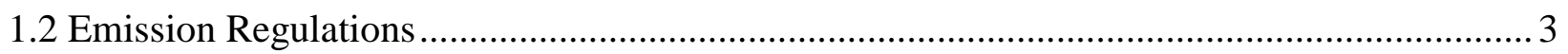

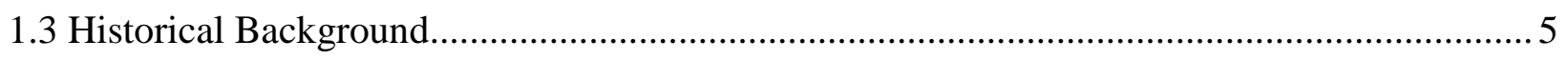

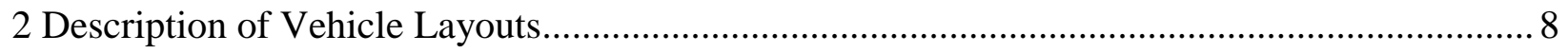

2.1 The Advantages and Disadvantages of Conventional Vehicles....................................... 8

2.2 The Advantages and Disadvantages of Electric Vehicles ............................................. 9

2.3 The Advantages and Disadvantages of Series HEVs................................................. 13

2.4 The Advantages and Disadvantages of Parallel HEVs ................................................. 14

2.5 The Potential Advantages of Combination HEV s........................................................ 18

3 An Analytical Investigation of the Planetary Combination Hybrid Electric Vehicle ............... 22

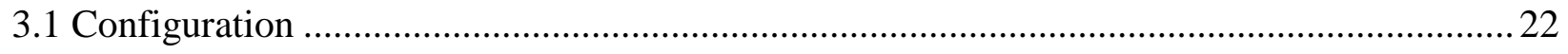

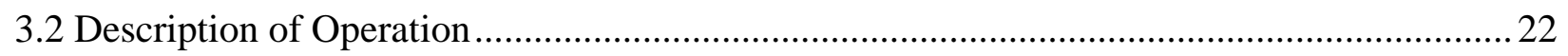

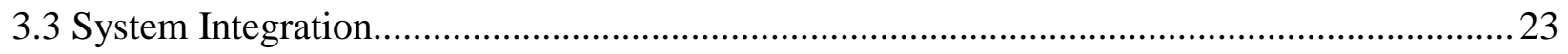

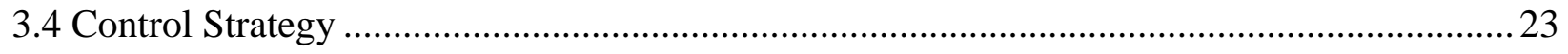

3.5 Flow Chart of the Hybrid Control ......................................................................... 25

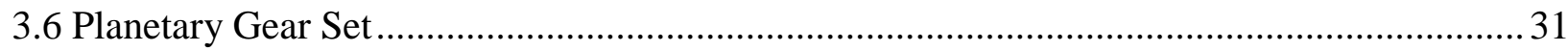


3.7 Planetary Configurations.

3.8 Configuration 1. (Engine on the sun, Alternator on the carrier, Motor on the ring) ...............38

3.9 Configuration 2. (Engine on the ring, Alternator on the carrier, Motor on the sun) ...............40

3.10 Configuration 3. (Engine on the sun, Alternator on the ring, Motor on the carrier. ) ...........42

3.11 Configuration 4. (Engine on the ring, Alternator on the sun, Motor on the carrier) .............45

3.12 Configuration 5. (Engine on the carrier, Alternator on the ring, Motor on the sun) .............47

3.13 Configuration 6. (Engine on the carrier, Alternator on the sun, Motor on the ring) ..............50

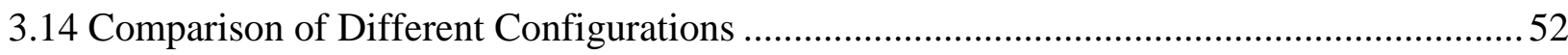

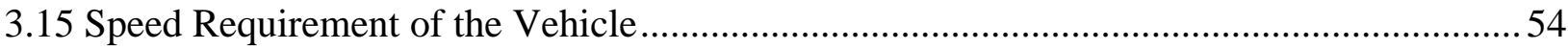

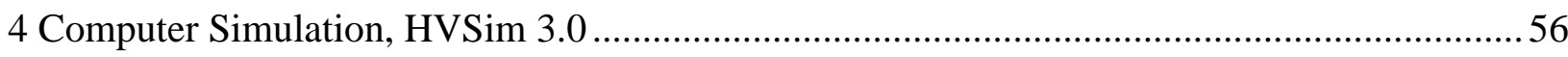

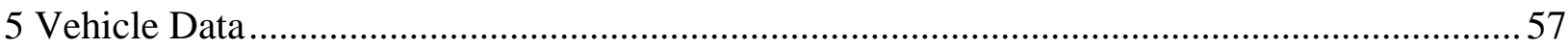

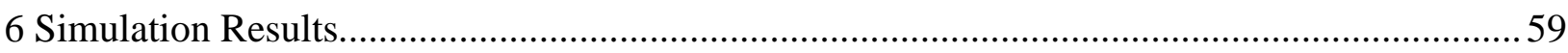

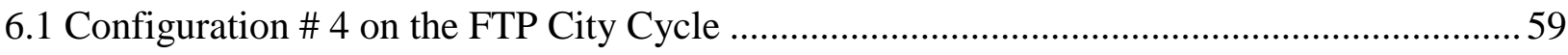

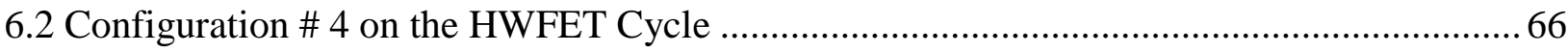

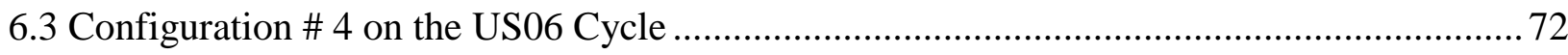

6.3.1 Configuration \# 4 on a 5\% grade at $55 \mathrm{mph}$ steady speed .................................................. 78

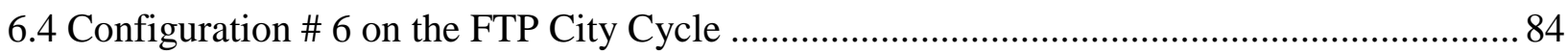

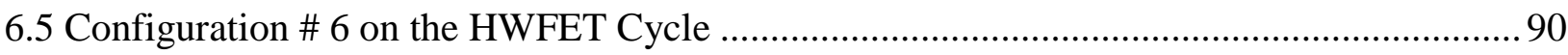

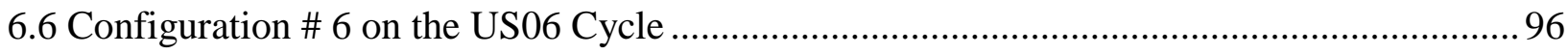

6.7 Configuration \# 6 on a 5\% grade at 55 mph steady speed .................................................. 102

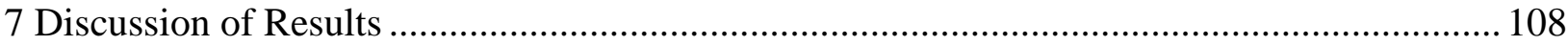

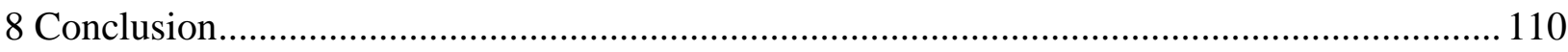

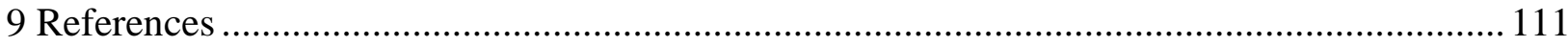




\section{Table of Figures}

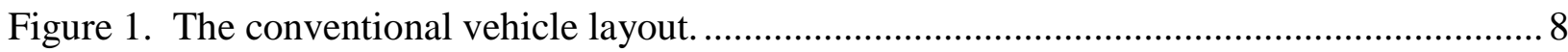

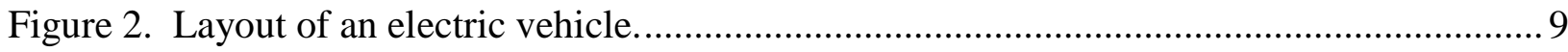

Figure 3. Power flow diagram for a typical series hybrid electric vehicle.............................. 13

Figure 4. Efficiency map of the Detroit Diesel Corporation 642 engine. ............................... 14

Figure 5. Power flow diagram for parallel HEV when the electric motor is before the

transmission and it assists the internal combustion engine................................................ 16

Figure 6. Power flow diagram for parallel HEV when the ICE assists electric motor.............. 16

Figure 7. Power Flow Diagram for the Series-Parallel HEV ............................................... 18

Figure 8. Power Flow Diagram for the Planetary Combination Hybrid. .................................. 20

Figure 9. The integrated design arrangement of the PC Hybrid. .......................................... 23

Figure 10. The primary control loop of the PC-Hybrid is based on battery state of charge....... 25

Figure 11. Flow chart of the Electric Vehicle operation...................................................26

Figure 12. Flow chart of the vehicle control as an HEV ................................................. 27

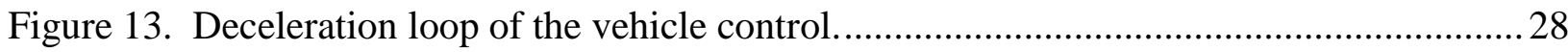

Figure 14. Acceleration loop for the PC-Hybrid in hybrid mode. ........................................ 30

Figure 14.1. A possible two-mode, compound-split, electro-mechanical, vehicular transmissions. [24] 35

Figure 15. Configuration 1. Engine on the sun, Alternator on the carrier, Motor on the ring.

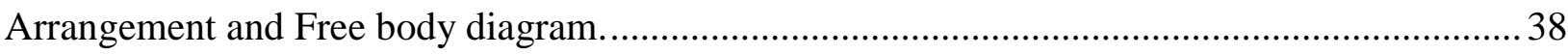

Figure 16. Configuration 2. Engine on the ring, Alternator on the carrier, Motor on the sun.

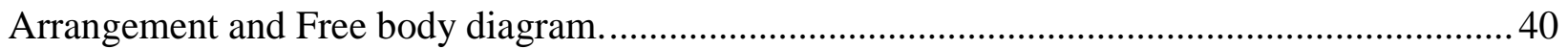


Figure 17. Configuration 3. Engine on the sun, Alternator on the ring, Motor on the carrier.

Arrangement and Free body diagram.

Figure 18. Configuration 4. Engine on the ring, Alternator on the sun, Motor on the carrier.

Arrangement and Free body diagram. 45

Figure 19. Configuration 5. Engine on the carrier, Alternator on the ring, Motor on the sun.

Arrangement and Free body diagram

Figure 20. Configuration 6. Engine on the carrier, Alternator on the sun, Motor on the ring.

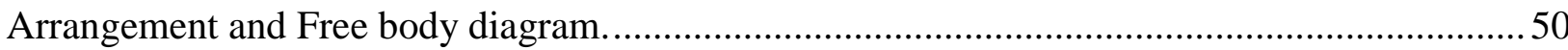

Figure 21. Speed vs. time on the FTP city cycle .........................................................5

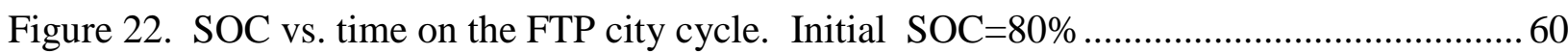

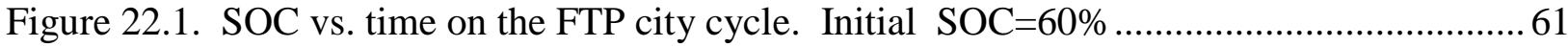

Figure 23. Engine speed, motor speed and alternator speed vs. time on the FTP city cycle......62

Figure 24. Engine torque, motor torque, and alternator torque vs. time on the FTP city cycle...62

Figure 25. Engine efficiency as the function of engine speed and engine torque 63

Figure 26. Motor efficiency as the function of motor speed and motor torque....................... 64

Figure 27. Alternator efficiency as the function of alternator speed and alternator torque. ........65

Figure 28. Speed vs. time on the HWFET test cycle. ....................................................... 66

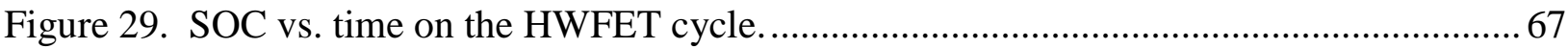

Figure 30. Engine speed, motor speed and alternator speed vs. time on the HWFET cycle. ......68

Figure 31. Engine torque, motor torque and alternator torque vs. time on the HWFET cycle.... 68

Figure 32. Engine efficiency as the function of engine speed and engine torque.....................69

Figure 33. Motor efficiency as the function of motor speed and motor torque....................... 70

Figure 34. Alternator efficiency as the function of alternator speed and alternator torque. ........71

Figure 35. Speed vs. time on the US06 test cycle........................................................ 72 


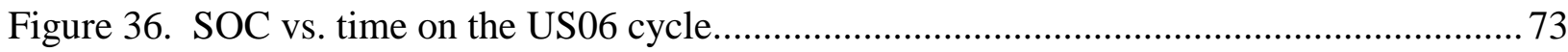

Figure 37. Engine speed, motor speed and alternator speed vs. time on the US06 cycle............ 74

Figure 38. Engine torque, motor torque and alternator torque vs. time on the US06 cycle..........74

Figure 39. Engine efficiency as the function of engine speed and engine torque.........................75

Figure 40. Motor efficiency as the function of motor speed and motor torque. ...........................76

Figure 41. Alternator efficiency as the function of alternator speed and alternator torque. .........77

Figure 41.1. Speed vs. time on a 5\% grade at 55 mph steady speed...........................................78

Figure 41.2. SOC vs. time on a 5\% grade at $55 \mathrm{mph}$ steady speed............................................ 79

Figure 41.3. Engine speed, motor speed and alternator speed vs. time on a 5\% grade at $55 \mathrm{mph}$

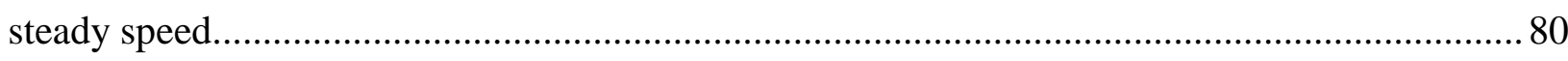

Figure 41.4. Engine torque, motor torque and alternator torque vs. time on a $5 \%$ grade at $55 \mathrm{mph}$

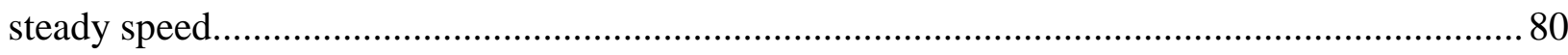

Figure 41.5. Engine efficiency as the function of engine speed and engine torque...................... 81

Figure 41.6. Motor efficiency as the function of motor speed and motor torque.........................8 82

Figure 41.7. Alternator efficiency as the function of alternator speed and alternator torque. ......83

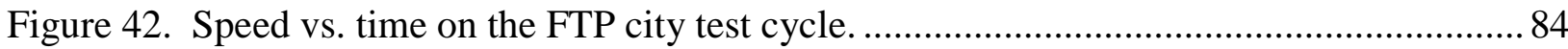

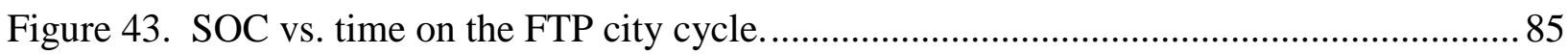

Figure 44. Engine speed, motor velocity and alternator speed vs. time on the FTP city cycle. .. 86

Figure 45. Engine torque, motor torque and alternator torque vs. time on the FTP city cycle.... 86

Figure 47. Motor efficiency as the function of motor speed and motor torque............................. 88

Figure 48. Alternator efficiency as the function of alternator speed and alternator torque. .........89

Figure 49. Speed vs. time on the HWFET test cycle ...............................................................90

Figure 50. SOC vs. time on the HWFET cycle

Figure 51. Engine speed, motor speed and alternator speed vs. time on the HWFET cycle. ...... 92 
Figure 52. Engine torque, motor torque and alternator torque vs. time on the HWFET cycle....92

Figure 53. Engine efficiency as the function of engine speed and engine torque.................... 93

Figure 54. Motor efficiency as the function of motor speed and motor torque........................ 94

Figure 55. Alternator efficiency as the function of alternator speed and alternator torque. ........95

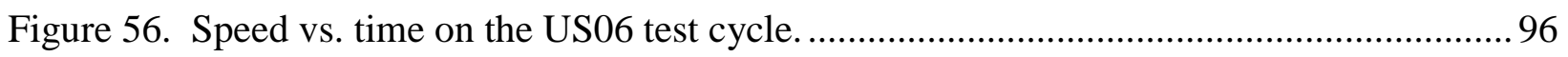

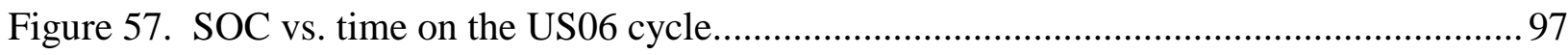

Figure 58. Engine speed, motor speed and alternator speed vs. time on the US06 cycle........... 98

Figure 59. Engine torque, motor torque and alternator torque vs. time on the US06 cycle.........98

Figure 60. Engine efficiency as the function of engine speed and engine torque.....................99

Figure 61. Motor efficiency as the function of motor speed and motor torque...................... 100

Figure 62. Alternator efficiency as the function of alternator speed and alternator torque...... 101

Figure 62.1. Speed vs. time on a 5\% grade at 55 mph steady speed................................... 102

Figure 62.2. SOC vs. time on a 5\% grade at $55 \mathrm{mph}$ steady speed..................................... 103

Figure 62.3. Engine speed, motor speed and alternator speed vs. time on a $5 \%$ grade at 55 mph

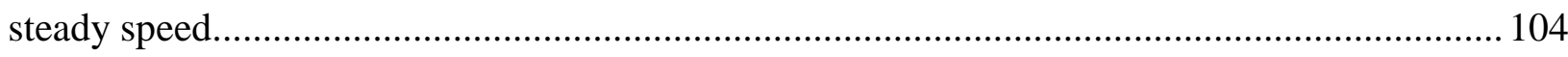

Figure 62.4. Engine torque, motor torque and alternator torque vs. time on a $5 \%$ grade at $55 \mathrm{mph}$

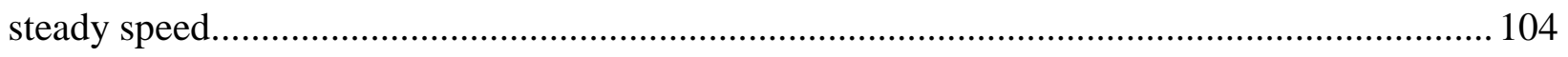

Figure 62.5. Engine efficiency as the function of engine speed and engine torque.................. 105

Figure 62.6. Motor efficiency as the function of motor speed and motor torque.................... 106

Figure 62.7. Alternator efficiency as the function of alternator speed and alternator torque. ... 107 


\section{Table of Tables}

Table 1. California LEV II emission standards for light and medium duty diesel vehicles.

(g/mile) Durability 120,000 miles. Year 2004-2010. [9] ................................................... 4

Table 2. EU Emission standards for diesel cars and light duty vehicles. (g/km) Year 2000. [9] 4

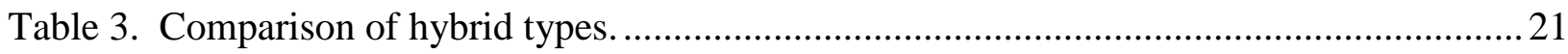

Table 3.1 Possible hybrid modes of the configuration can be seen in Figure 14.1................... 34

Table 3.2. Components of the two-mode compound-split electro-mechanical, vehicular

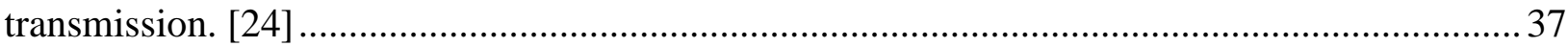

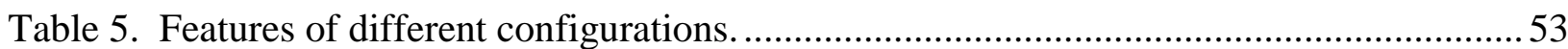

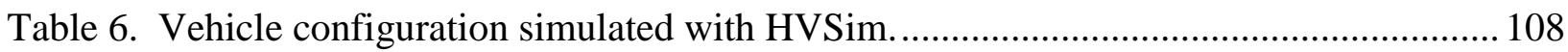

Table 7. Fuel economy of the different configurations on the FTP city, on the FTP highway and

on the US06 cycles. These fuel economy results are not corrected by any EPA factors. 109

\section{Table of Pictures}

Picture 1. Planetary gear set. 


\section{Nomenclature}

\begin{tabular}{|c|c|}
\hline APS & -Accelerator Pedal Signal \\
\hline Alt.S & -Alternator Speed \\
\hline Alt.T & -Alternator Torque \\
\hline$\alpha$ & -Grade of the road \\
\hline BPS & -Brake Pedal Signal \\
\hline $\mathrm{C}$ & -Capacity \\
\hline $\mathrm{C}_{\mathrm{d}}$ & -Drag Coefficient \\
\hline $\mathrm{CO}$ & -Carbon monoxide \\
\hline $\mathrm{CO}_{2}$ & -Carbon dioxide \\
\hline CVT & -Continuously Variable Transmission \\
\hline Eng.S & -Engine Speed \\
\hline Eng.T & -Engine Torque \\
\hline $\mathrm{EV}$ & -Electric Vehicle \\
\hline EU & -European Union \\
\hline $\mathrm{F}_{\mathrm{c}}$ & -Force on the planetary Carrier \\
\hline $\mathrm{F}_{\mathrm{s}}$ & -Force on the Sun gear \\
\hline $\mathrm{F}_{\mathrm{r}}$ & -Force on the Ring gear \\
\hline FTP & -Federal Test Procedure \\
\hline$\sigma$ & -gravitational force \\
\hline & -HydroCarbons \\
\hline & -Hybrid Electric Vehicle \\
\hline
\end{tabular}




\begin{tabular}{|c|c|}
\hline HWFET & -High Way Federal Emission Test \\
\hline ICE & -Internal Combustion Engine \\
\hline Mot.S & -Motor Speed \\
\hline Mot.T & -Motor Torque \\
\hline$\mu$ & -Coefficient of rolling resistance \\
\hline LEV & -Low Emission Vehicle \\
\hline $\mathrm{m}$ & -mass \\
\hline NMOG & -Non Methane OrGanic compound \\
\hline NOx & -Oxides of Nitrogen \\
\hline PC Hybrid & -Planetary Combination Hybrid Electric Vehicle \\
\hline PM & -Particulate Matter \\
\hline PNGV & -Partnership for a New Generation of Vehicles \\
\hline $\mathrm{R}_{\mathrm{c}}$ & -Radius of the planetary Carrier \\
\hline $\mathrm{R}_{\mathrm{s}}$ & -Radius of the Sun \\
\hline $\mathrm{R}_{\mathrm{r}}$ & -Radius of the Ring \\
\hline$\rho$ & -Density of air \\
\hline $\mathrm{S}_{\mathrm{c}}$ & -Speed of the planetary Carrier \\
\hline $\mathrm{S}_{\mathrm{s}}$ & -Speed of the Sun \\
\hline $\mathrm{S}_{\mathrm{c}}$ & -Speed of the Ring \\
\hline SOC & -State Of Charge \\
\hline SULEV & -Super Ultra Low Emission Vehicle \\
\hline $\mathrm{T}_{\mathrm{c}}$ & -Torque on the planetary Carrier \\
\hline $\mathrm{T}_{\mathrm{s}}$ & -Torque on the Sun gear \\
\hline $\mathrm{T}_{\mathrm{r}}$ & -Torque on the Ring gear \\
\hline
\end{tabular}




$\begin{array}{ll}\text { ULEV } & \text {-Ultra Low Emission Vehicle } \\ \mathrm{v} & \text {-velocity } \\ \mathrm{V} & \text {-Voltage } \\ \text { ZEV } & \text {-Zero Emission Vehicle }\end{array}$




\section{Introduction}

The high level of air pollution caused by the ever increasing number of vehicles on the roads have generated a need for alternative power sources in transportation offering better fuel efficiency and lower exhaust emissions. Governments have designed regulations to keep the emissions of the vehicles on the public roads low. This forces automobile manufacturers to develop new propulsion technologies.

Also decreasing crude oil supplies urge the development of alternative fuel vehicles and require better fuel economy from present conventional vehicles. For this reason a government and industry partnership was formed called Partnership for a New Generation of Vehicles (PNGV). PNGV's goal is to produce prototype vehicles that reach 3 times the fuel economy of today's vehicle.

Electric vehicles seem to be an obvious solution for the problem since the 1980s when semiconductors became usual in power electronics. It is not obvious yet that what will be the energy source of these vehicles. It can be solar, wind, geothermal energy or something that is unknown this time. One thing is for sure: electric vehicles will have energy storage on board. At this point batteries fulfill this task but they are very inefficient, heavy and have low capacity. Today's electric vehicle is limited to approximately 100 miles range and condemned to spend hours being recharged. Customers typically do not tolerate these limitations.

Hybrid vehicles have emerged as the leading technology to solve this problem for the next 10-15 years until high capacity advanced energy storages become available. Hybrid Electric Vehicles use less fuel and produce less emission than conventional vehicles and do not have to be recharged from an off-board electrical source unlike Electric Vehicles. 
The two main configurations of hybrids are the Series Hybrid, which shows excellent fuel consumption in city traffic (transient driving) and the Parallel Hybrid, which consumes significantly less than a conventional vehicle in highway driving (less transient).

Both designs have an internal combustion engine on board as well as an electric motor with an energy storage device. The improvement of their fuel consumption is gained by the optimal use of the engine, by the regenerative braking and by the advanced drive train that is used in Hybrids.

A Combination Hybrid Electric Vehicle design unites all the advantages of both basic modes, thus eliminating the disadvantages of each.

West Virginia University is developing a Combination Hybrid Electric Vehicle for a full size SUV, which will imply the advantages of both basic hybrid configurations. The PCHybrid (Planetary Combination Hybrid) will reach the fuel consumption of the series in city driving and the fuel consumption of the parallel on highway driving while maintaining similar dynamic performance to that of the stock vehicle. 


\subsection{Emission Regulations}

According to present days concept, which is called wells to wheels concept, all emissions must be counted that are involved with the fuel in any kind of form such as production and transportation as well as vehicular exhaust emissions. This sort of calculation is needed because vehicular emissions are getting lower. In some cases, such as in the case of electric vehicles, vehicular emissions become zero or negligible so what really counts is power-plant emissions and emissions from transporting the given fuel.

- Wells to wheels emissions stage by stage [7]

- Feedstock production

- Feedstock transportation

- Fuel distribution

- Vehicular emissions

The wells to wheels emissions that people are concerned about are

- Oxides of nitrogen

- Carbon monoxide

- Hydrocarbons

- Particulate matter

- Carbon dioxide and other greenhouse goses

Oxides of nitrogen, carbon monoxide and the unburned hydrocarbons are poisonous to people, particulate matter causes respiratory diseases such as silicosis, and carbon dioxide is a green house gas that is responsible for global warming [8]. 
Table 1 shows the regulated emissions in California for light duty and medium duty vehicles. California has the most stringent exhaust emission standards in the USA.

\begin{tabular}{|l|l|l|l|l|l|l|}
\hline Weight $[\mathrm{lb}]$ & Category & NMOG & CO & NOx & PM & HCHO \\
\hline$<8,500$ & LEV & 0.090 & 4.2 & 0.07 & 0.01 & 0.018 \\
\hline$<8,500$ & ULEV & 0.055 & 2.1 & 0.07 & 0.01 & 0.011 \\
\hline$<8,500$ & SULEV & 0.010 & 1.0 & 0.02 & 0.01 & 0.004 \\
\hline$<10,000$ & LEV & 0.195 & 6.4 & 0.2 & 0.12 & 0.032 \\
\hline$<10,000$ & ULEV & 0.143 & 6.4 & 0.2 & 0.06 & 0.016 \\
\hline$<10,000$ & SULEV & 0.100 & 3.2 & 0.1 & 0.06 & 0.008 \\
\hline$<14,000$ & LEV & 0.230 & 7.3 & 0.4 & 0.12 & 0.040 \\
\hline$<14,000$ & ULEV & 0.167 & 7.3 & 0.4 & 0.06 & 0.021 \\
\hline$<14,000$ & SULEV & 0.117 & 3.7 & 0.2 & 0.06 & 0.010 \\
\hline
\end{tabular}

Table 1. California LEV II emission standards for light and medium duty diesel vehicles.

(g/mile) Durability 120,000 miles. Year 2004-2010. [9]

Table 2 shows the regulated emissions in the European Union for light duty vehicles and passenger cars.

\begin{tabular}{|l|l|l|l|l|l|l|}
\hline $\begin{array}{l}\text { Weight } \\
{[\mathrm{kg}]}\end{array}$ & Tier & Year & HC+NOx & NOx & CO & PM \\
\hline$<1305$ & Euro II & 1994 & 0.97 & - & 2.72 & 0.14 \\
\hline$<1305$ & Euro III & 2000 & 0.56 & 0.50 & 0.64 & 0.05 \\
\hline$<1305$ & Euro IV & 2005 & 0.30 & 0.25 & 0.50 & 0.025 \\
\hline \multirow{2}{*}{$\begin{array}{l}1305 \\
\text { to } \\
1760\end{array}$} & Euro II & 1994 & 1.40 & - & 5.17 & 0.19 \\
\cline { 2 - 7 } & Euro III & 2001 & 0.72 & 0.65 & 0.80 & 0.07 \\
\hline$>1760$ & Euro IV & 2006 & 0.39 & 0.33 & 0.63 & 0.04 \\
\hline$>1760$ & Euro II & 1994 & 1.70 & - & 6.90 & 0.25 \\
\hline$>1760$ & Euro III & 2001 & 0.86 & 0.78 & 0.95 & 0.10 \\
\hline
\end{tabular}

Table 2. EU Emission standards for diesel cars and light duty vehicles. (g/km) Year 2000. [9] 


\subsection{Historical Background}

The idea of the electric and hybrid electric vehicles is not new. The history goes back to 1790 when Nathan Read made the first drawings of a steam carriage and fifteen years later a self-propelled car was invented. [4] After the first attempts to make self-powered vehicles, which was driven by the steam engine, two main power sources became usual. One of them was the electric motor, and the other one was the internal combustion engine.

The development of the electric motor can be traced back to the Danish scientist Hans Christian Orsted, to the early 19th century, when he discovered that electricity in motion generates a magnetic field. In seeking to demonstrate the converse of this finding, the English physicist and chemist Michael Faraday constructed a primitive model of the electric motor in 1821. In the early 1870 s the first commercially viable electric motor was created by Gramme, a Belgium-born electrical engineer, and the first induction motor was invented by the Czech Telsa in 1888. [3]

The first electric vehicle was made by Professor Stratingh in the Dutch town of Groningen in 1835. Although several electric vehicle manufacturers were established in Europe as well as in America before internal combustion engines became available the electric vehicle did not become a viable option until the Frenchmen, Gaston Plante, and Camille Faure invented (1865) and improved (1881) the storage battery. On the turn of the century (1899) Baker Electric, US manufactured an electric vehicle that was reputedly easy to drive, and could cruise a distance of 80 kilometers when fully charged. Although it seems a little high reference [2] says the vehicle was capable of reaching a top speed of $40 \mathrm{~km} / \mathrm{h}$ top speed. A $1 \mathrm{hp}$ DC motor powered it. Its operating voltage was $20 \mathrm{~V}$. The vehicle had rechargeable batteries as an energy storage device. [2] 
The first successful gas engine was made by Étienne Lenoir in Paris 1859. Although the engine worked it was only in 1878 when it became commercially available due to the work of the German inventor Nikolaus Otto.

In 1892 Rudolf Diesel, also of Germany invented the diesel engine. At first, it was fine coal powder that Diesel injected in the cylinder and later he used oil products.

The use of liquid fuel was exclusively in diesel engine until 1893, when two Hungarian scientists Donát Bánki \& János Csonka invented the carburetor. This made the liquid fuel available for the Otto engine as well. [6]

Various countries claim to be the first to produce a gasoline-powered automobile. Although there is room for argument, Germany's Karl Benz is now accorded this distinction with the three-wheeler he produced in 1886 . The engine, placed over the rear axle, was a horizontal, four-cycle, single-cylinder type with $984 \mathrm{cc}$-volume displacement. The engine was capable of providing $0.9 \mathrm{hp}$ at $400 \mathrm{rpm}$ and could propel the vehicle as fast as $15 \mathrm{mph}$. It was the first automobile equipped with a differential gear. [2]

Between 1890 and 1910, many hybrid electric cars were built. The purpose of hybrids was basically to improve the handicaps of the single propulsion systems. They were a transition between electric and gasoline cars. Electric cars were more expensive than gasoline cars while electric vehicles were considered more reliable, safer and more convenient.

With the development of the starter motor for gasoline cars and their increased range the public interest turned from electric to gasoline after 1913. That was the year when Henry Ford set up the new assembly line for the famous Model T. It took just 93 minutes for a Model T to be assembled. [5]

Electric vehicles and hybrids were forgotten for a long while. Although adventurous engineers never stopped designing electric vehicles, the lack of advanced batteries, lack of 
efficient control and the cheap price of gasoline pushed electric and hybrid electric vehicles into the background until recent years. Nowadays, decreasing crude oil resources and increasing environmental concerns revitalize the concept of electric vehicles. Hybrids have already returned as the first stage of the change. They fulfill the same role now as they did 100 years ago only in reverse. Hybrids were a transition between electric and gasoline vehicles at the turn of the last century. Now they are a transition between gasoline and electric vehicles. 


\section{Description of Vehicle Layouts}

\subsection{The Advantages and Disadvantages of Conventional Vehicles}

Although everybody is familiar with conventional vehicles, their features are summarized here to form a basis of comparison. Figure 1 shows the layout of a conventional vehicle.

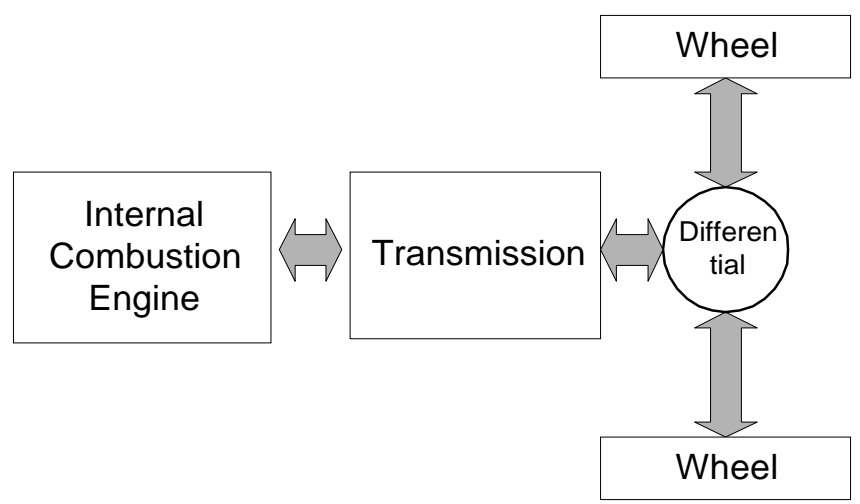

\section{$\square$ Mechanical Energy Flow}

Figure 1. The conventional vehicle layout.

In a conventional vehicle an internal combustion engine drives a transmission that drives the differential that drives the wheels. The engine can be diesel or gasoline. The transmission can be manual, automatic or continuously variable transmission (CVT). A conventional vehicle is relatively cheap and easy to control. It does not require extra control besides the engine control unit and, the automatic transmission control unit if an automatic transmission is applised. 


\subsection{The Advantages and Disadvantages of Electric Vehicles}

The electric vehicle has a powertrain consists of an electric motor, an energy storage device and a controller. The electric motor provides the power required to propel the vehicle. The energy storage device stores the electrical energy and supplies it to the electric motor. Although the energy storage device could be a flywheel or an ultra-capacitor as well it is usually a battery pack. Figure 2 shows the layout of a typical electric vehicle.

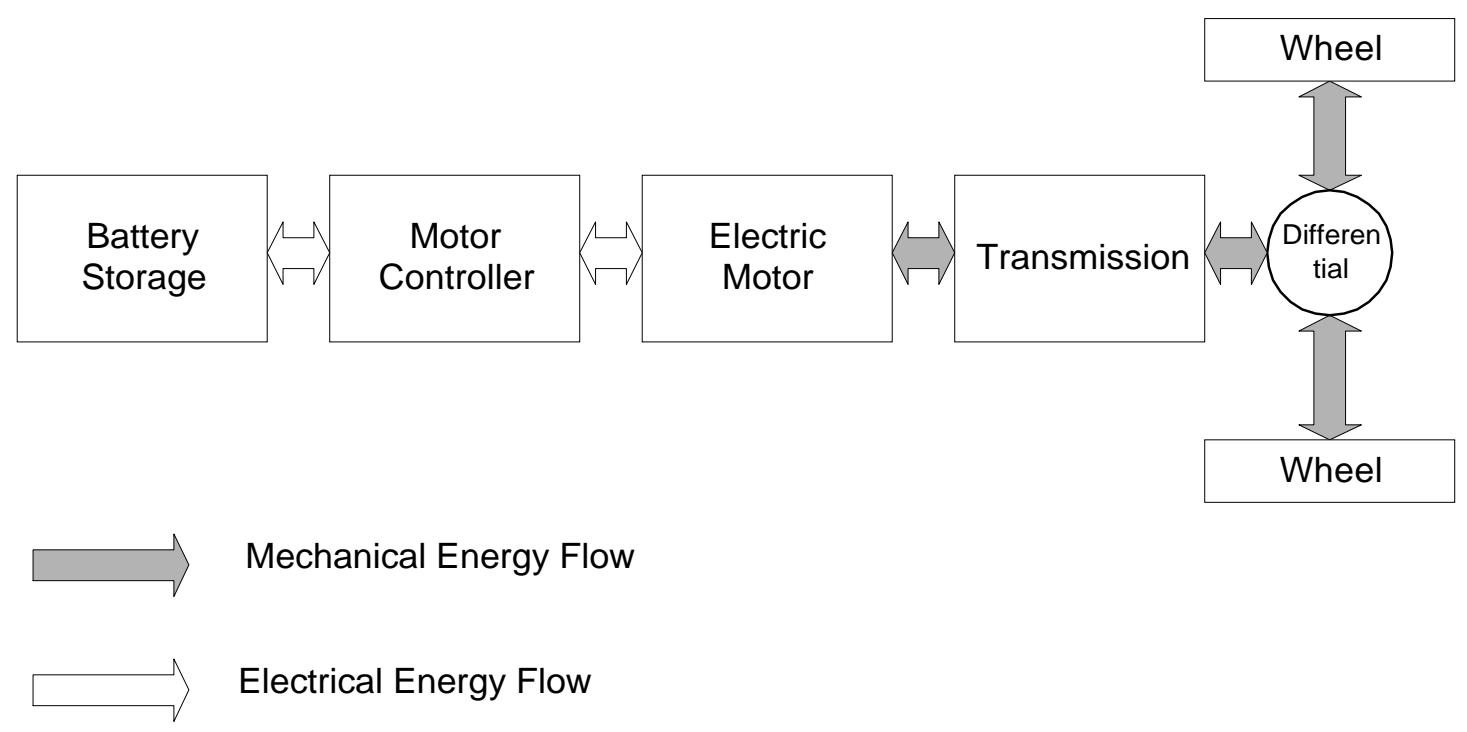

Figure 2. Layout of an electric vehicle.

The main advantage of electric vehicles is that they don't emit exhaust gases from their tailpipes. Although, they are called zero emission vehicles (ZEVs), the electrical energy production is not free of emissions. According the "wells to wheels" concept the emissions of the vehicle must be increased by the emissions of any kind related to the vehicle such as production and transportation. In that sense EVs are not zero emission vehicles. (See chapter 1.2)

The other advantage of EVs is their noiseless operation. EVs would decrease the noise level in cities significantly. 
EVs are competitive with conventional vehicles in complexity and price and even lees complicated to control. The disadvantage of the electric vehicle is its short range. It is limited by the capacity of the battery pack. Present battery technology provides approximately 100 miles on a single charge depending on vehicle size, battery size and capacity and driving conditions. For example GM claims that the EV1 has a range 160 miles. [17] The range of an EV can be determined as it is shown in Equation 1 using the data of the EV1 assuming the vehicle is cruising $65 \mathrm{mph}$ on flat road with no wind.

\section{EV1 data [18]}

Mass:

Drag coefficient:

Frontal area:

Rolling resistance:

Grade:

Air density:

Velocity of the vehicle:

Battery voltage:

Battery capacity:

$$
\mathrm{m}=1350 \mathrm{~kg}
$$$$
\mathrm{C}_{\mathrm{d}}=0.019
$$

$$
A=1.7 \mathrm{~m}^{2}
$$

$\mu=0.018$

$\alpha=0^{\circ}$

$$
\rho=1.23 \mathrm{~kg} / \mathrm{m}^{3}
$$

$\mathrm{v}=65 \mathrm{mph}=29 \mathrm{~m} / \mathrm{s}$

$\mathrm{V}=343$ volts

$\mathrm{C}=77 \mathrm{Ah}$

The power required to drive the vehicle be calculated using the driving resistance equation.

$$
\begin{aligned}
& \mathrm{P}=\mu * \mathrm{~m} * \mathrm{~g} * \cos (\alpha) * \mathrm{v}+\frac{1}{2} * C_{\mathrm{d}} * \rho * \mathrm{~A} * \mathrm{v}^{3}+m^{*} \mathrm{a} * \mathrm{v}+\mathrm{m}^{*} \mathrm{~g} * \sin (\alpha) * \mathrm{v} \\
& \mathrm{P}=0.018 * 1350 \mathrm{~kg} * 9.81 \frac{\mathrm{m}}{\mathrm{s}^{2}} * \cos (0) * 29 \frac{\mathrm{m}}{\mathrm{s}}+\frac{1}{2} * 0.019 * 1.23 \frac{\mathrm{kg}}{\mathrm{m}^{3}} * 1.7 \mathrm{~m}^{2} *\left(29 \frac{\mathrm{m}}{\mathrm{s}}\right)^{3}+ \\
& +1350 \mathrm{~kg} * 0 \frac{\mathrm{m}}{\mathrm{s}^{2}} * 29 \frac{\mathrm{m}}{\mathrm{s}}+1350 \mathrm{~kg} * 9.81 \frac{\mathrm{m}}{\mathrm{s}^{2}} * \sin 0 * 29 \frac{\mathrm{m}}{\mathrm{s}}= \\
& \mathrm{P}=7397.6 \mathrm{~W}
\end{aligned}
$$


The total energy stored in the battery

$$
\mathrm{E}=\mathrm{C} * \mathrm{~V}=77 \mathrm{Ah} * 343 \mathrm{~V}=26411 \mathrm{~W}
$$

The range that can be traveled on a single charge supposing $70 \%$ of the stored energy is usable without damaging the batteries and 0.9 conversion efficiency for the electrical system

at $65 \mathrm{mph}$ and zero grade.

$$
\text { Range }=\frac{\mathrm{E}}{\mathrm{P}} * \mathrm{v}=\frac{26411 \mathrm{Wh}}{7397.6 \mathrm{~W}} * 65 \mathrm{mph} * 0.7 * 0.9=146.2 \mathrm{mile}
$$

The short range of electric vehicles is not the main problem though. While conventional vehicles can be refilled in a couple of minutes, batteries of EVs need several hours of charging once they were discharged. Consumers are not used to being without their vehicles for hours every day. The next calculation is for comparison of a conventional vehicle's refueling rate and an electric vehicle's recharging rate.

Density of gasoline: [19] $\rho=0.78 \mathrm{~kg} / 1$

Energy density of gasoline: [19] $\mathrm{E} \rho=44 \mathrm{MJ} / \mathrm{kg}$

Volume flow rate of gasoline: [20] $\mathrm{V}=0.51 / \mathrm{sec}$

Recharging time for lead acid batteries: [21] $\mathrm{t}=60 \mathrm{~min}$.

Energy flow rate of gasoline:

$$
\mathrm{Eg}=\frac{\mathrm{E} \rho}{\rho} * 0.5=\frac{44000000}{0.87} * 0.5=282050 \mathrm{~J} / \mathrm{s}
$$

Average energy flow rate into a battery while being charged:

$$
\mathrm{E}=\frac{\mathrm{E}}{3600^{2}} * 1000000=2037.9 \mathrm{~J} / \mathrm{s}
$$


As a conclusion to recharge the batteries takes 138 times as much time as it takes to fill up the fuel tank for the same trip. 


\subsection{The Advantages and Disadvantages of Series HEVs}

Series HEVs have the motor coupled either straight to the differential through a gear or chain drive or coupled thorough a gearbox, while the internal combustion engine (ICE) is coupled to the alternator. Figure 3 displays the typical layout of a series hybrid electric
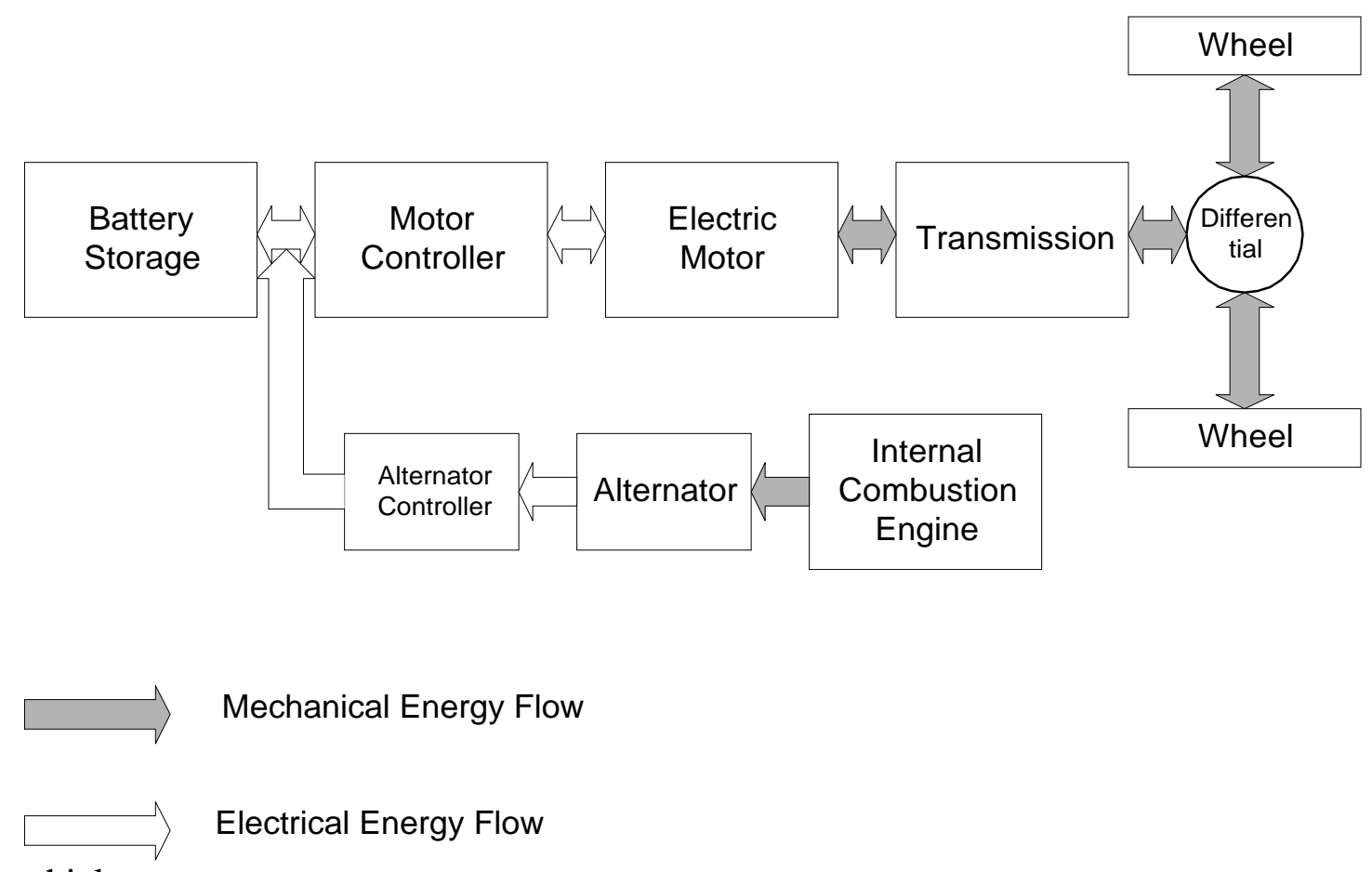

vehicle.

Figure 3. Power flow diagram for a typical series hybrid electric vehicle.

In series HEVs there is no physical coupling between the engine and the transaxle. This can reduce the transient operation of the ICE that is especially helpful from an emissions standpoint allowing optimal fueling and ignition control. Under heavy acceleration often an engine will fuel heavily to prevent a misfire situation due to an instantaneously high air to fuel ratio. The drawback to a series hybrid electric vehicle is the associated mechanical to electrical to mechanical energy conversion losses. However this makes it possible for the engine to operate in its most efficient region. A diesel engine efficiency map can be seen in Figure 4. 


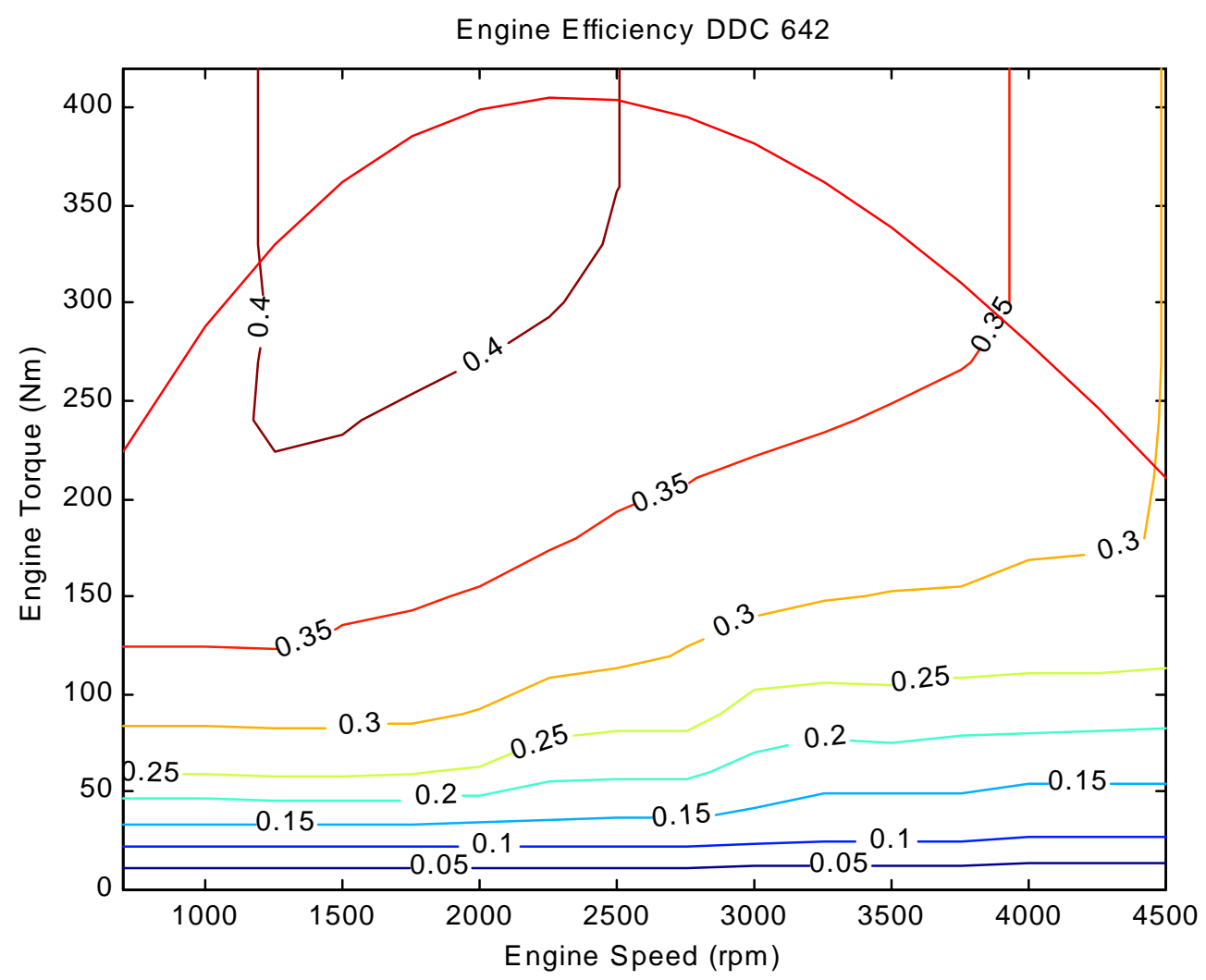

Figure 4. Efficiency map of the Detroit Diesel Corporation 642 engine.

The fact that the engine can operate in its most efficient region compensates the energy conversion losses and results fuel economy improvement that is significant in the city and moderate on the highway. The design also offers regenerative braking to capture the braking energy and store it in the battery instead of wasting it on the brake disks in the form of heat. The hardware of the series HEV is more expensive than the hardware of EVs or conventional vehicles because it requires two electric machines and an ICE. In addition to that the control of it is more complicated than the control of electric and conventional vehicles.

\subsection{The Advantages and Disadvantages of Parallel HEVs}

Parallel Hybrid Electric Vehicles have both the engine and the electric motor coupled directly to the wheels through some type of transmission. This direct coupling infers 
that the ICE does undergo significant transients in speed but in torque as it can be assisted by the electric motor. The speed transients are a drawback from the vehicle's emissions standpoint compared to the series setup. On the other hand the motor can be used to level the torque load that the ICE is subjected to operate in a more efficient range. Typically ICEs operate more efficiently at higher loads (at moderate speeds). When a low load is required by the vehicle the engine can either be shut off while the motor alone drives the vehicle or the engine load can be increased by the motor as it acts as a generator.

The engine is typically not allowed to operate in an inefficient range at low load as it does in a conventional vehicle. In turn it supplies an extra energy to the batteries to be stored for later use. The greatest advantage of a parallel HEV (over series HEVs with the same size components) is in its performance. Parallel HEVs have the potential to use both their electric motor and ICE as power sources, simultaneously propelling the vehicle.

There are two basic types of parallel HEV schemes. One is when the main power source is the engine and the electric motor assists. In the other one the electric motor is the main power source and the ICE assists. Figure 5 shows the Power Flow Diagram for Parallel HEV when the electric motor assists the internal combustion engine. Figure 6 shows the Power Flow Diagram for Parallel HEV when the ICE assists the electric motor. 


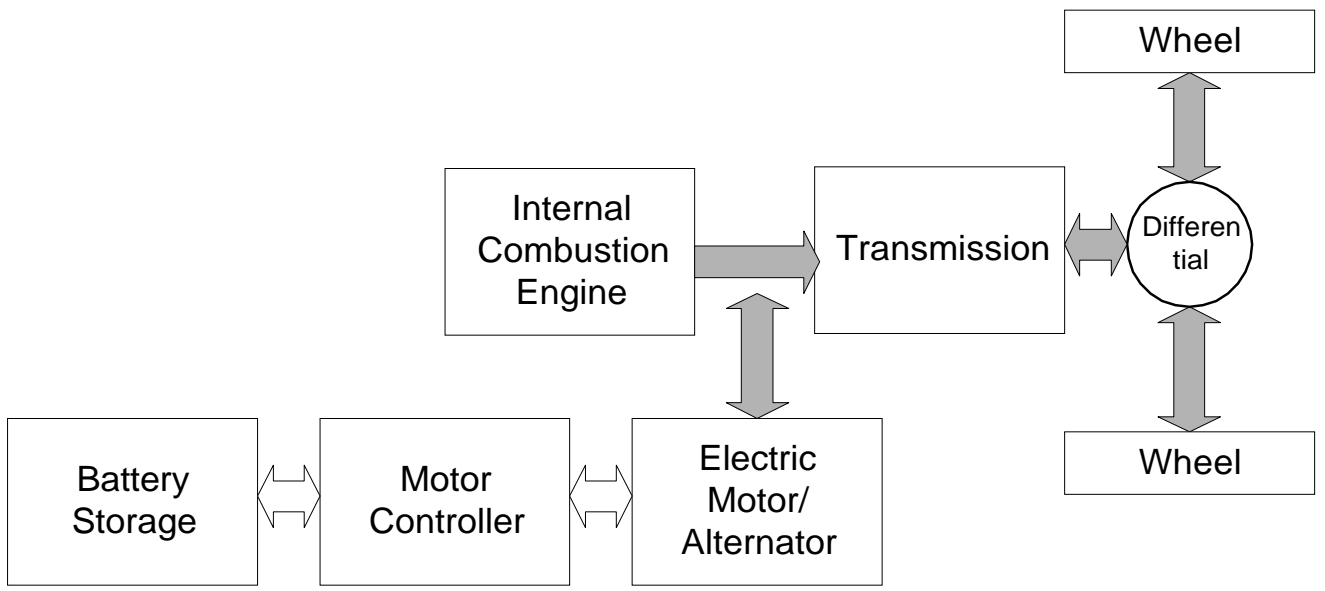

Mechanical Energy Flow

Electrical Energy Flow

Figure 5. Power flow diagram for parallel HEV when the electric motor is before the transmission and it assists the internal combustion engine.

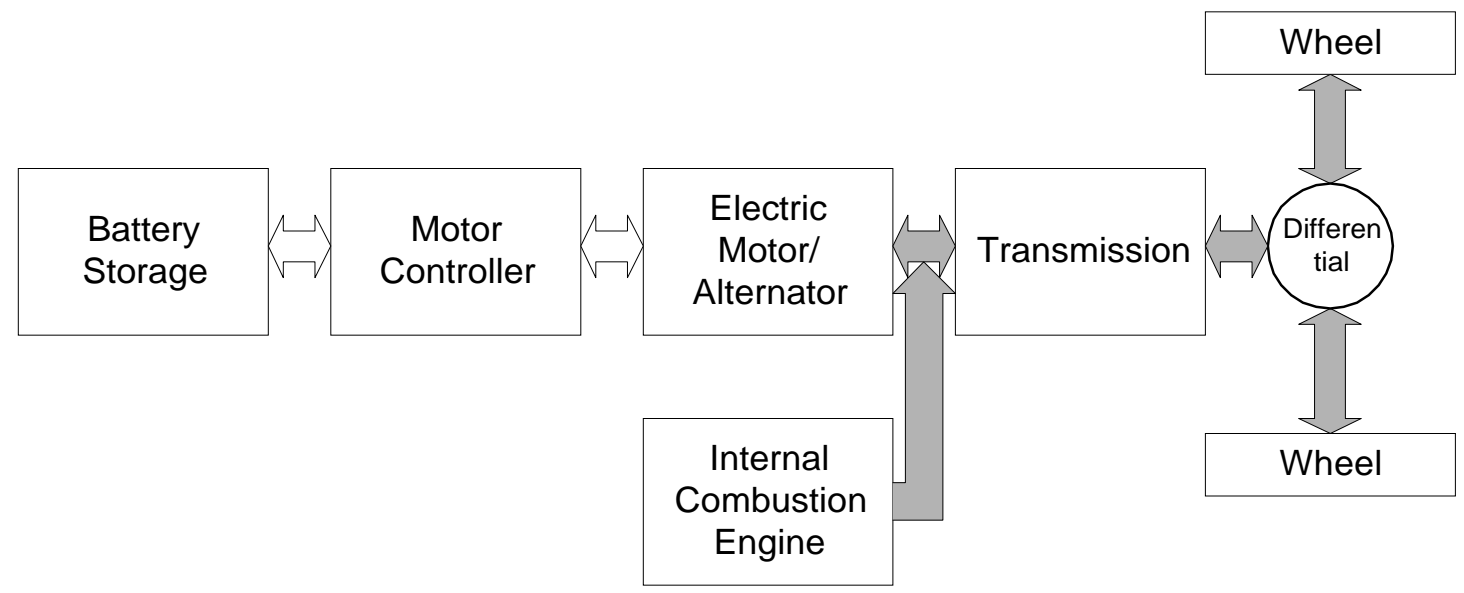

Mechanical Energy Flow

Electrical Energy Flow

Figure 6. Power flow diagram for parallel HEV when the ICE assists electric motor. 
Another version of parallel HEVs is when the electric motor is after the transmission. In that case the inefficiency of the transmission does not affect the power of the motor.

The hardware of a parallel HEV is less expensive than a series HEV because one electric motor is enough. The control, on the other hand, is much more complicated since there is physical coupling between the engine and the motor. 


\subsection{The Potential Advantages of Combination HEVs}

It is possible to build a vehicle that can be operated either as a series or as a parallel or even some combination of both for different driving conditions. This would utilize the advantages of both drive train types. For example in heavy traffic the vehicle can operate as a series HEV or it can operate as a parallel HEV when full power is required. There are several ways to create a drive train that has the characteristics of both a series HEV and a parallel HEV but the two main layouts are the series-parallel combination and the Planetary Combination HEVs.

The series-parallel combination has two electric machines and an ICE coupled with a combination of clutches that can be engaged in such a way that in one instance the powertrain is operating as a series HEV and at another instance operated as a parallel HEV.

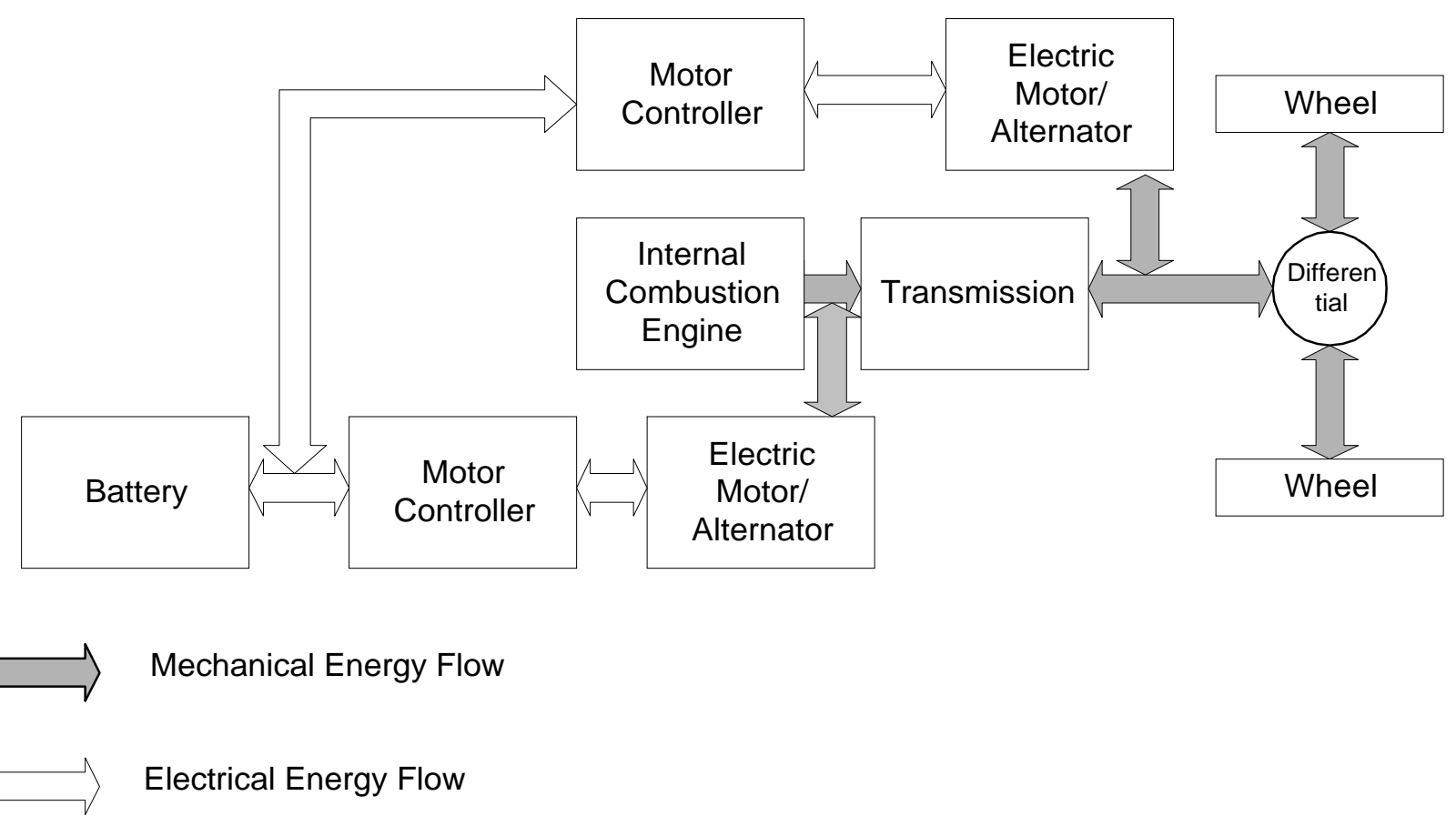

Figure 7. Power Flow Diagram for the Series-Parallel HEV 
Depending on driving conditions the various modes would be selected to utilize the most advantageous individual mode. This however would involve even more components than either a series or a parallel further increasing the size and complexity of the powertrain and the complexity of the control. Figure 7 shows the series-parallel combination HEV.

The other main design is the planetary combination hybrid electric vehicle. Several possible setups can be arranger around a planetary gear set. [22] One of those versions is employed by the Toyota Prius. The PC-Hybrid in the Prius couples an ICE, an alternator, and a motor via a planetary gear set. The engine is linked to the planet carrier; the alternator to the sun gear and the output is the ring that transmits the torque to the differential. The motor is also linked to the ring gear so that it is able to add torque to the output shaft so to the differential. With this setup there are three degrees of freedom, with the alternator being used to control the extra degree of freedom on the sun. Changes in the alternator operation affect the engine operation yielding total control over the engine at all driving conditions (within reason). Because the alternator controls the torque on the engine, the engine can operate at the most efficient point at each speed of operation. In addition to that because there is no gear changing involved with the PC Hybrid the engine operation is less transient than at the parallel configuration. It is not as steady as the series though.

In this setup the vehicle acts as a series HEV, only when the stationary vehicle starts moving. All the power from the engine is transmitted through the alternator and the electric motor. As soon as the vehicle starts moving, besides the electrical path, power gets transmitted mechanically through the planetary gear set. For the rest of its operation the vehicle works as a combination of a series and a parallel $\mathrm{HEV}$, once again taking advantage of both configurations. If the alternator could be stopped the vehicle would operate as a parallel vehicle. Off course the alternator cannot operate at less than its lowest operating speed 
because as it loses motion it loses the ability to generate electricity. Thus the vehicle will never operate as a pure parallel HEV.

The hardware cost of the PC Hybrid is of course more than that of an electric or a conventional vehicle. It needs two electric motors and an engine but it also eliminates the need for the transmission that makes the PC Hybrid one of the cheapest most integrated designs.

The control of the PC Hybrid is more complicated than that of the series and less complicated than that of the parallel HEV. Figure 8 shows the basic layout of the PC Hybrid. Table 3 compares all efficient types of hybrids to conventional vehicles in terms of fuel economy emissions potential and ease of control.

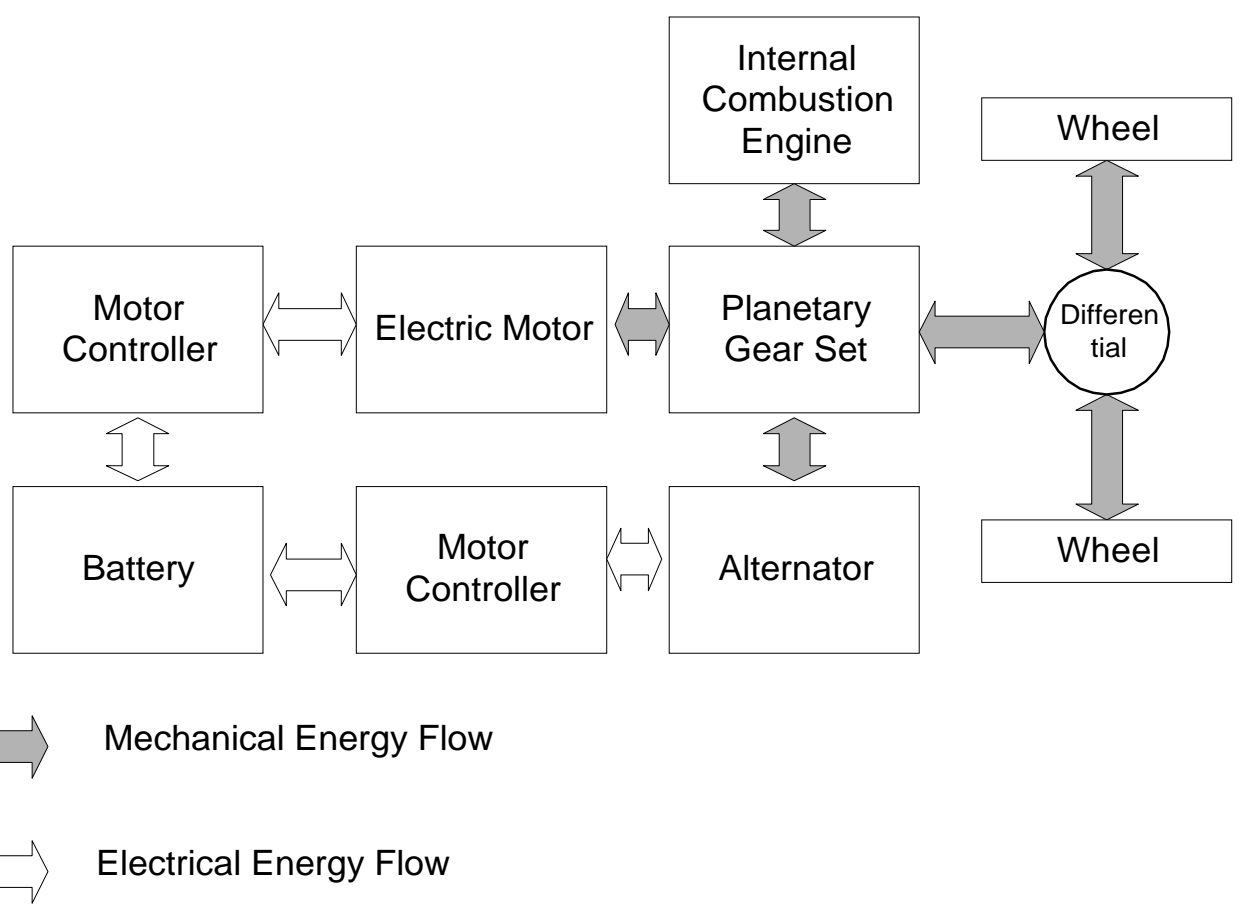

Figure 8. Power Flow Diagram for the Planetary Combination Hybrid. 


\begin{tabular}{|l|l|l|l|l|}
\hline & Series & Parallel & S-P HEV & PC-Hybrid \\
\hline Highway Fuel Efficiency & + & ++ & ++ & ++ \\
\hline City Fuel Efficiency & ++ & + & ++ & ++ \\
\hline Over the Road Fuel Efficiency & + & ++ & ++ & ++ \\
\hline Low Emissions Potential & ++ & + & ++ & ++ \\
\hline Cost & -- & - & -- & - \\
\hline Complexity & & & & \\
\hline Ease of Control & - & - & -- & - \\
\hline
\end{tabular}

Table 3. Comparison of hybrid types.

++ much better than a similar conventional vehicle

+ better than a similar conventional vehicle

- worse than a similar conventional vehicle

-- much worse than a similar conventional vehicle 


\section{An Analytical Investigation of the Planetary Combination Hybrid}

\section{Electric Vehicle}

\subsection{Configuration}

The Planetary Combination Hybrid integrates a somewhat undersized internal combustion engine, an electric motor and an alternator through a planetary gear set. This configuration allows the engine to operate in its most efficient range at any time using the electric motor, the alternator and the planetary gear set effectively as an electronic CVT. The vehicle has moderately sized energy storage that stores the energy recaptured during regenerative braking and provides energy under high load situations so that the motor can assist the engine to meet high power demand. The motor, the alternator and the battery pack are on the same electrical bus. This way the alternator can either provide energy to the traction motor or recharge the batteries. Also the traction motor can use the energy either directly from the alternator or from the batteries or can capture the braking energy and send it to the batteries during braking.

\subsection{Description of Operation}

The main power source of the vehicle is the engine. The electric motor adds power to the output shaft only at starting the vehicle or at severe load conditions. The engine provides power to the planetary gear set. The planetary gear set splits the power two ways. Part of the power flows mechanically to the wheels through the planetary gear set, the transfer case and the differential. The other part of the power flows through the planetary gear set to the alternator from where it flows electrically to the bus and either to the traction motor or to the battery pack. The ratio of the power split changes with the speed of the components but the 
ratio of the torque remains constant because of its geometrical characteristics. This mode of operation requires the motor to have high torque at low speed and also requires regenerating capabilities of the alternator even at low alternator speed.

\subsection{System Integration}

Figure 9 shows the integrated design of the PC Hybrid. This design requires a hollow shaft generator and a through-shaft motor. In this way the motor, the alternator and the planetary gear set, as an integrated unit, will fit in the place of the conventional vehicles transmission.

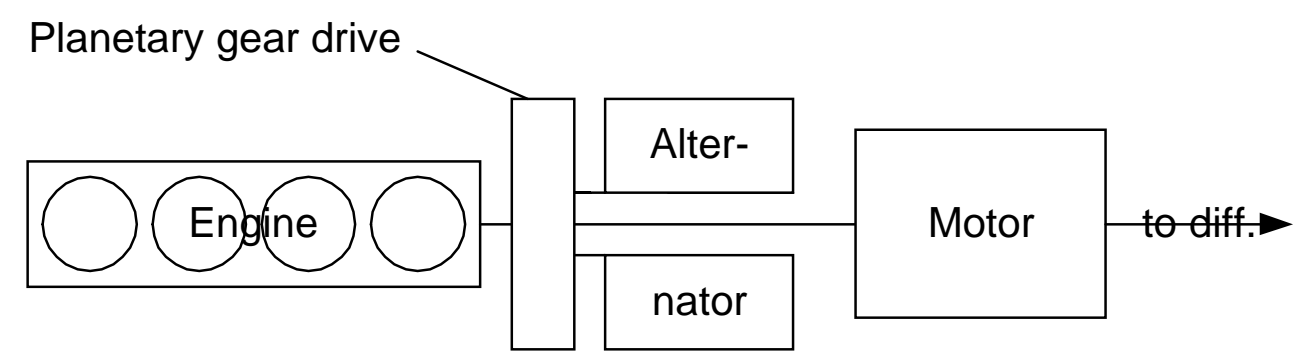

Figure 9. The integrated design arrangement of the PC Hybrid.

\subsection{Control Strategy}

The control is the uncertain part of the PC-Hybrid. Although, there are some reports talking about the vehicle control vaguely, there is no paper that would fully explain the entire control strategy probably because of the proprietary nature of the control. Figure 14 shows the flow chart that can be interpreted from the reports $[10,11,12,13]$.

The only active control input to the system is the accelerator pedal signal (APS) which defines the torque demand from the traction motor. The traction motor will pull current from the electrical bus on one side while the alternator will provide current to the bus on the other side. A current sensor monitors the current in to and out of the batteries. When the sensor indicates an out-flowing current it implies that the alternator is not providing enough power to 
the motor. The computer increases the power demand signal of alternator, which increases the torque until it reaches the maximum torque of the engine at the given speed. When the engine reaches its maximum torque at that speed the computer increases the engine speed moving the engine to a higher power zone. If the current sensor indicates an in-flowing current it means the alternator is generating too much energy and the driver does not require the electric motor to consume it. The computer decreases the speed signal to the engine that results in a decreasing engine speed and hence a lower power is generated by the alternator. At high power demand the batteries can provide extra power to the electric motor and the engine speeds up to its maximum power capability. However, there is an optimization loop in the control that aims to keep the engine speed as low as possible at all road speeds and to utilize all the available torque of the engine at that speed. This way the power required to propel the vehicle is provided by the engine operating in its highest efficiency range. It also minimizes the transient operation of the engine. 


\subsection{Flow Chart of the Hybrid Control}

The PC-Hybrid has two basic operations depending on state of charge. See Figure 10. At high SOC the engine is off, and the vehicle operates as an electric vehicle. At low SOC the vehicle operates as in hybrid mode. When current flowing out of the battery is higher than the set maximum (400A) the control switches to HEV mode independently from the SOC.

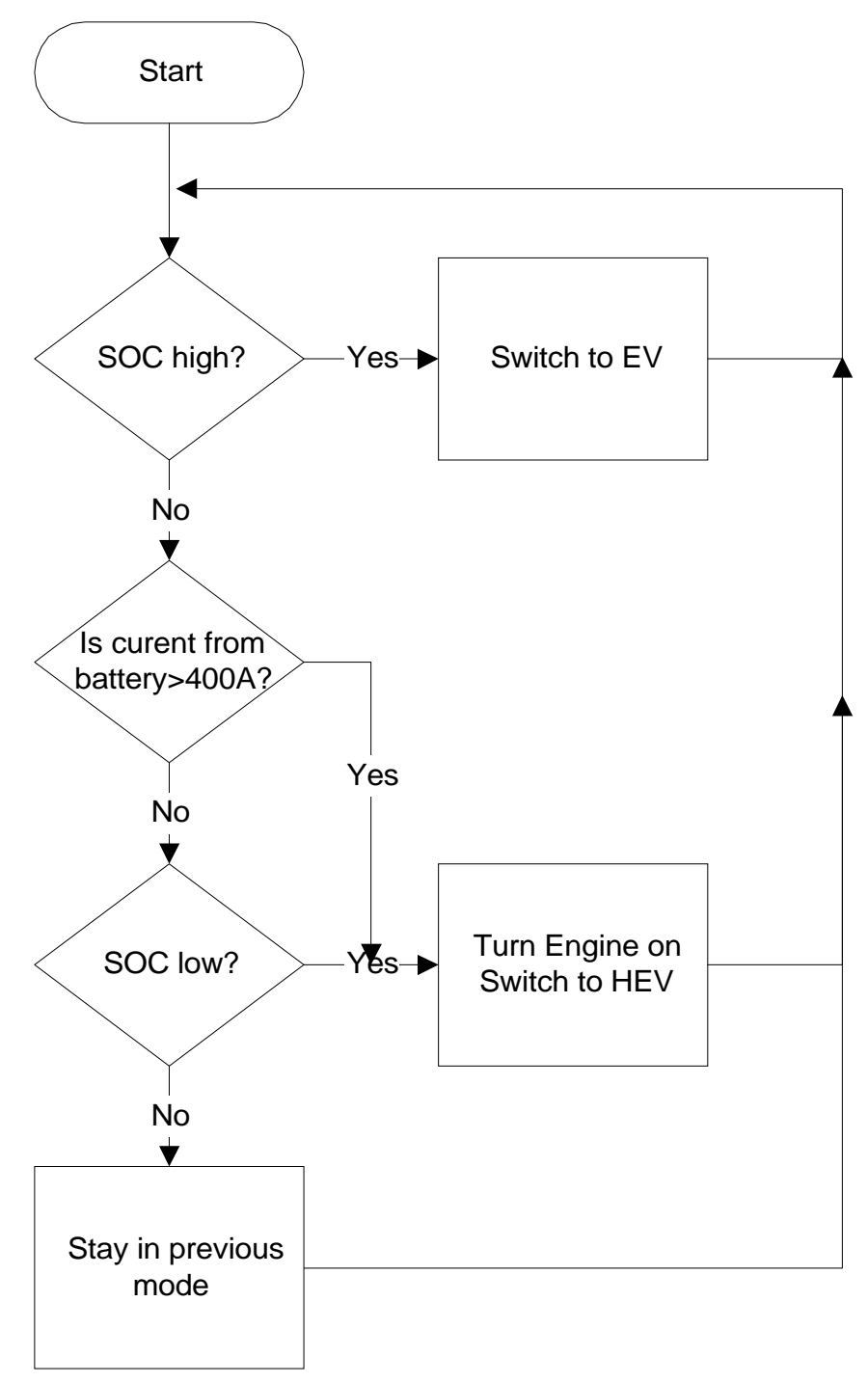

Figure 10. The primary control loop of the PC-Hybrid is based on battery state of charge.

SOC charge of the battery can not be measured directly. SOC is a linear function of the steady state battery voltage. After charging or discharging a battery its voltage will be higher or lower, respectively, then the steady state battery voltage. The battery reaches its steady 
state voltage after resting for 24 hours. Therefore the actual battery voltage can only be used as a rough estimate of the SOC. [20]

Figure 11 shows the flow chart of the EV mode. The control is very simple in this mode. The gas pedal gives a torque request and the brake pedal gives a regenerating request signal to the electric motor.

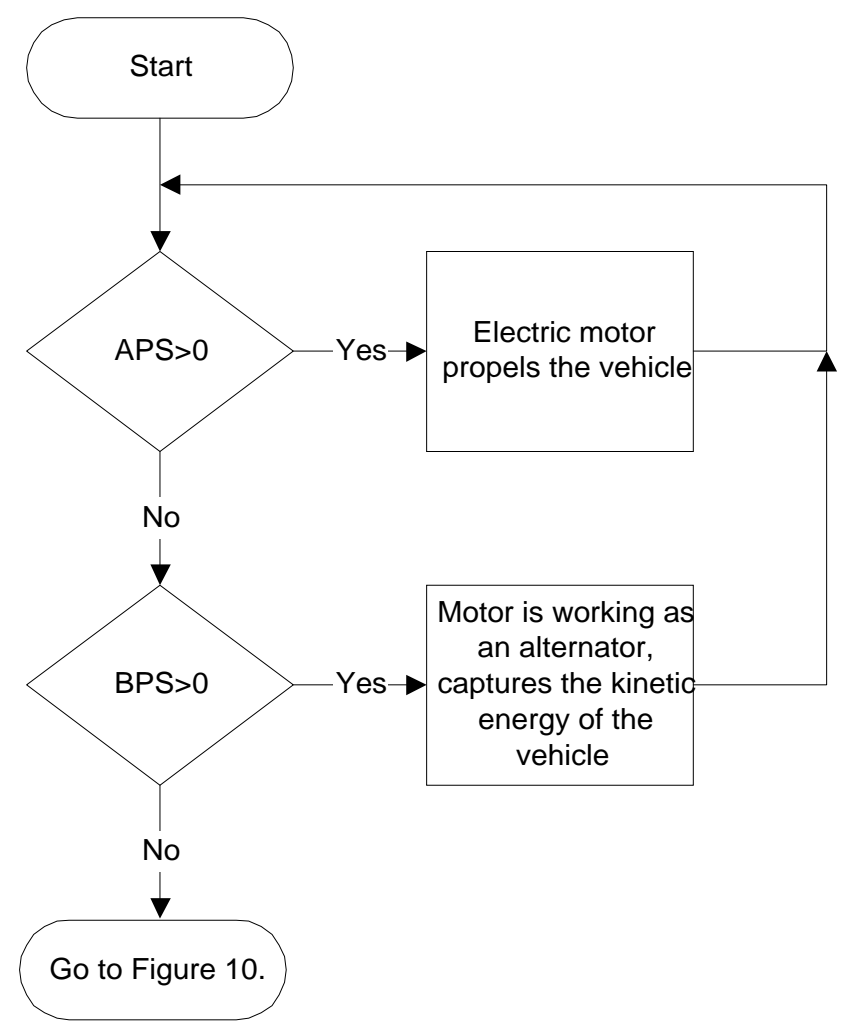

Figure 11. Flow chart of the Electric Vehicle operation.

SOC-State of charge of the battery pack

APS- Accelerator pedal signal

BPS- Brake pedal signal 
When SOC is low the computer turns on the engine and runs the vehicle as a hybrid.

See Figure 11.

Figure 12 shows the basic loop of control in HEV mode. It shows that the only inputs to the system from the driver are brake pedal and gas pedal signals.

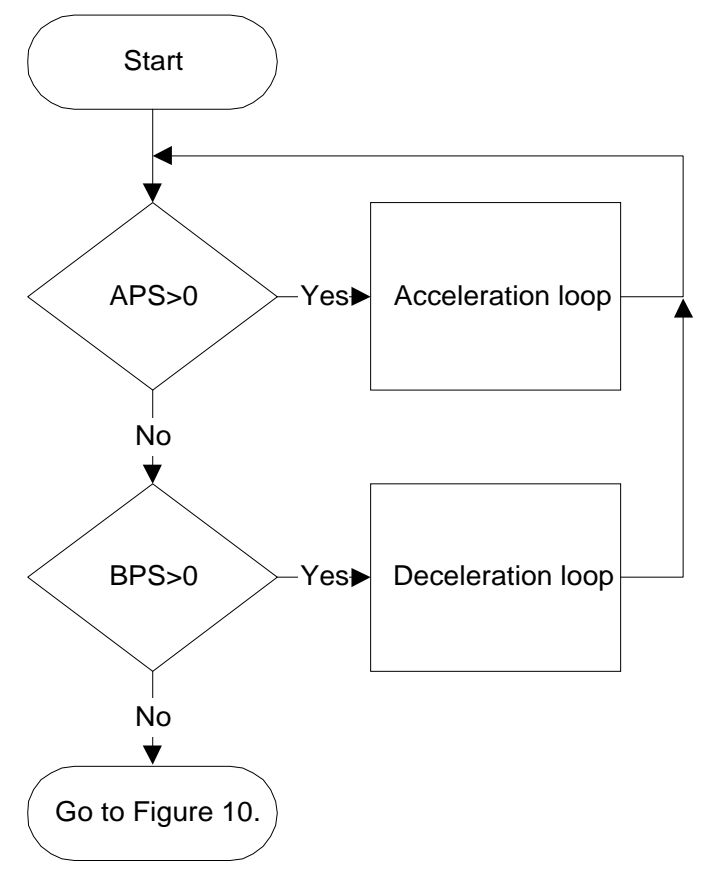

Figure 12. Flow chart of the vehicle control as an HEV.

The next flowcharts in Figure 13 and Figure 14 give a deeper insight into the deceleration loop and the acceleration loop, respectively. 


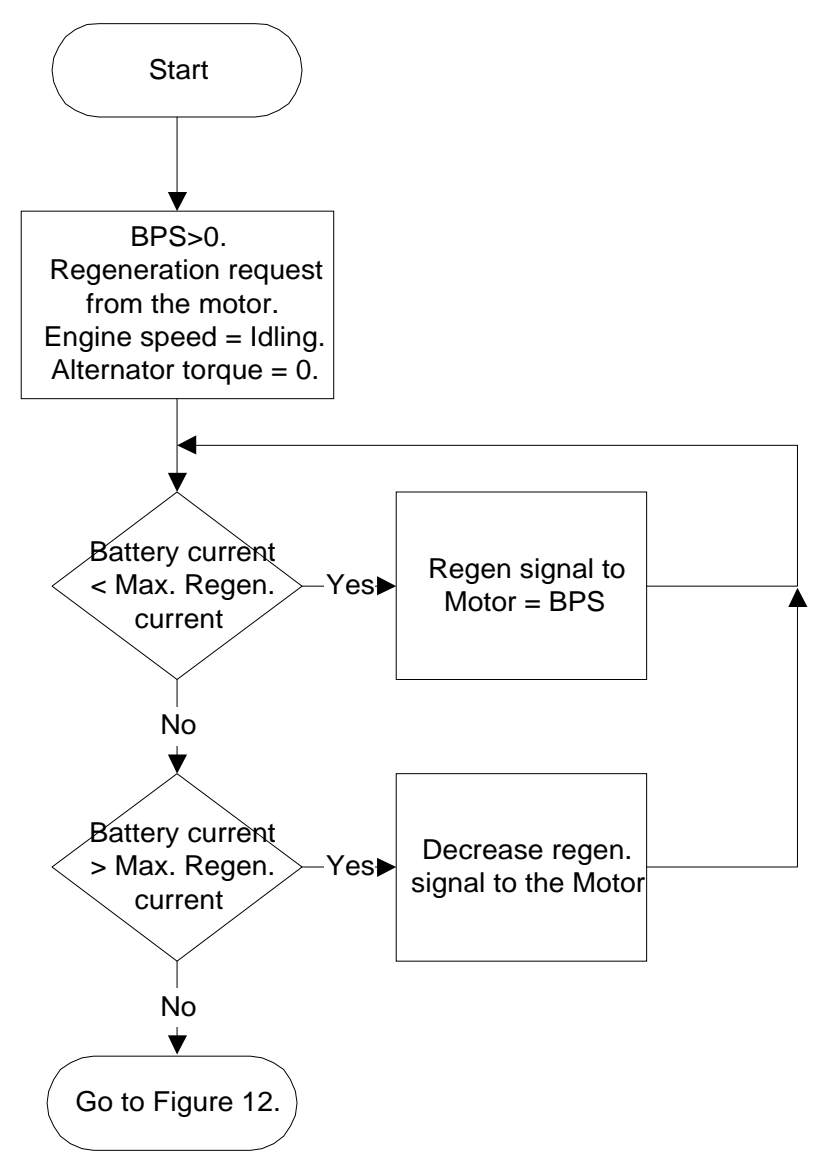

Figure 13. Deceleration loop of the vehicle control.

As soon as the brake pedal is pressed in the computer sets the engine speed to idle and the alternator torque request to zero. Since the alternator torque controls the engine torque, the engine neither provides nor consumes torque so all the kinetic energy of the vehicle can be captured during braking. The first part of the brake pedal throw makes the motor act as a generator to regenerate energy from the momentum of the vehicle. The braking torque signal is proportional to the pedal travel and at about one fourth of the maximum travel it reaches the maximum regenerative capability of the motor. (Mechanical brakes are not applied yet.) If the driver needs more severe deceleration that would exceed the regenerative torque capability of 
the electric motor, the driver simply presses the brake pedal further down. This activates the mechanical brakes as needed while keeping the regenerative braking at the maximum. The current flowing in to the battery also needs to be monitored. Too high a current can damage the batteries or shorten their life significantly. For this reason the maximum regenerative capability is usually defined by the battery current and not the maximum torque capability of the electric motor. The brake control is the same in this case as it was described above. Toyota explains the operation and control of the brake in reference [14].

Figure 14 shows the acceleration loop of the PC-Hybrid control. As soon as the accelerator pedal is pressed it gives a motoring signal to the electric motor. The motor pulls current from the bus, which receives current from the alternator and/or the batteries. The system is optimized to use as little energy from the battery as possible. Whenever energy is used from the battery the computer increases the alternator output and with that the engine output. The upper limit of the alternator output is the third of the maximum brake horsepower output of the engine. Whenever energy is supplied to the battery the computer lowers the alternator output and with that the engine output. The lower limit is the idling speed of the engine. Figure 14 shows the acceleration loop for the hybrid mode. 


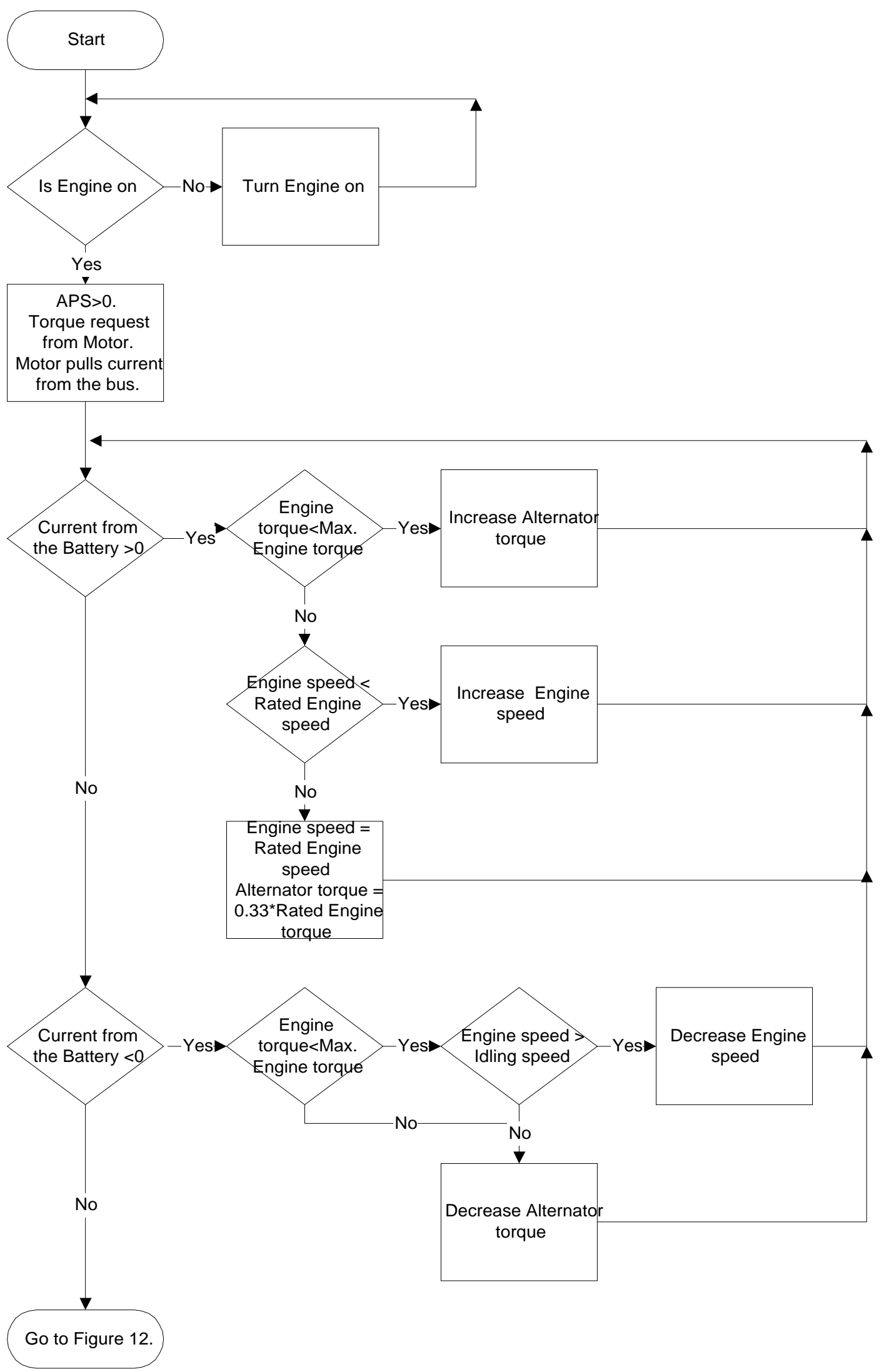

Figure 14. Acceleration loop for the PC-Hybrid in hybrid mode. 


\subsection{Planetary Gear Set}

Planetary gear drives are widely used as speed reducers in power transmission applications. They consist of 4 main components: a sun gear, planets, a planetary carrier and an internally toothed ring gear. See picture 1.

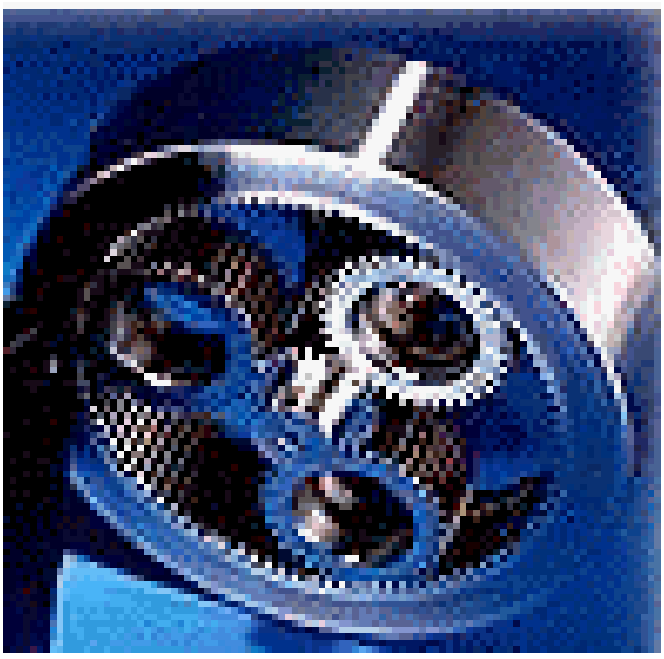

\section{Picture 1. Planetary gear set.}

Planetary gear sets have three input and/or output shafts that give them two degrees of freedom of motion. This makes them great candidates for transmissions. The three degrees of freedom can be defined as the motion of shaft of the ring gear, the motion of the shaft of the planetary carrier and the motion of the shaft of the sun gear. The variables on the shafts are speed and torque. This gives two sets of triple variables, three for speed and three for torque. Fixing any two given degrees of freedom defines the third one. In transmissions and speed reducers usually one shaft, one degree of freedom, is held stationary. This results the other two degrees of freedom being the linear function of each other.

In the PC-Hybrid none of the elements are held fixed. The speed of the engine and the torque of the alternator are controlled, resulting in the desired speed and the torque at the wheels. 
The required gearing ratio of the planetary gear set depends on the maximum speed and torque of the components. Using a DDC642 engine and two 75kW UQM PM brushless motors Engine speed @ maximum power 4500rpm Maximum alternator speed $\quad$ 7500rpm

The requirement of the planetary gear set is to minimize alternator torque and maximize alternator speed and output torque. Calculations are shown in Chapters 3.8, 3.9, $3.10,3.11,3.12,3.13$. 


\subsection{Planetary Configurations}

The components of PC Hybrid can be configured in six different basic layouts, using a single planetary gear set, depending on what component is linked to what part of the planetary gear set. The six basic configurations will be investigated in Chapters 3.8, 3.9, 3.10, 3.11, 3.12, and 3.13. These are

$\begin{array}{ll}\text { Configuration \#1 } & \text {-Engine on the sun, Alternator on the carrier, Motor on the ring } \\ \text { Configuration \#2 } & \text {-Engine on the ring, Alternator on the carrier, Motor on the sun } \\ \text { Configuration \#3 } & \text {-Engine on the sun, Alternator on the ring, Motor on the carrier } \\ \text { Configuration \#4 } & \text {-Engine on the ring, Alternator on the sun, Motor on the carrier } \\ \text { Configuration \#5 } & \text {-Engine on the carrier, Alternator on the ring, Motor on the sun } \\ \text { Configuration \#6 } & \text {-Engine on the carrier, Alternator on the sun, Motor on the ring }\end{array}$

Schmidt and Klemen describe four of the six basic configurations in reference [22]. They describe four-four possible arrangements for configuration \#4 and configuration \#6 and shows a layout for configuration \#3 and \#5. He calls them "one mode, input split, parallel, hybrid transmission". Schmidt has probably recognized the fact that configurations \#1 and \#2 make the alternator torque high and alternator speed low, which is against the nature of alternators. See description and calculations in Chapter 3.8 and 3.9.

Schmidt also describes 7 possible combinations of the six basic configurations in [23]. He calls them "two mode, input split, parallel, hybrid transmission". He describes six possible arrangement of the combination of configurations \#2 and \#4 and one combination of configuration \#5 and \#6. These combinations give more flexibility to the transmission. Such that the transmission will be able to increase either output torque or output speed significantly.

Then Schmidt goes further and introduces the "two mode, compound split, electromechanical, vehicular transmissions", as he calls them, in [24]. These arrangements are also 
combinations of the six basic configurations using one or two extra planetary gear sets. These configurations do not split the power at the input. They split the power before the output. He describes combinations of configurations \#4 and \#6, configurations \#2 and \#4 and configurations \#1 and \#3 in [24]. For example, he describes a configuration, with two planetary gear sets and three clutches, which gives the combination of configurations \#2, \#4, ZEV and high power output parallel. Figure 14.1 shows this configuration. Table 3.1 shows the possible modes of the configuration.

\begin{tabular}{|l|l|l|l|l|l|}
\hline Configuration & Clutch \#1 & Clutch \#2 & Clutch \#3 & Motor \#1 & Motor \#2 \\
\hline ZEV & Disengaged & Engaged & Engaged & Motor & Motor \\
\hline \#2 & Engaged & Engaged & Disengaged & Alternator & Motor \\
\hline Parallel & Engaged & Engaged & Engaged & Motor & Motor \\
\hline
\end{tabular}

Table 3.1 Possible hybrid modes of the configuration can be seen in Figure 14.1.

The compound configuration, that Schmidt describes in [24], works as a ZEV when clutch \#1 is disengaged, clutch \#2 and \#3 are engaged and both motors work as an alternator. The compound configuration acts as a configuration \#2 when clutch \#1 and \#2 are engaged clutch \#3 is disengaged, motor \#1 is an alternator and motor \#2 is a motor. The compound configuration acts like a configuration \#4 when clutch \#1 and \#2 are engaged, clutch \#3 is disengaged, motor \#1 works as a motor and motor \#2 works as an alternator. The compound configuration acts like a super high output parallel HEV when all the clutches are engaged and both motors work as motors. 


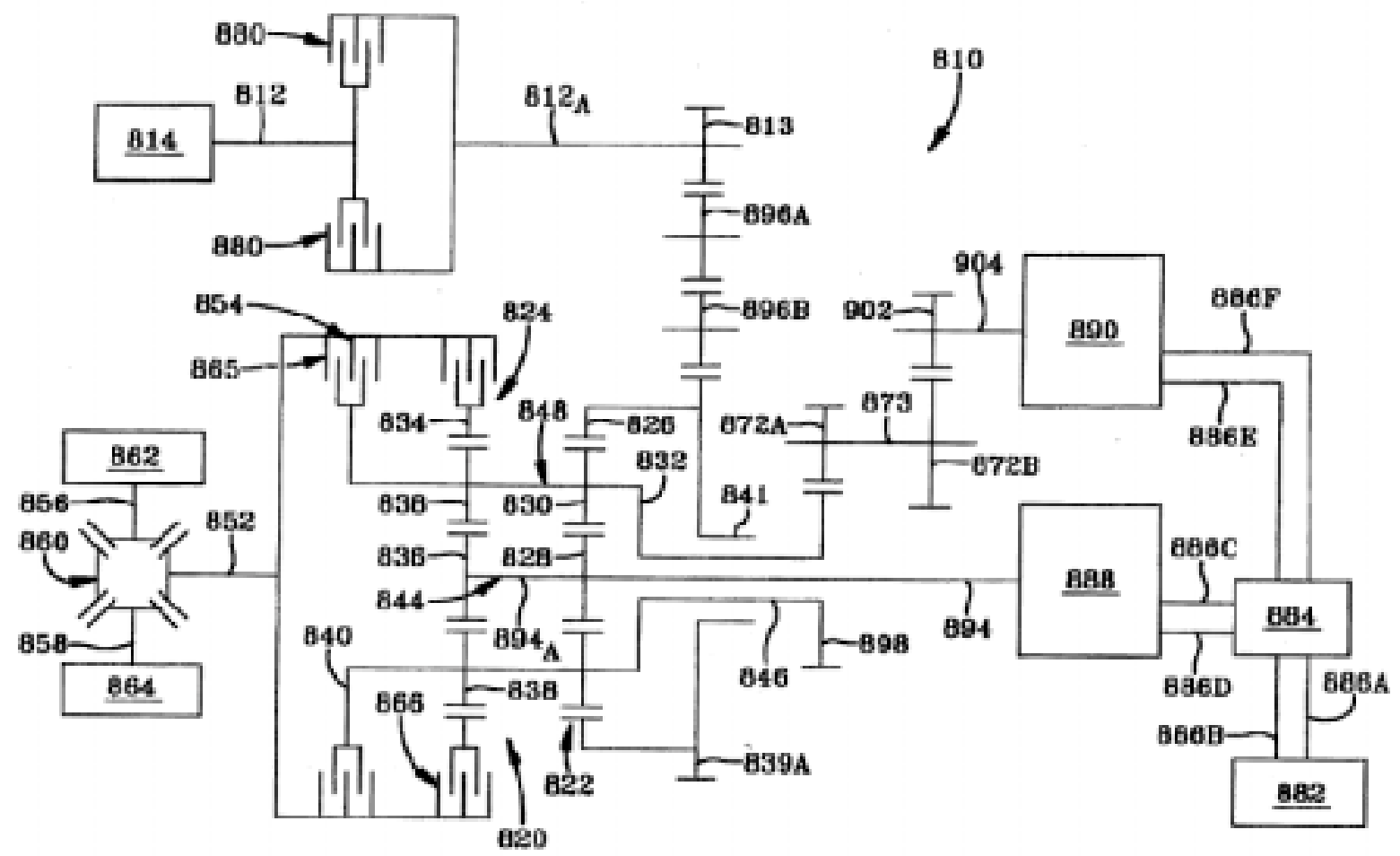

Figure 14.1. A possible two-mode, compound-split, electro-mechanical, vehicular transmissions. [24] 
-Hybrid transmission

812

-Input shafts

812A

-Input shaft extension

813

-Input gear

814

-Engine

820

-Compound planetary gear set

822

-Planetary gear subset

824

-Planetary gear subset

826

-Ring gear

828

-Sun gear

830

-Planet gears

832

-Planet carrier

834

-Ring gear

836

-Sun gear

838

-Planet gears

839A

-Transfer gear

840

-Planet carrier

841

-Outer sleeve shaft

844

-Compounded gear member

846

-Inner sleeve shaft

848

-Compounded gear member

852

-Output shaft

854

-Compounded gear member

856

-Drive axle 
858

860

862

864

865

866

872A, 872B

873

880

882

884

886A, 886B, 886C, 886D,886E,886F

888

890

896A, 896B

902

904

894

898
-Drive axle

-Differential

-Wheel

-Wheel

- Torque transfer device (Clutches \#2)

-Torque transfer device (Clutches \#3)

-Idler gears

-Idler shaft

-Torque transfer device (Clutch \#1)

-Electric storage device

-Electrical control unit

-Transfer conductors

-Motor/generator \#2

-Motor/generator \#1

-Idler gears

-Drive gear

-Motor/alternator shafts

-Motor/alternator shafts

-Transfer gear

Table 3.2. Components of the two-mode compound-split electro-mechanical, vehicular transmission. [24] 


\subsection{Configuration 1. (Engine on the sun, Alternator on the carrier, Motor on the} ring)

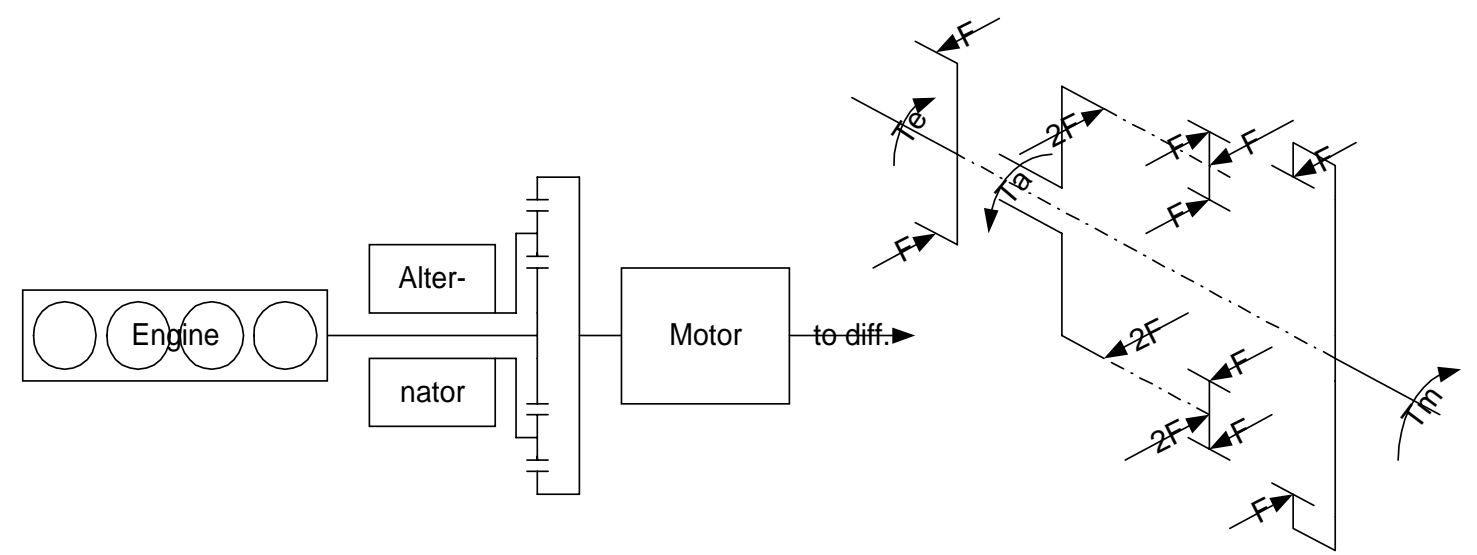

Figure 15. Configuration 1. Engine on the sun, Alternator on the carrier, Motor on the ring. Arrangement and Free body diagram.

The engine spins the sun gear while the alternator turns on the planetary carrier in the same direction providing the counter torque when loaded. The torque of the alternator and the speed of the engine are controlled by the computer. Thus the torque of the engine on the sun and the torque of the alternator on the carrier results a reversed torque on the ring.

The torque on the shaft of the ring gear, which is the output torque

$$
T_{r}=\frac{T_{s}}{R_{s}} * R_{r}
$$

The torque on the shaft of the planetary carrier is the alternator torque

$$
T_{c}=2 * \frac{T_{s}}{R_{s}} *\left(R_{s}+\frac{R_{r}-R_{s}}{2}\right)
$$

The Equation 7 calculates the speed of the carrier as a function of the speeds of the sun gear and the ring gear.

$$
S_{c}=\frac{S_{s}}{1+\frac{R_{r}}{R_{s}}}+\frac{S_{r}}{1+\frac{R_{s}}{R_{r}}}
$$


The alternator speed is highest when the vehicle is stationary and the engine spins at its highest speed. The maximum engine speed is 4500rpm. The maximum alternator speed is $7500 \mathrm{rpm}$.

$$
\begin{aligned}
& S_{c}=\frac{S_{s}}{1+\frac{R_{r}}{R_{s}}} \\
& \frac{S_{s}}{S_{c}}=1+\frac{R_{r}}{R_{s}} \\
& \frac{R_{r}}{R_{s}}=\frac{S_{s}}{S_{c}}-1=\frac{4500}{7500}-1=-0.4 \\
& \frac{R_{s}}{R_{r}}=\frac{1}{-0.4}=-2.5
\end{aligned}
$$

The gearing ratio is negative, which means that the required speed ratio is practically impossible using a planetary gear set. This setup will never provide higher alternator speed than the engine speed. The design requires a low speed, high torque alternator, which is not typical, or additional speed reduction.

Using 1:1.5 as a gearing ratio, the maximum alternator speed would be

$$
S_{c}=\frac{S_{s}}{1+\frac{R_{r}}{R_{s}}}=\frac{4500}{1+\frac{1.5}{1}}=1800 \mathrm{rpm}
$$

To utilize the full alternator speed range a 1:2.7 gearing is needed.

Maximum output speed

$$
S_{r}=S_{s} * \frac{R_{s}}{R_{r}}=4500 * \frac{1}{1.5}=3000 \mathrm{rpm}
$$


Torque on the alternator

$T_{c}=2 * \frac{T_{s}}{R_{s}} *\left(R_{s}+\frac{R_{r}-R_{s}}{2}\right)=2 * \frac{T_{s}}{1} *\left(1+\frac{1.5-1}{2}\right)=2.5 * T_{s}$

Torque on the ring gear

$$
T_{r}=\frac{T_{s}}{R_{s}} * R_{r}=\frac{T_{s}}{1} * 1.5=1.5 * T_{s}
$$

\subsection{Configuration 2. (Engine on the ring, Alternator on the carrier, Motor on the}

sun)

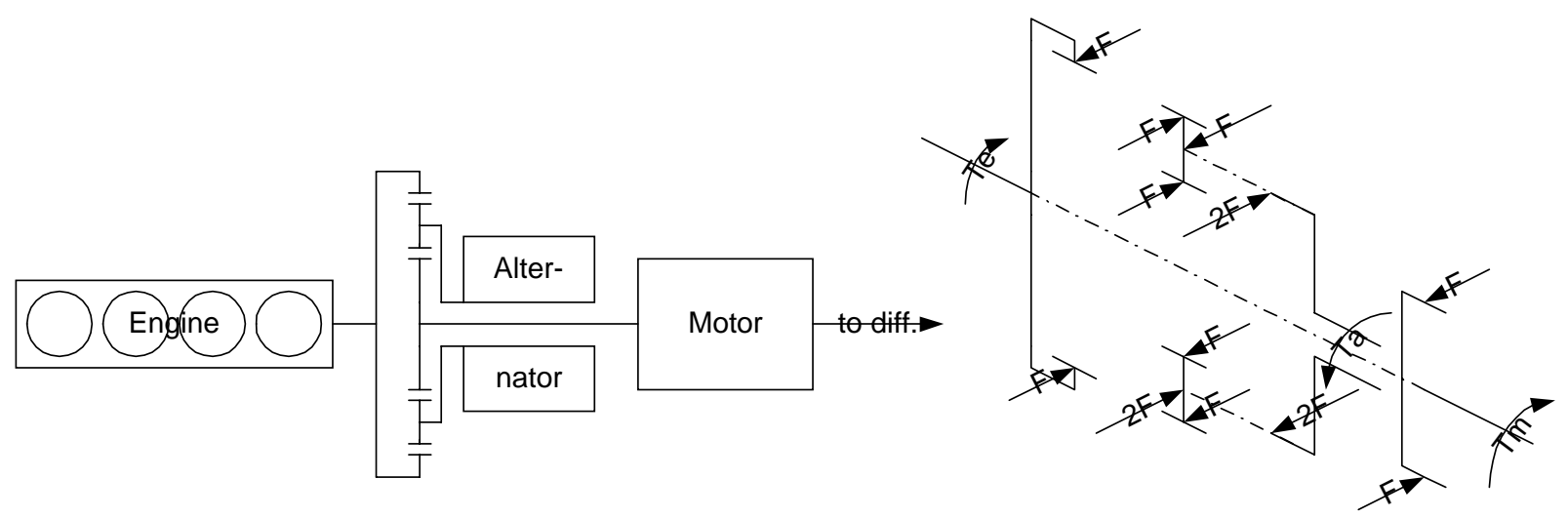

Figure 16. Configuration 2. Engine on the ring, Alternator on the carrier, Motor on the sun. Arrangement and Free body diagram.

The engine spins the ring gear while the alternator turns on the planetary carrier in the same direction providing counter torque when loaded. The torque of the alternator and the speed of the engine are controlled by the computer. Thus the torque of the engine on the ring and the torque of the alternator on the carrier results a reversed torque on the sun.

The torque on the shaft of the sun gear, which is the output torque

$$
T_{s}=\frac{T_{r}}{R_{r}} * R_{s}
$$


The torque on the shaft of the planetary carrier, which is the alternator torque

$$
T_{c}=2 * \frac{T_{r}}{R_{r}} *\left(R_{s}+\frac{R_{r}-R_{s}}{2}\right)
$$

The Equation 14 calculates the speed of the carrier in the function of the speeds of the sun gear and the ring gear.

$$
S_{c}=\frac{S_{s}}{1+\frac{R_{r}}{R_{s}}}+\frac{S_{r}}{1+\frac{R_{s}}{R_{r}}}
$$

The alternator speed is highest when the vehicle is stationary and the engine spins at its highest speed.

$$
\begin{aligned}
& S_{c}=\frac{S_{r}}{1+\frac{R_{s}}{R_{r}}} \\
& \frac{S_{r}}{S_{c}}=1+\frac{R_{s}}{R_{r}} \\
& \frac{R_{s}}{R_{r}}=\frac{S_{r}}{S_{c}}-1=\frac{4500}{7500}-1=-0.4
\end{aligned}
$$

The negative gearing ratio means that such a planetary gear set does not exist. This setup will never provide higher alternator speed than the engine speed. The design also requires a low speed, high torque alternator, which is not typical, or an additional gearbox.

Using 1:1.5 as a gearing ratio, the maximum alternator speed would be

$$
S_{c}=\frac{S_{r}}{1+\frac{R_{s}}{R_{r}}}=\frac{4500}{1+\frac{1}{1.5}}=2700 \mathrm{rpm}
$$

To utilize the full alternator speed range a 1:4.16 gearing is needed. 
The maximum output speed is

$$
S_{s}=S_{r} * \frac{R_{r}}{R_{s}}=4500 * \frac{1.5}{1}=6750 \mathrm{rpm}
$$

Torque on the alternator

$$
T_{c}=2 * \frac{T_{r}}{R_{r}} *\left(R_{s}+\frac{R_{r}-R_{s}}{2}\right)=2 * \frac{T_{r}}{1.5} *\left(1+\frac{1.5-1}{2}\right)=1.667 * T_{r}
$$

Torque on the sun gear

$$
T_{s}=\frac{T_{r}}{R_{r}} * R_{s}=\frac{T_{r}}{1.5} * 1=0.6667 * T_{r}
$$

\subsection{Configuration 3. (Engine on the sun, Alternator on the ring, Motor on the} carrier. )

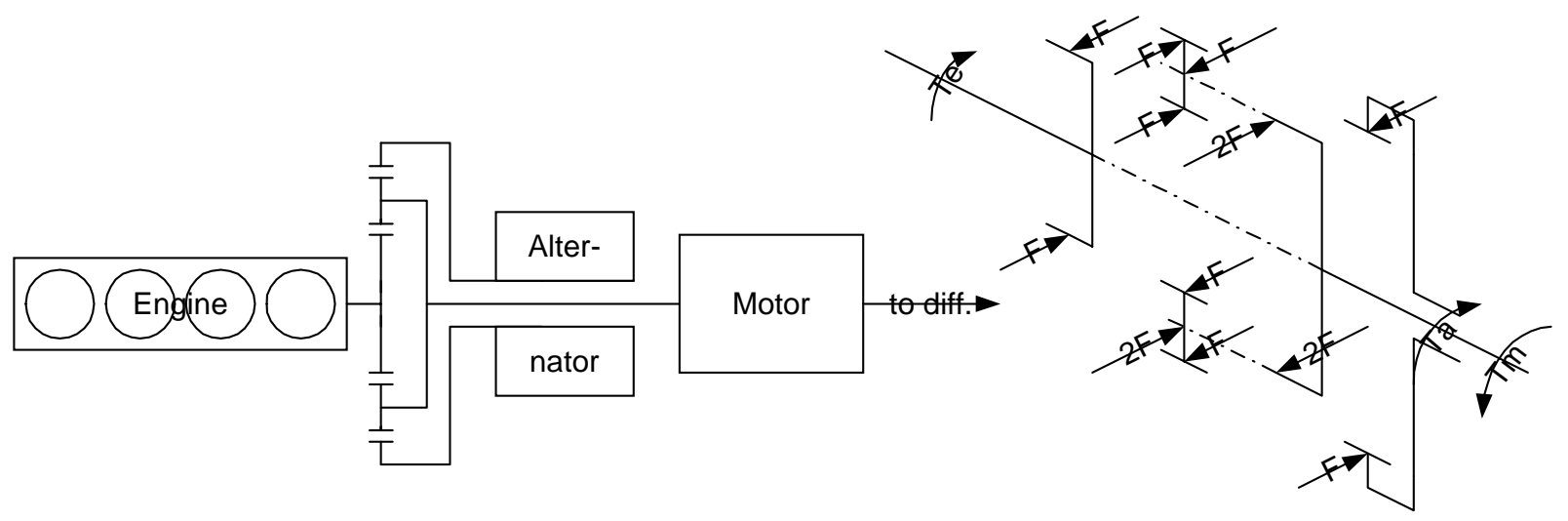

Figure 17. Configuration 3. Engine on the sun, Alternator on the ring, Motor on the carrier. Arrangement and Free body diagram.

The engine spins the sun gear while the alternator turns on the ring gear in reversed direction providing counter torque when loaded. The torque of the alternator and the speed of the engine are controlled by the computer. Thus the torque of the engine on the sun and the torque of the alternator on the ring results a torque on the carrier in the same direction as the engine torque. 
The torque on the shaft of the planetary carrier, which is the output torque

$$
T_{c}=2 * \frac{T_{s}}{R_{s}} *\left(R_{s}+\frac{R_{r}-R_{s}}{2}\right)
$$

The torque on the shaft of the ring gear, which is the alternator torque

$$
T_{r}=-\frac{T_{s}}{R_{s}} * R_{r}
$$

The Equation 22 calculates the speed of the ring gear as a function of the speeds of the sun gear and the planetary carrier.

$$
S_{r}=-S_{s} * \frac{R_{s}}{R_{r}}+S_{c} *\left(1+\frac{R_{s}}{R_{r}}\right)
$$

The alternator speed is highest when the vehicle is stationary and the engine spins at its highest speed.

$$
\begin{aligned}
& S_{r}=-S_{s} * \frac{R_{s}}{R_{r}} \\
& \frac{R_{s}}{R_{r}}=-\frac{S_{r}}{S_{s}} \\
& \frac{R_{s}}{R_{r}}=-\frac{7500}{4500}=-1.6667
\end{aligned}
$$

Planetary gearing ratio must be smaller than $1.6667: 1$, which is impossible without a gearbox between the carrier and the alternator. The negative sign only means that the output torque and speed will be in the reverse direction compared to the input torque and speed (as it was supposed to be).

This design requires a low speed, high torque alternator, what is not a typical alternator, an additional gearbox or just the engine needs to go on the ring and alternator on the sun. 
Using 1:1.5 as a gearing ratio, the maximum alternator speed would be

$$
S_{r}=-S_{s} * \frac{R_{s}}{R_{r}}=-S_{s} * \frac{1}{1.5}=-0.6667 * S_{s}=3000 \mathrm{rpm}
$$

To utilize the full alternator speed range a 1:2.7 gearing is needed.

The maximum output speed

$$
S_{c}=\frac{S_{s}}{1+\frac{R_{r}}{R_{s}}}=\frac{4500}{1+\frac{1.5}{1}}=1800 \mathrm{rpm}
$$

Torque on the alternator

$$
T_{r}=-\frac{T_{s}}{1} * 1.5=-1.5 * T_{s}
$$

Torque on the carrier

$$
T_{c}=2 * \frac{T_{s}}{R_{s}} *\left(R_{s}+\frac{R_{r}-R_{s}}{2}\right)=2 * \frac{T_{s}}{1} *\left(1+\frac{1.5-1}{2}\right)=2.5
$$




\subsection{Configuration 4. (Engine on the ring, Alternator on the sun, Motor on the carrier)}

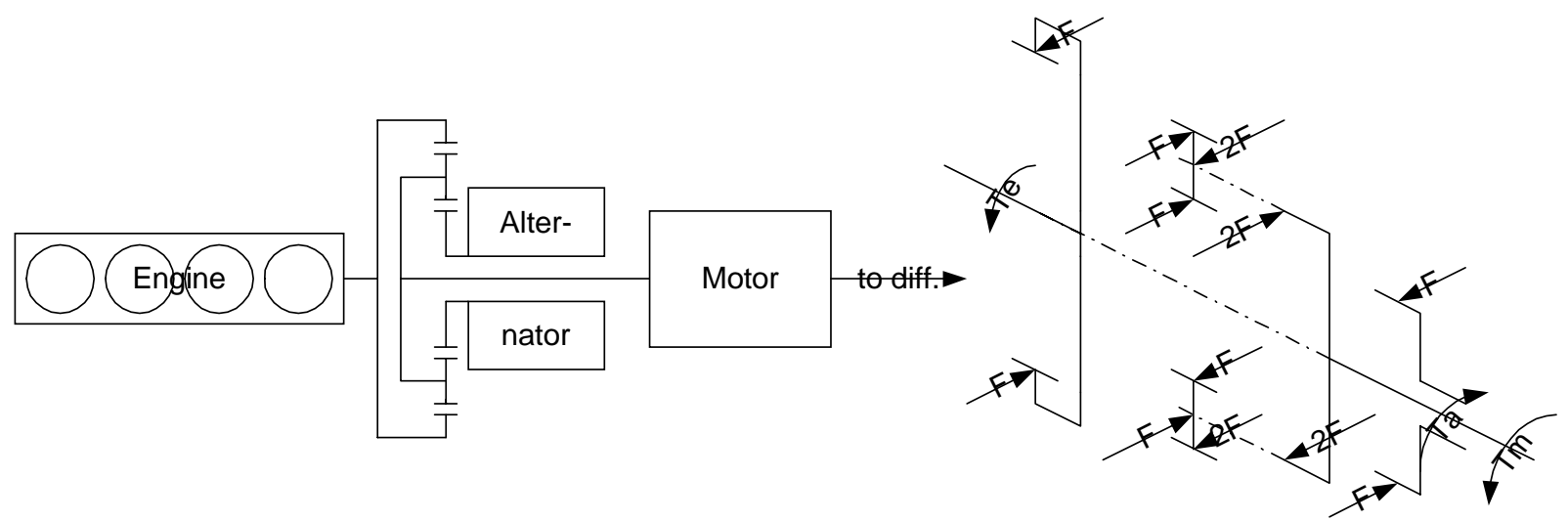

Figure 18. Configuration 4. Engine on the ring, Alternator on the sun, Motor on the carrier. Arrangement and Free body diagram.

The engine spins the ring gear while the alternator turns on the sun gear in reversed direction providing the counter torque when loaded. The torque of the alternator and the speed of the engine are controlled by the computer. Thus the torque of the engine on the ring and the torque of the alternator on the sun results a torque on the carrier in the same direction as the engine torque.

The torque on the shaft of the planetary carrier, which is the output torque

$$
T_{c}=2 * \frac{T_{r}}{R_{r}} *\left(R_{s}+\frac{R_{r}-R_{s}}{2}\right)
$$

The torque on the shaft of the sun gear, which is the alternator torque

$$
T_{s}=-\frac{T_{r}}{R_{r}} * R_{s}
$$


The Equation 30 calculates the speed of the sun gear as a function of the speeds of the sun gear and the planetary carrier.

$$
S_{s}=-S_{r} * \frac{R_{r}}{R_{s}}+S_{c} *\left(1+\frac{R_{r}}{R_{s}}\right)
$$

The alternator speed is highest when the vehicle is stationary and the engine spins at the highest speed.

$$
\begin{aligned}
& S_{s}=-S_{r} * \frac{R_{r}}{R_{s}} \\
& \frac{R_{r}}{R_{s}}=-\frac{S_{s}}{S_{r}}=-\frac{7500}{4500}=-1.666 \\
& \frac{R_{s}}{R_{r}}=-0.6
\end{aligned}
$$

The negative sign only means that the output torque and speed will be reversed direction to the input torque and speed. Planetary gearing ratio must be smaller than 1.667 from safety point of view so the alternator is not going to over spin. On the other hand, the alternator does not work at low speeds so the gearing ratio must be as large as possible. The largest possible is 1.66. This gives the following relative radii ratios for the sun, the ring and the planets

$$
\begin{aligned}
& \mathrm{Rs}=1 \\
& \mathrm{Rr}=1.66 \\
& \mathrm{R} p=0.33
\end{aligned}
$$

The maximum speed of the alternator

$$
S_{s}=-S_{r} * \frac{R_{r}}{R_{s}}=-S_{r} * \frac{1.667}{1}=-1.6667 * S_{r}=7500 \mathrm{rpm}
$$


The maximum output speed

$$
S_{c}=\frac{S_{r}}{1+\frac{R_{s}}{R_{r}}}=\frac{4500}{1+\frac{1}{1.667}}=2812.3 \mathrm{rpm}
$$

The torque on the shaft of the planetary carrier, which is the output torque using the relative radii calculated above will be

$$
T_{c}=T_{r} * 2 * \frac{R_{s}+\frac{\left(R_{r}-R_{s}\right)}{2}}{R_{r}}=T_{s} * 2 * \frac{1+\left(\frac{1.66-1}{2}\right)}{1.66}=1.6 * T_{r}
$$

The torque on the sun will be

$$
T_{s}=-\frac{T_{r}}{R_{r}} * R_{s}=\frac{1}{1.667} *-T_{r}=-0.6 * T_{r}
$$

This setup looks to be an excellent candidate for a vehicle application.

\subsection{Configuration 5. (Engine on the carrier, Alternator on the ring, Motor on the}

sun)

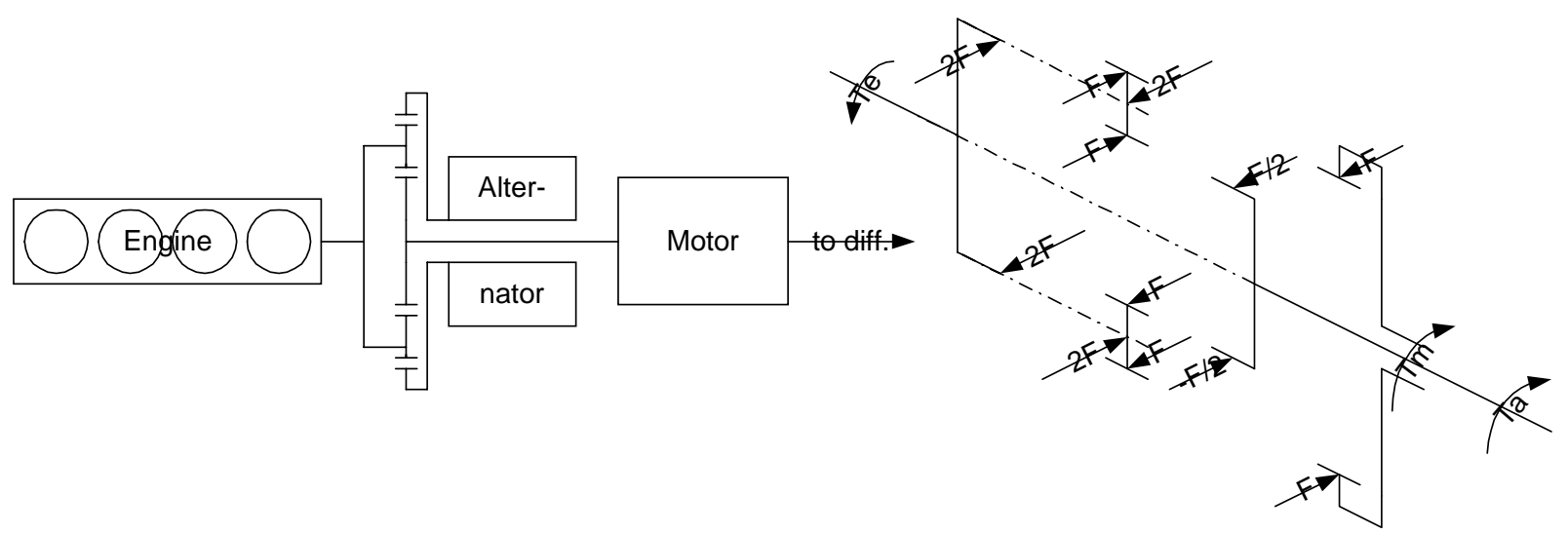

Figure 19. Configuration 5. Engine on the carrier, Alternator on the ring, Motor on the sun. Arrangement and Free body diagram.

The engine turns the planetary carrier while the alternator spins on the ring gear giving the counter torque when loaded. The torque of the alternator and the speed of the engine are 
controlled by the computer. So the torque of the engine on the planetary carrier and the counter-torque of the alternator on the ring results in a torque on the sun in the same direction as the engine torque.

The torque on the shaft of the sun gear, which is the output torque

$$
T_{s}=\frac{\frac{T_{c}}{R_{s}+\frac{R_{r}-R_{s}}{2}}}{2} * R_{s}
$$

The torque on the shaft of the ring gear, which is the alternator torque

$$
T_{r}=\frac{\frac{T_{c}}{R_{s}+\frac{R_{r}-R_{s}}{2}}}{2} * R_{r}
$$

The Equation 38 calculates the speed of the ring gear in the function of the speeds of the sun gear and the planetary carrier.

$$
S_{r}=S_{s}+\left(S_{c}-S_{s}\right) *\left(1+\frac{R_{s}}{R_{r}}\right)
$$

The alternator speed is the highest when the vehicle is stationary and the engine spins at the highest speed.

$$
\begin{aligned}
& S_{r}=S_{c} *\left(1+\frac{R_{s}}{R_{r}}\right)=S_{c}+S_{c} * \frac{R_{s}}{R_{r}} \\
& \frac{R_{s}}{R_{r}}=\frac{S_{r}-S_{c}}{S_{c}}=\frac{7500-4500}{4500}=0.6667
\end{aligned}
$$

The planetary gearing ratio must be smaller than 0.667 what is absolutely impossible without a gearbox between the ring and the alternator. This design, again, requires a low 
speed, high torque alternator, which is not typical for an alternator. It either requires an additional gearbox or the motor has to be mounted on the ring and the alternator on the sun.

Using 1:1.5 as gearing ratio, the maximum alternator speed would be

$$
S_{r}=S_{c} *\left(1+\frac{R_{s}}{R_{r}}\right)=4500 *\left(1+\frac{1}{1.5}\right)=1.6667 * S_{c}=7500 \mathrm{rpm}
$$

The maximum output speed

$$
S_{s}=S_{c} *\left(1+\frac{R_{r}}{R_{s}}\right)=4500 *\left(1+\frac{1.5}{1}\right)=11250 \mathrm{rpm}
$$

Torque on the alternator

$$
T_{s}=\frac{\frac{T_{c}}{1+\frac{1.5-1}{2}}}{2}=0.4 * T_{c}
$$

Torque on the ring gear

$$
T_{r}=\frac{\frac{T_{c}}{1+\frac{1.5-1}{2}}}{2} * 1.5=0.6 * T_{c}
$$

This arrangement can be a candidate too for hybrid vehicle application. 


\subsection{Configuration 6. (Engine on the carrier, Alternator on the sun, Motor on the} ring)

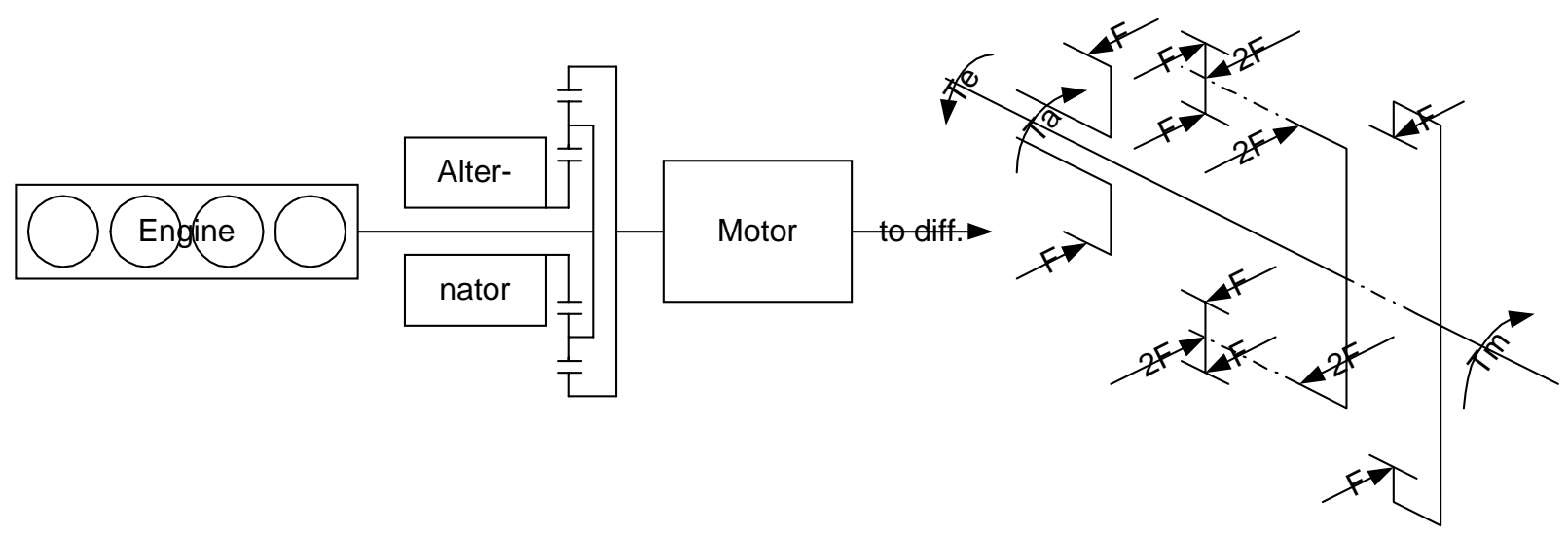

Figure 20. Configuration 6. Engine on the carrier, Alternator on the sun, Motor on the ring. Arrangement and Free body diagram.

The engine spins the planetary carrier while the alternator turns on sun gear giving the counter torque when loaded. The torque of the alternator and the speed of the engine are controlled by the computer. Thus the torque of the engine on the planetary carrier and the counter-torque of the alternator on the sun result a torque on the ring in the same direction as the engine torque.

The torque on the shaft of the ring gear, which is the output torque

$$
T_{r}=\frac{\frac{T_{c}}{R_{s}+\frac{R_{r}-R_{s}}{2}}}{2} * R_{r}
$$

The torque on the shaft of the sun gear, which is the alternator torque

$$
T_{s}=\frac{\frac{T_{c}}{R_{s}+\frac{R_{r}-R_{s}}{2}}}{2} * R_{s}
$$


The Equation 45.1 calculates the speed of the sun gear in the function of the speeds of the ring gear and the planetary carrier.

$$
S_{s}=S_{r}+\left(S_{c}-S_{r}\right) *\left(1+\frac{R_{r}}{R_{s}}\right)
$$

The alternator speed is the highest when the vehicle is stationary and the engine spins at the highest speed.

$$
\begin{aligned}
& S_{s}=S_{c} *\left(1+\frac{R_{r}}{R_{s}}\right)=S_{c}+S_{c} * \frac{R_{r}}{R_{s}} \\
& \frac{R_{r}}{R_{s}}=\frac{S_{r}-S_{c}}{S_{c}}=\frac{7500-4500}{4500}=0.6667 \\
& \frac{R_{s}}{R_{r}}=\frac{1}{0.667}=1.5
\end{aligned}
$$

The planetary gearing ratio must be larger than $1.5: 1$ from safety point of view so the alternator is not going to over speed. This is practically impossible. It means the alternator will be in the danger of over speeding. This can be taken care of by the control. This configuration also gives the possibility of using the alternator in its efficient region all the time.

Using 1:0.6667 as a gearing ratio the maximum alternator speed will be

$$
S_{s}=S_{c} *\left(1+\frac{R_{r}}{R_{s}}\right)=4500 *\left(1+\frac{1.5}{1}\right)=11250 \mathrm{rpm}
$$

The maximum output speed is

$$
S_{r}=S_{c} *\left(1+\frac{R_{s}}{R_{r}}\right)=4500 *\left(1+\frac{1}{1.5}\right)=1.6667 * S_{c}=7500 \mathrm{rpm}
$$

This speed is too high for the alternator. It might need a speed reducer or the control must have a speed limit for the alternator. That will limit the power output at low speed. 
The torque on the shaft of the ring gear, which is the output torque, will be

$T_{r}=\frac{\frac{T_{c}}{1+\frac{1.5-1}{2}}}{2} * 1.5=0.6 * T_{c}$

The torque on the sun will be

$T_{s}=\frac{\frac{T_{c}}{1+\frac{1.5-1}{2}}}{2}=0.4 * T_{c}$

\subsection{Comparison of Different Configurations}

Although all the six configurations discussed above are feasible and will work some of them have drawbacks and others have advantages. Some of them are more suitable for an existing vehicle design based on engine and motor speeds and torque than others. Table 5 summarizes the features of different configurations. These features are:

T.Eng. -Engine torque. (Basically the input torque to the system)

T.Mot. - The torque transmitted mechanically through the planetary gear drive. (It is the shaft to which the motor is connected.)

T.Alt. -Torque on the alternator shaft. (This torque is a counter torque. This controls the third degree of freedom in the planetary.)

S.Eng. -Engine speed. (Input speed to the system.)

S.Mot. -Maximum motor speed (planetary output speed), when alternator speed is zero.

S.Alt. -Maximum alternator speed, when motor speed is zero (vehicle is stationary).

Configuration \#1 -Engine on the sun, Alternator on the carrier, Motor on the ring

Configuration \#2 -Engine on the ring, Alternator on the carrier, Motor on the sun

Configuration \#3 -Engine on the sun, Alternator on the ring, Motor on the carrier 
Configuration \#4 -Engine on the ring, Alternator on the sun, Motor on the carrier Configuration \#5 -Engine on the carrier, Alternator on the ring, Motor on the sun Configuration \#6 -Engine on the carrier, Alternator on the sun, Motor on the ring

\begin{tabular}{|l|l|l|l|l|l|l|}
\hline Configuration & T.Eng. & T.Mot. & T.Alt. & S.Eng. & S.Mot. & S.Alt. \\
\hline$\# 1$ & 1 & 1.5 & 2.5 & 4500 & 3000 & 1800 \\
\hline$\# 2$ & 1 & 0.667 & 1.667 & 4500 & 6750 & 2700 \\
\hline$\# 3$ & 1 & 1.5 & -2.5 & 4500 & 1800 & -3000 \\
\hline$\# 4$ & 1 & 1.6 & -0.6 & 4500 & 2812 & -7500 \\
\hline$\# 5$ & 1 & 0.4 & 0.6 & 4500 & 11250 & 7500 \\
\hline$\# 6$ & 1 & 0.6 & 0.4 & 4500 & 7500 & 11250 \\
\hline
\end{tabular}

Table 5. Features of different configurations. 


\subsection{Speed Requirement of the Vehicle}

The input speed to the differential required to propel a Chevrolet Suburban at a road speed of 100mph using the existing final drive ratio of 3.72 is given by

$$
S=\frac{\frac{v^{*} 1605}{3600}}{D * \Pi} * 60 * Z=\frac{\frac{100 * 1605}{3600}}{0.8 * \Pi} * 60 * 3.72=3960 \mathrm{rpm}
$$

The input speed to the differential at $75 \mathrm{mph}$ is

$$
S=\frac{\frac{v^{*} 1605}{3600}}{D * \Pi} * 60 * Z=\frac{\frac{75 * 1605}{3600}}{0.8 * \Pi} * 60 * 3.72=2969 \mathrm{rpm}
$$

According to the calculations above only two configurations of the six possible can fulfill the speed requirement. They are \#5 and \#6. Configuration \#6 transmits $60 \%$ of the input torque mechanically and $40 \%$ of it electronically while configuration \#5 transmits only $40 \%$ mechanically and $60 \%$ of the input torque electronically. This implies that configuration \#6 has a better efficiency because the mechanical to electrical and electrical to mechanical conversion losses are lower in configuration \#6. This means that configuration \#6 is the best choice for the given application. Configuration \#6 is the same setup as the one used in the Toyota Prius.

Although configuration \#4 cannot meet the speed requirement using the original differential, it is the best choice if the differential is replaced by another one with a differential ratio of 2 . 
The required input speed to the differential in a Chevrolet Suburban to maintain a speed of 100mph using a novel final drive ratio of 2:1 is

$$
S=\frac{\frac{v^{*} 1605}{3600}}{D * \Pi} * 60 * Z=\frac{\frac{100 * 1605}{3600}}{0.8 * \Pi} * 60 * 2=2128 \mathrm{rpm}
$$

The input speed to the differential at $75 \mathrm{mph}$ is

$$
S=\frac{\frac{v^{*} 1605}{3600}}{D * \Pi} * 60 * Z=\frac{\frac{75 * 1605}{3600}}{0.8 * \Pi} * 60 * 3.72=1596 \mathrm{rpm}
$$

The advantage of configuration \#4 over configuration \#6 with proper sizing is that the alternator can not be over-speeded. Thus it can start off from stationary vehicle position with maximum power while configuration \#6 reaches its maximum power at about $10 \mathrm{mph}$. 


\section{Computer Simulation, HVSim 3.0}

The computer simulation of the Planetary Combination Hybrid was based on HVSim. HVSim is an effective hybrid vehicle simulator tool that has been developed at West Virginia University. HVSim has been described in the thesis of Kellermeyer [15].

HVSim can simulate a number of different vehicles with different hybrid configurations on different driving cycles. The vehicle configuration can vary from conventional vehicle to electric vehicle through many kind of hybrid vehicles.

HVSim is using a backward-looking kinetic simulation model. As a first step it uses the road load equation to calculate the power to propel the vehicle required at the wheels from the vehicle data and the driving cycle. Then it uses efficiency constants for the gearboxes and the differential to calculate the power required from the engine and the motor. HVSim uses lookup tables, or empirical maps, to define engine efficiency and motor efficiency as a function of torque and speed.

Using engine efficiency and motor efficiency the program calculates instantaneous fuel consumption and integrates it throughout the whole cycle. As a final step HVSim makes a correction on fuel economy taking into account the difference in state of charge of the battery pack over the cycle and yields the real fuel economy of the simulated vehicle. HVSim uses a modified battery pack model, described by Kellermeyer [15], to simulate the losses involved in the internal resistance of the battery.

HVSim 3.0 is extended by the simulation model of the PC-Hybrid. With this it is capable to simulate the whole spectrum of HEVs, EVs and conventional vehicles. It can simulate 10 different vehicles with 10 different engines on 10 different driving cycles. It provides the choice between manual, automatic and continuously variable transmissions. The 
output of the simulation program includes the instantaneous torque, speed and efficiency of different components and battery current, voltage and SOC on a second-by-second basis. The base of comparison for different configurations is the fuel economy corrected with the difference in SOC.

\section{Vehicle Data}

The simulated vehicle was a year 2000 Chevrolet Suburban. This vehicle is the subject of the FutureTruck Challenge project at West Virginia University. The vehicle ran and performed well in the FutureTruck2000 student competition as a parallel HEV. It is going to be modified to be a PC-Hybrid for year 2001.

\section{Chevrolet Suburban data [16]}

Mass:

$3220 \mathrm{~kg}$

Drag coefficient:

0.446

Frontal area:

$3.169 \mathrm{~m}^{2}$

Coefficient of rolling resistance: 0.0059

Differential ratio:

3.72 (configuration \# 6)

Differential ratio:

1.5 (configuration \# 4)

Wheel diameter:

$0.8 \mathrm{~m}$

\section{Component data}

Battery pack: $\quad 27 \times 12$ V Panasonic 17Ah batteries.

Engine: Detroit Diesel Corporation 642, inline 6 cylinder, $119 \mathrm{~kW}$ peak torque output.

Motor: $\quad$ Unique Mobility SR218, $75 \mathrm{~kW}$, permanent magnet brushless DC motor. 
Alternator:

Unique Mobility SR218, $75 \mathrm{~kW}$, permanent magnet brushless DC alternator.

Driving cycles used: HWFET cycle, FTP city cycle, US06 cycle 


\section{Simulation Results}

Simulation was performed on two of the possible configurations using four driving cycles. The two configurations were configuration \#4 and configuration \# 6. The driving cycles were the FTP city, the highway FET and, the US06 cycles and a cycle on 5\% grade at 55 mph steady speed.

\subsection{Configuration \# 4 on the FTP City Cycle}

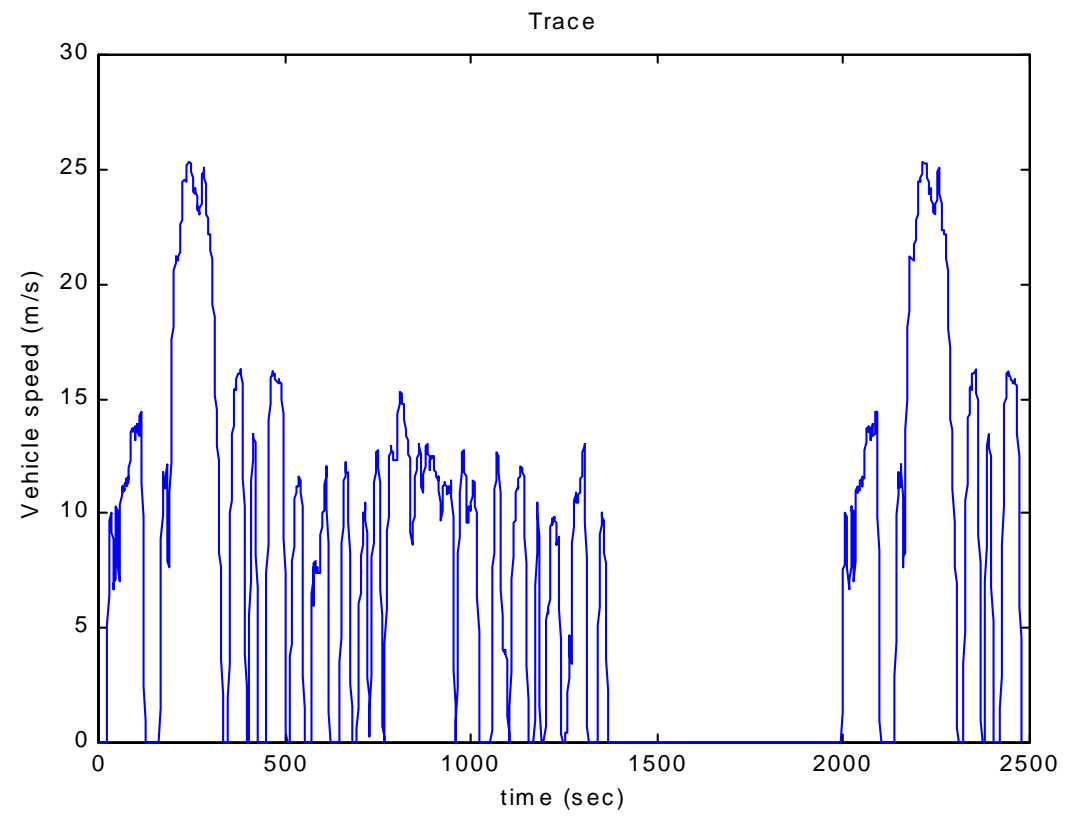

Figure 21. Speed vs. time on the FTP city cycle

Figure 22 shows the state of charge of the battery during the FTP city cycle starting from an initial SOC of $80 \%$. The chart shows that the vehicle takes off as an EV causing a rapidly decreasing SOC initially. As soon as the SOC drops to the set minimum (70\% in this case) the engine turns on and SOC starts increasing. The battery SOC never reaches the set upper limit during the FTP city cycle. The reason for this is the control system turns the engine off after 5 seconds of idling, whenever the vehicle came to a full stop and stayed stationary for more than 5 seconds, independently from the SOC is. 


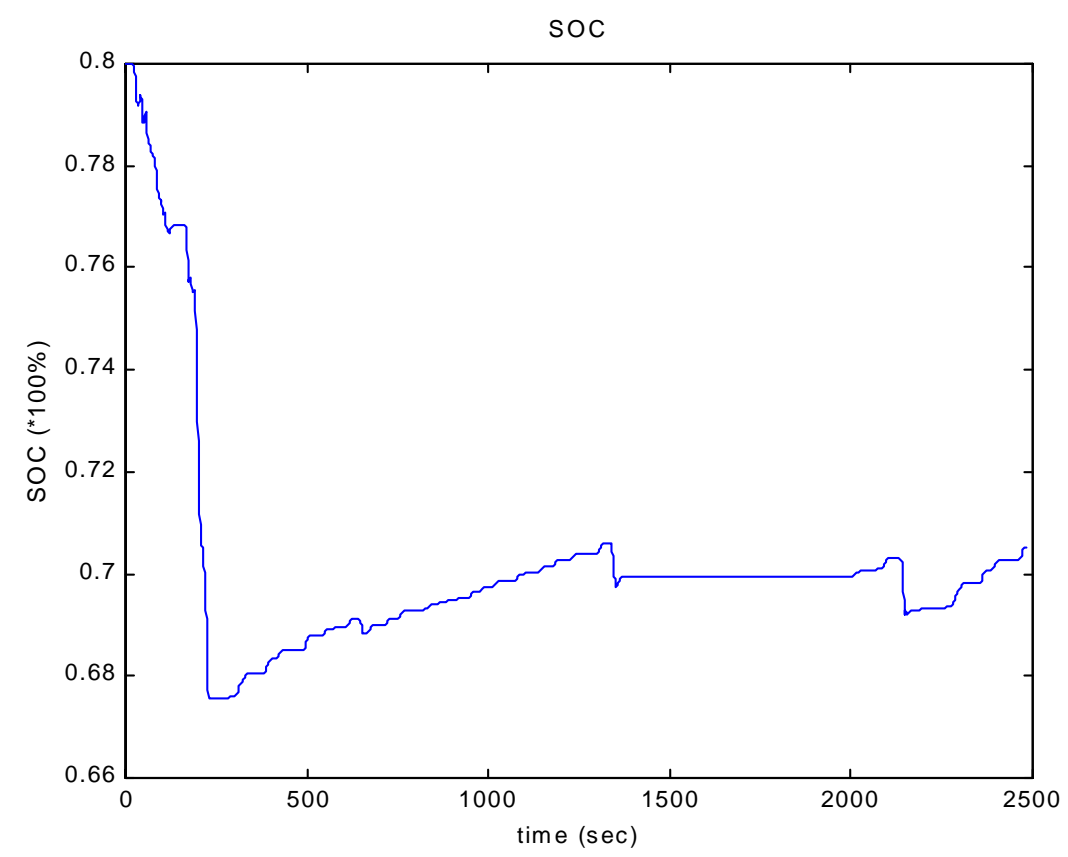

Figure 22. SOC vs. time on the FTP city cycle. Initial $\mathrm{SOC}=80 \%$

It can be seen in Figure 22 that the kinetic energy is captured and stored during the regenerative braking. Basically the engine gives a small rate of charge to the battery pack. The steep rises in SOC are due to the regenerative braking.

Figure 22.1 shows the battery SOC on the FTP city cycle starting from an initial SOC of $60 \%$. The lower limit of the SOC, where engine is programmed to turn on, was set to $70 \%$ so the engine immediately turns on and SOC starts increasing. Although the SOC never goes above the set maximum, where the engine is scheduled to turn off, the engine turns off twice due to the fuel saving control strategy. The computer turns the engine off as soon as vehicle stops and stays stationary for 5 seconds. Figure 22.1 shows that the vehicle is charge sustaining. 


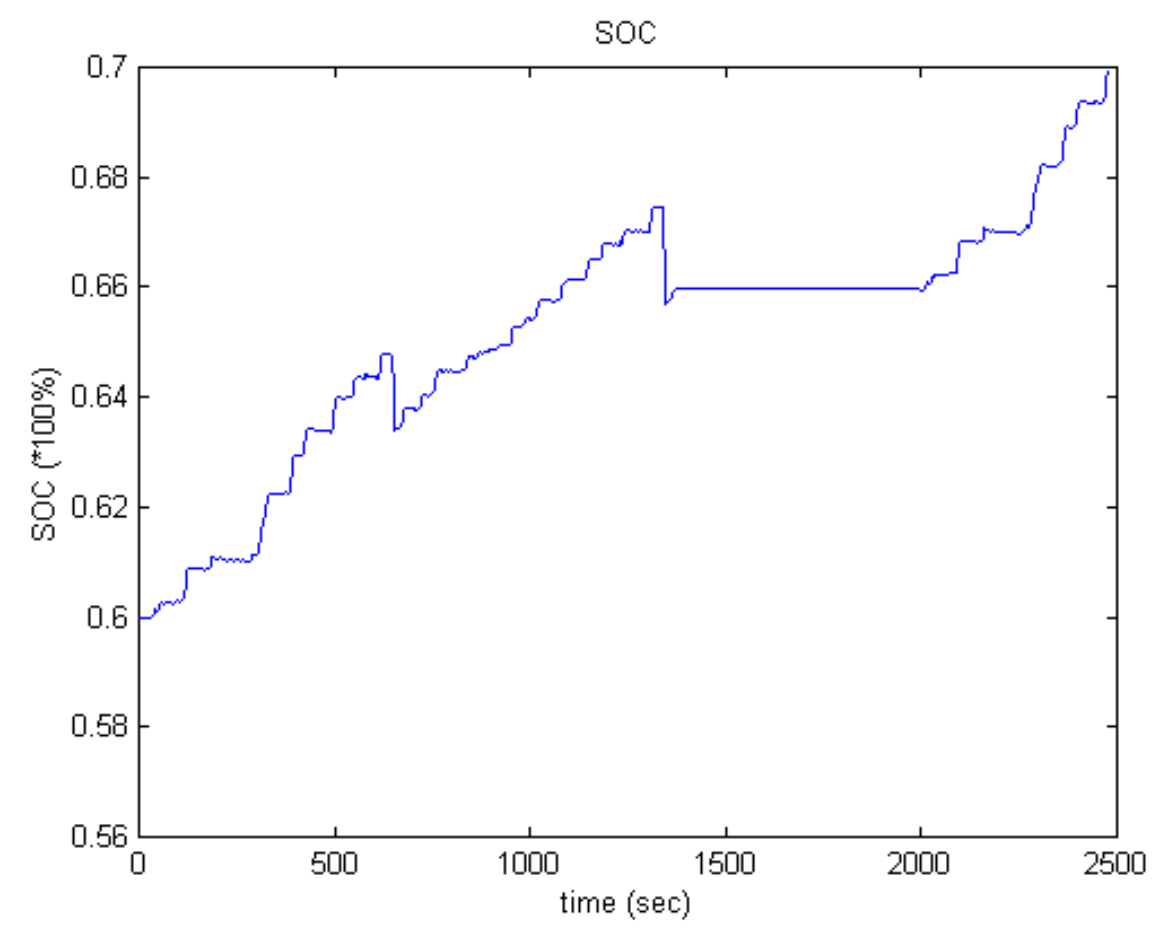

Figure 22.1. SOC vs. time on the FTP city cycle. Initial SOC $=60 \%$

Figure 23 shows the speed of the engine, the speed of the electric motor and the speed of the alternator. It is obvious that the engine is oversized for the FTP city cycle. Most of the time it is spinning at $1000 \mathrm{rpm}$, which is hardly above idling speed. The engine speeds up only to increase vehicle speed whenever the alternator reaches close to zero rpm so the unit has reached its maximum overdrive capability. The alternator speed gets close to zero, in order to maintain vehicle speed the engine has to rev up. Figure 23 also shows that the alternator is spinning backward whenever the engine is on. When the engine is off the alternator is spinning forward. 


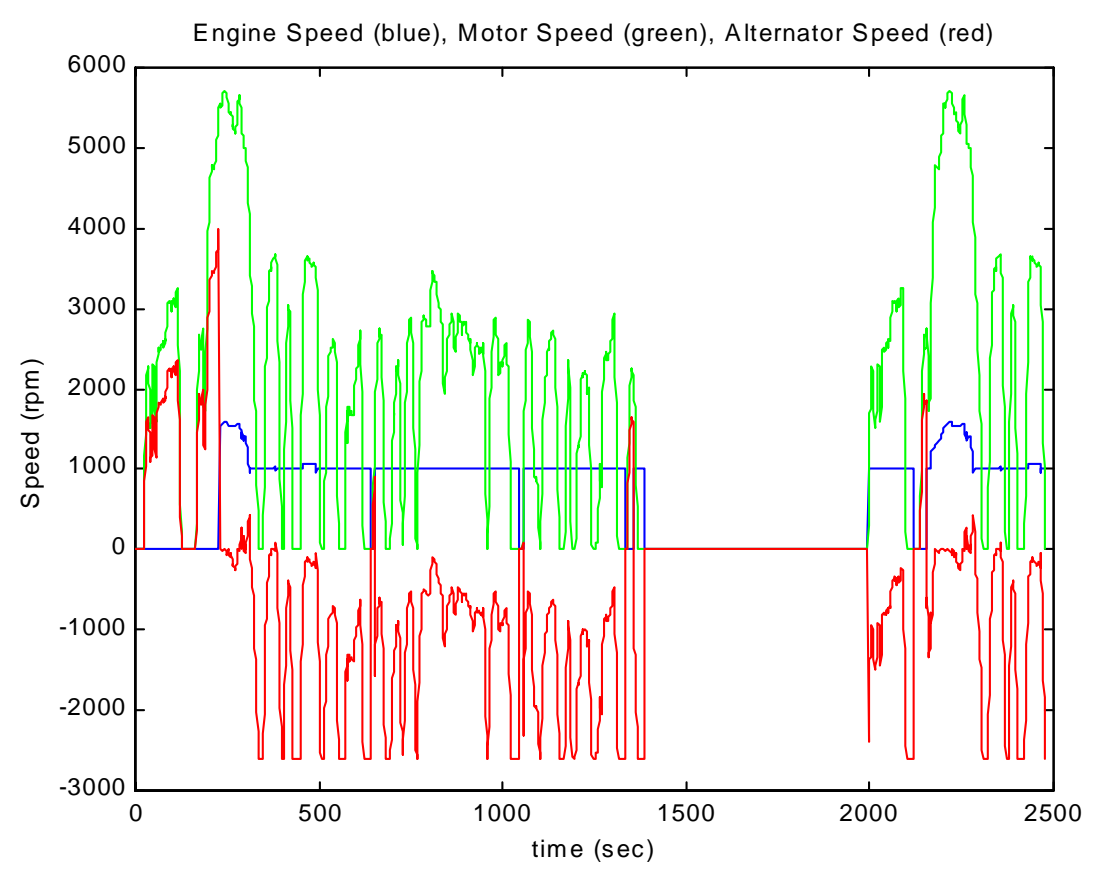

Figure 23. Engine speed, motor speed and alternator speed vs. time on the FTP city cycle.

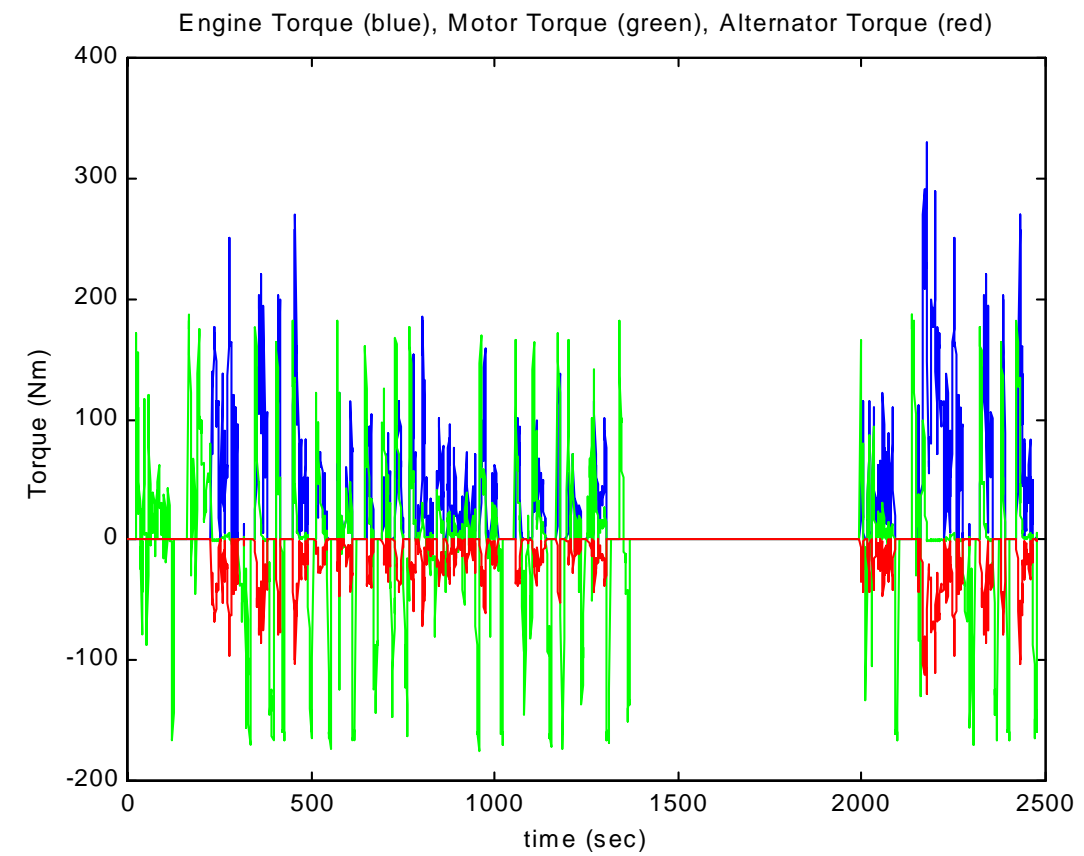

Figure 24. Engine torque, motor torque, and alternator torque vs. time on the FTP city cycle. 
Figure 24 shows the engine torque, motor torque and the alternator torque vs. time. It can be seen that the engine torque is proportional to the alternator torque. Alternator torque is opposite in direction to engine torque. Both alternator speed and torque have the same direction so the alternator is producing power. It is providing power to the electrical bus.

The negative torque on the motor can be seen only at braking. It shows clearly that the electric motor provides braking power while working as an alternator. It captures the kinetic energy of the vehicle.

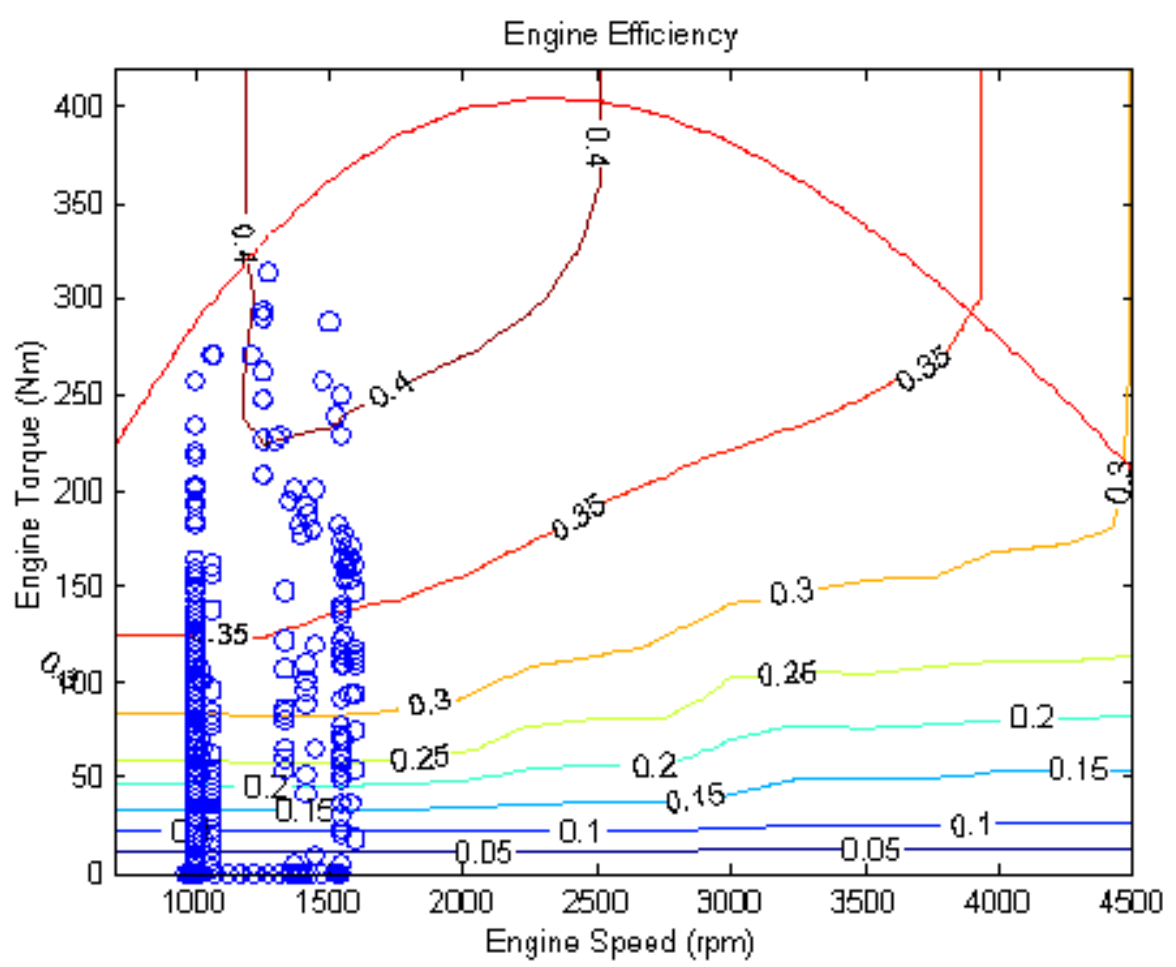

Figure 25. Engine efficiency as the function of engine speed and engine torque.

Figure 25 shows the engine efficiency as the function of engine speed and engine torque. It clearly shows that the engine mostly works at a speed of $1000 \mathrm{rpm}$ at relatively low torque. It does not need to operate at a high power output to provide enough power for propelling the Suburban on the FTP city cycle. The engine is oversized for this application.

Figure 26 shows the motor efficiency as a function of motor speed and motor torque. The points shown with an o on the plot are positive torque from motoring, points shown with 
an $\mathrm{x}$ are negative torque from regenerating and the blue color means that the rotational direction is the same as the engine rotational direction. The motor operates at low torque most of the time. Figure 24 shows that high torque is required from the motor only when the engine is off or during regenerative braking.

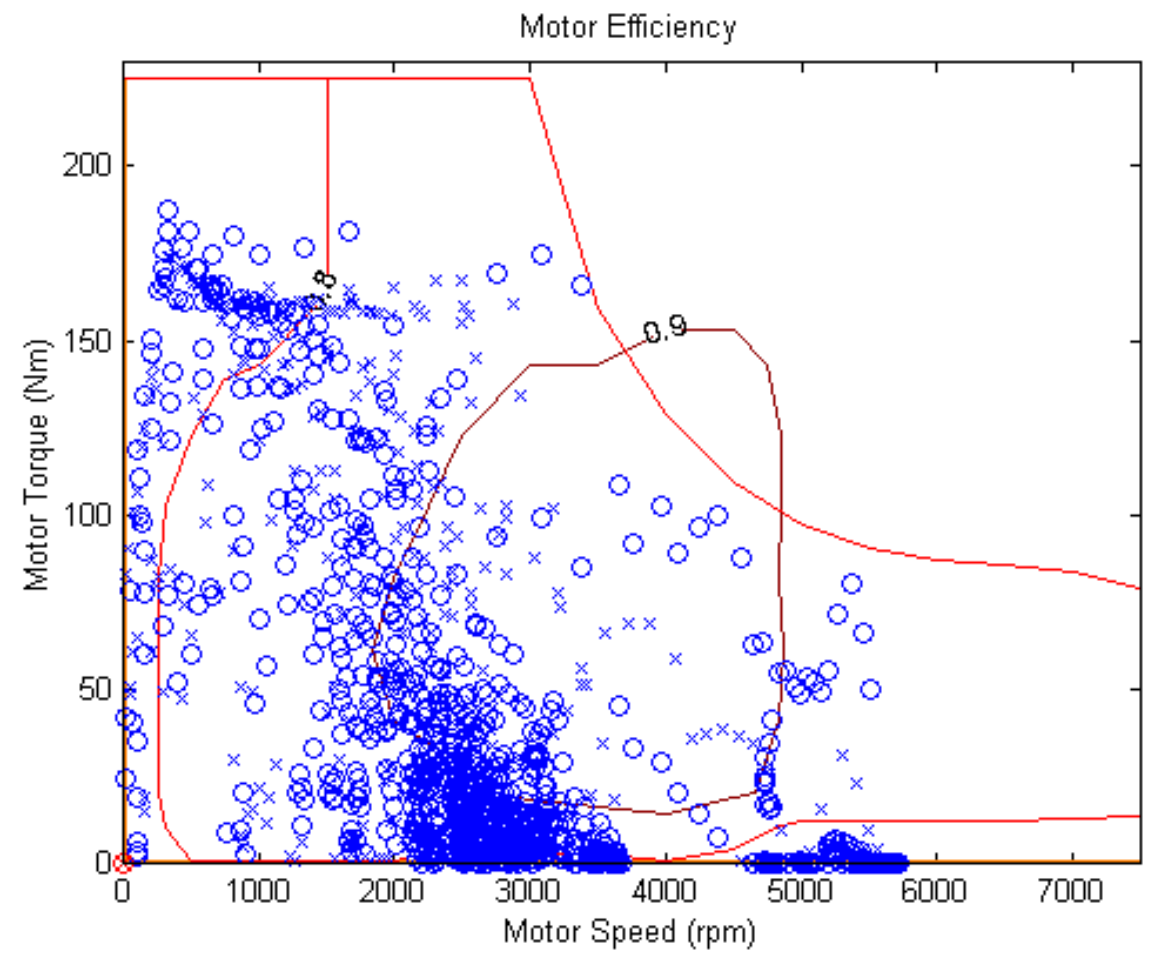

Figure 26. Motor efficiency as the function of motor speed and motor torque.

Figure 27 shows the alternator efficiency as the function of alternator speed and alternator torque. The points shown with an $\mathrm{x}$ are defining regenerative torque and the red color shows that the rotational direction is opposite to the engine rotational direction. Some blue circles can be seen but only at zero torque and when the engine is turned off. It means that when the engine is off the alternator is spinning forward with no load on it acting only as a flywheel. The motor is properly sized for this application. 


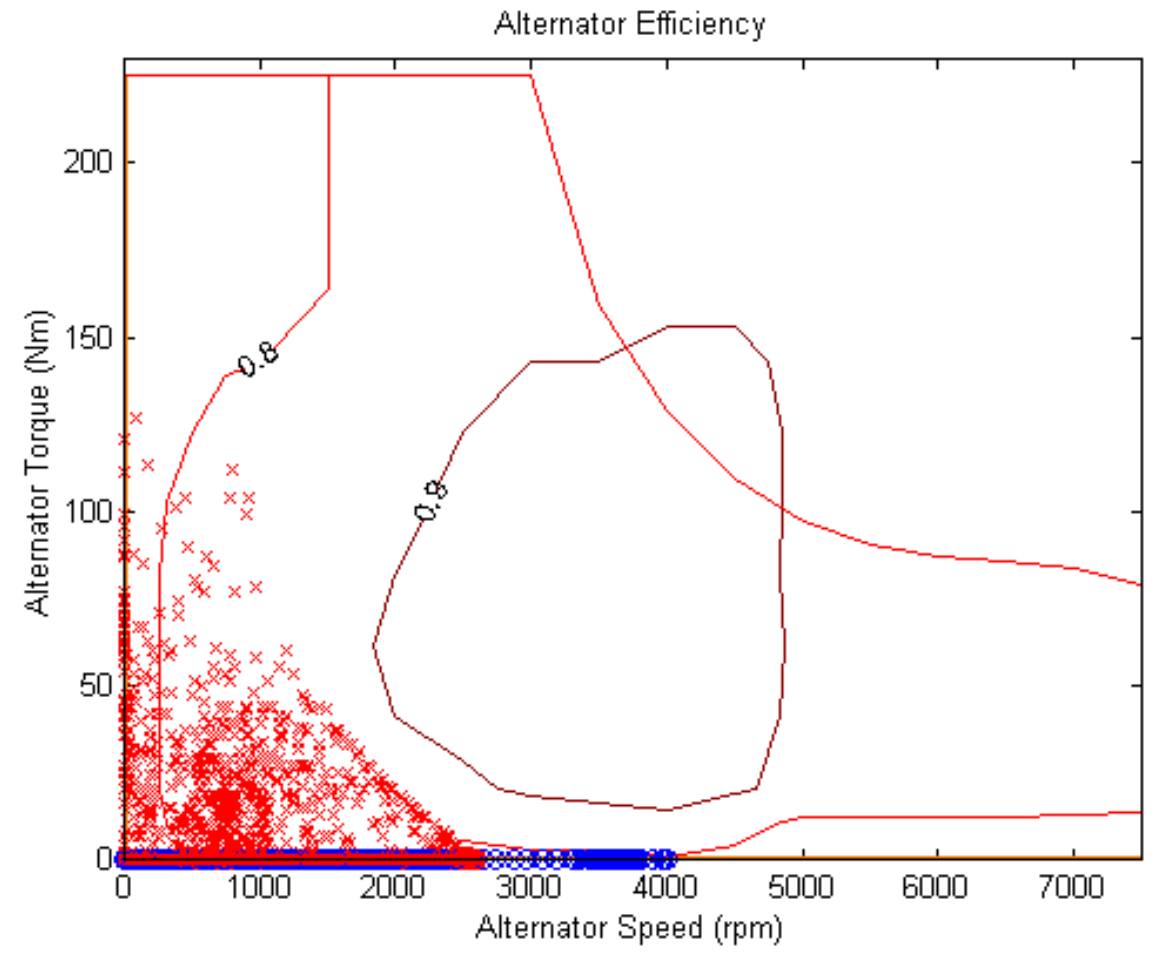

Figure 27. Alternator efficiency as the function of alternator speed and alternator torque. 


\subsection{Configuration \# 4 on the HWFET Cycle}

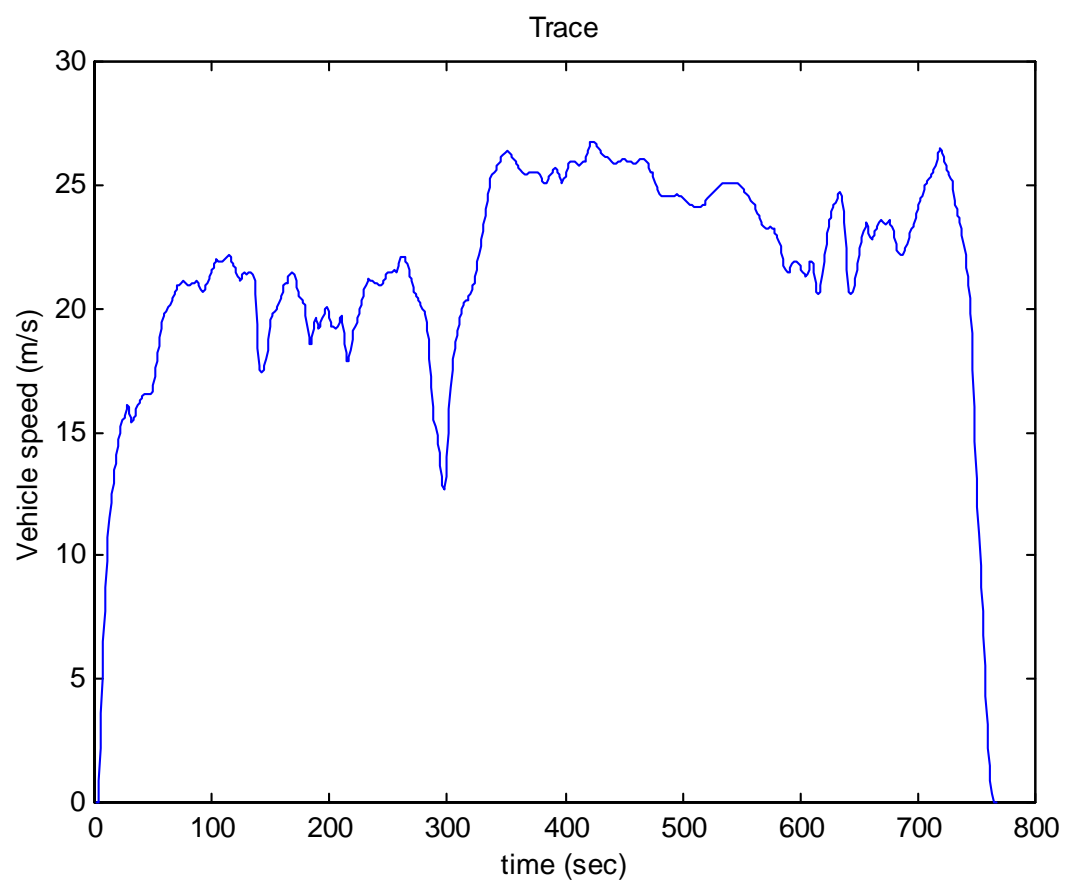

Figure 28. Speed vs. time on the HWFET test cycle.

Figure 29 shows the state of charge of the battery during the HWFET cycle. The chart shows that the vehicle takes off as an EV causing a rapidly decreasing SOC initially. As soon as the SOC drops to the set minimum the engine turns on and SOC starts increasing. The difference in SOC throughout the cycle is negative. On the other hand looking only at the section when the engine is on the difference in SOC is positive. The battery SOC never reaches the set upper limit during the HWFET cycle. This is because when the engine is off the battery gets depleted rapidly and the increase of SOC is moderate. The reason is that the control is optimized and does not charge the battery more than it is ideal and the trace is too short for a complete charge so the engine does not turn off on the highway cycle. The engine turns back on again as soon as current out of batteries exceeds the set limit of 400 amps. 


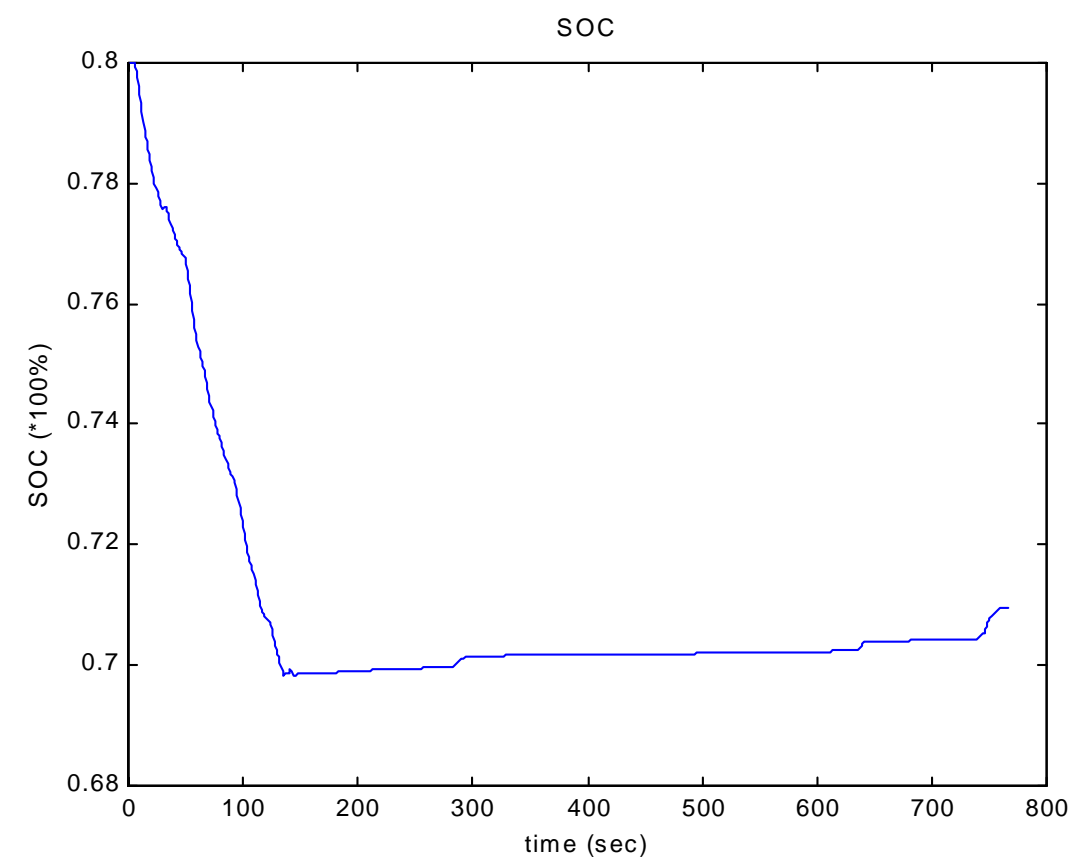

Figure 29. SOC vs. time on the HWFET cycle.

It can be seen in Figure 29 that the kinetic energy is captured and stored during the regenerative braking. Basically the engine gives a small rate of charge to the battery pack. The steep rises in SOC are from the regenerative braking.

Figure 30 shows the speed of the engine, the speed of the electric motor and the speed of the alternator. It can be seen that the vehicle speed is higher than on the city cycle. The alternator speed is close to zero, so in order to maintain vehicle speed the engine has to speeds up. This places the engine out of its most efficient range. Figure 30 also shows that the alternator is spinning backward whenever the engine is on. When the engine is turned off the alternator is spinning forward. 


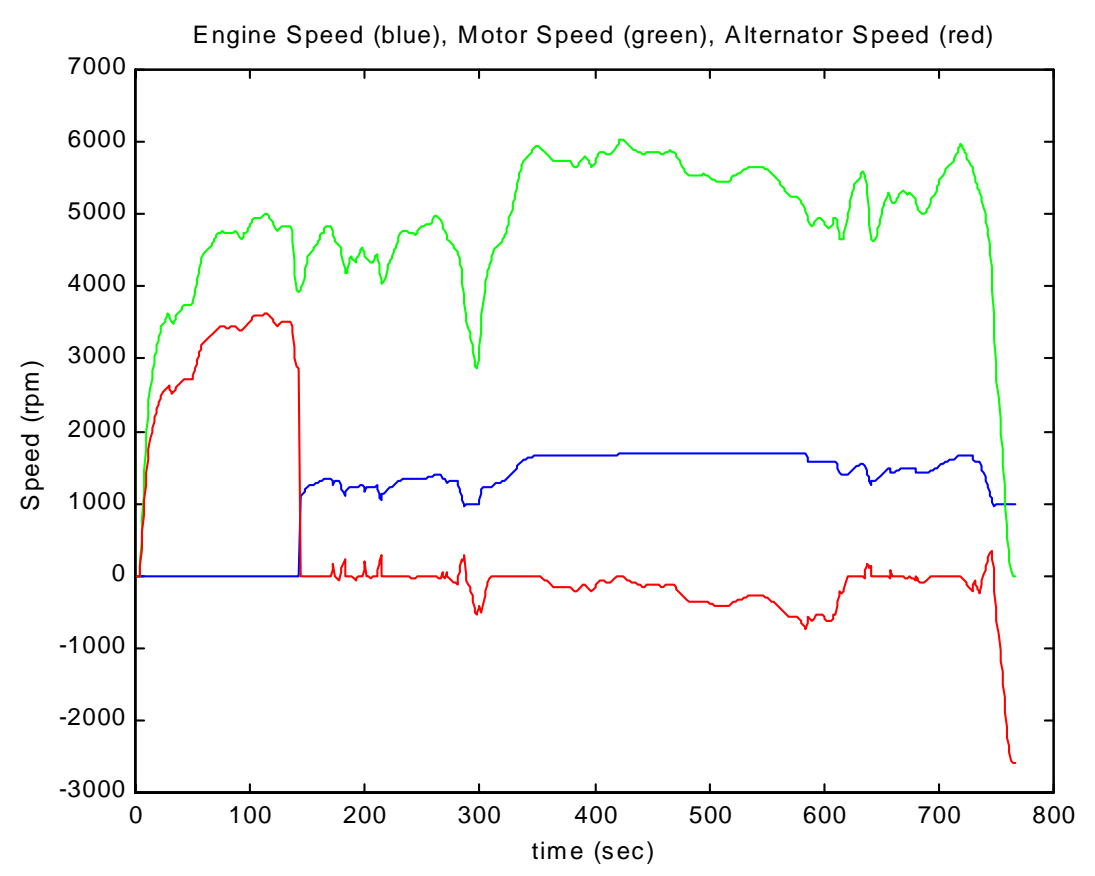

Figure 30. Engine speed, motor speed and alternator speed vs. time on the HWFET cycle.

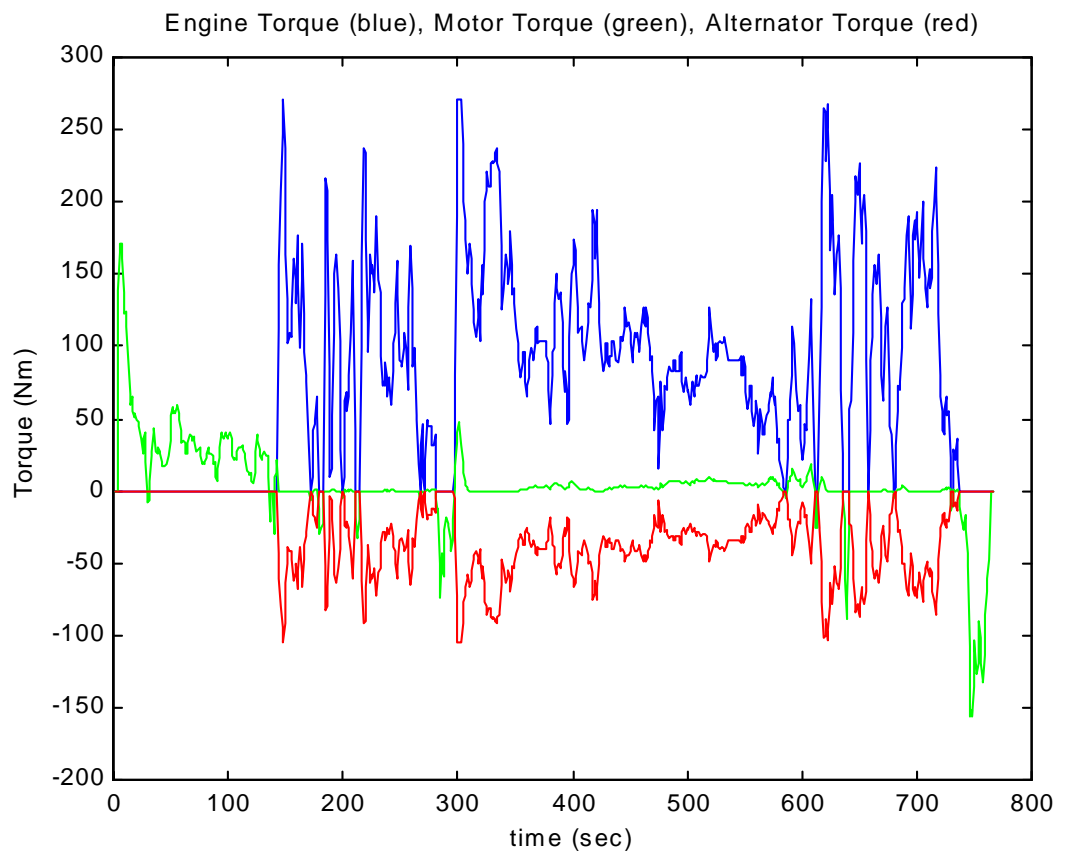

Figure 31. Engine torque, motor torque and alternator torque vs. time on the HWFET cycle. 
Figure 31 shows the engine torque, motor torque and the alternator torque vs. time. It can be seen that the engine torque is proportional to the alternator torque. Alternator torque is opposite in direction to engine torque. Both alternator speed and torque have the same direction so the alternator produces power. It is provides power to the electrical bus.

The negative torque on the motor can be seen only at braking. It shows clearly that the electric motor provides braking power while working as an alternator. It captures the kinetic energy of the vehicle. When the vehicle has reached its cruising speed the electric motor has hardly any torque on it. That shows that the vehicle is uses mainly the engine as a power source so it operates very close to a conventional vehicle with an above average overdrive ratio $(0.6)$.

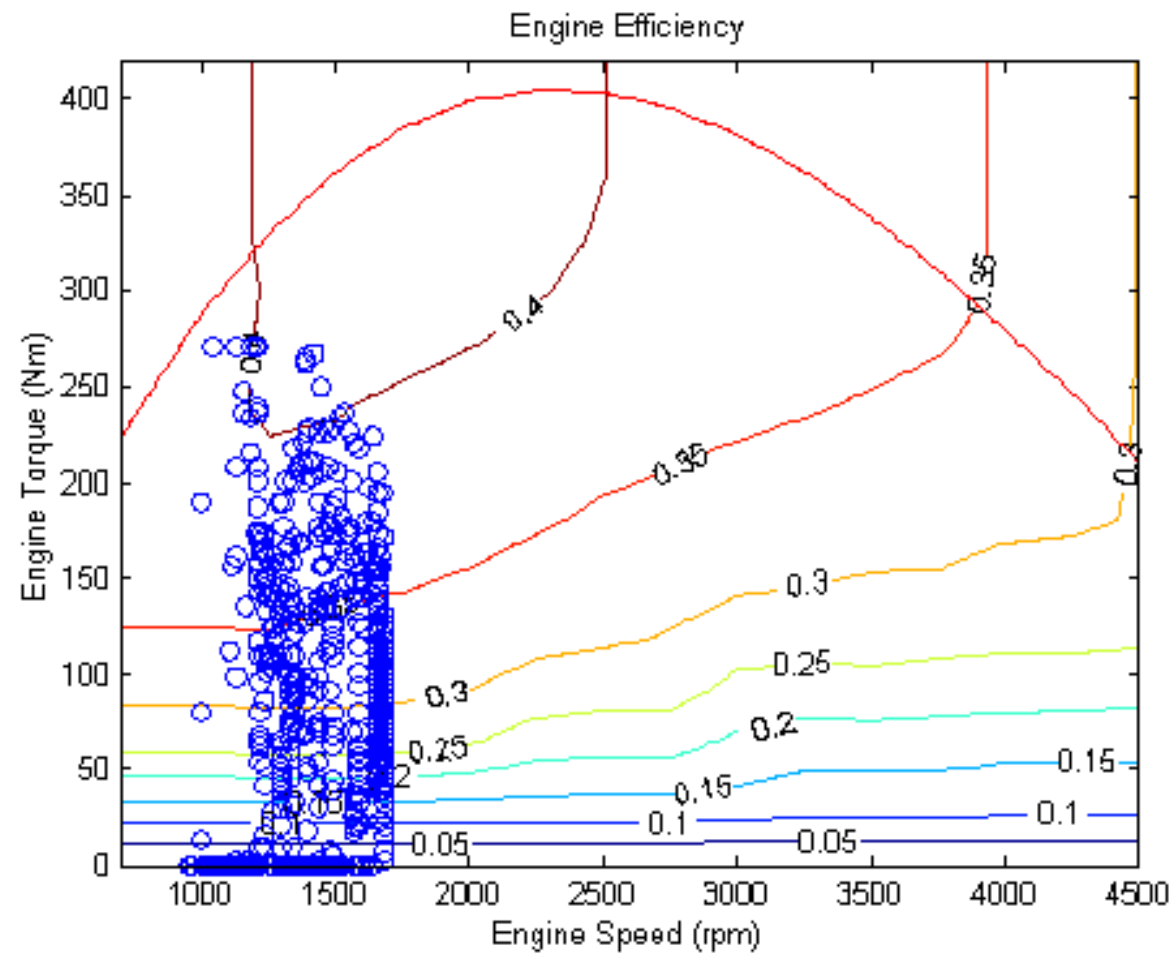

Figure 32. Engine efficiency as the function of engine speed and engine torque. 
Figure 32 shows the engine efficiency as the function of engine speed and engine torque on the HWFET cycle. It clearly shows that the maximum engine speed is 1600rpm. It does not need to operate at a high power output to provide enough power for propelling the Suburban on the HWFET cycle. It does not need to operate at a high speed either due to high overdrive. The engine never operates at the maximum available torque, that the engine is oversized for this application too.

Figure 33 shows the motor efficiency as a function of motor speed and motor torque. The points shown with an o on the plot are positive torque from motoring, points shown with an $\mathrm{x}$ are negative torque from regenerating and the blue color means that the rotational direction is the same as the engine rotational direction. The motor operates at close to zero torque most of the time. Figure 31 shows that high torque is required from the motor only when the engine is off or during regenerative braking.

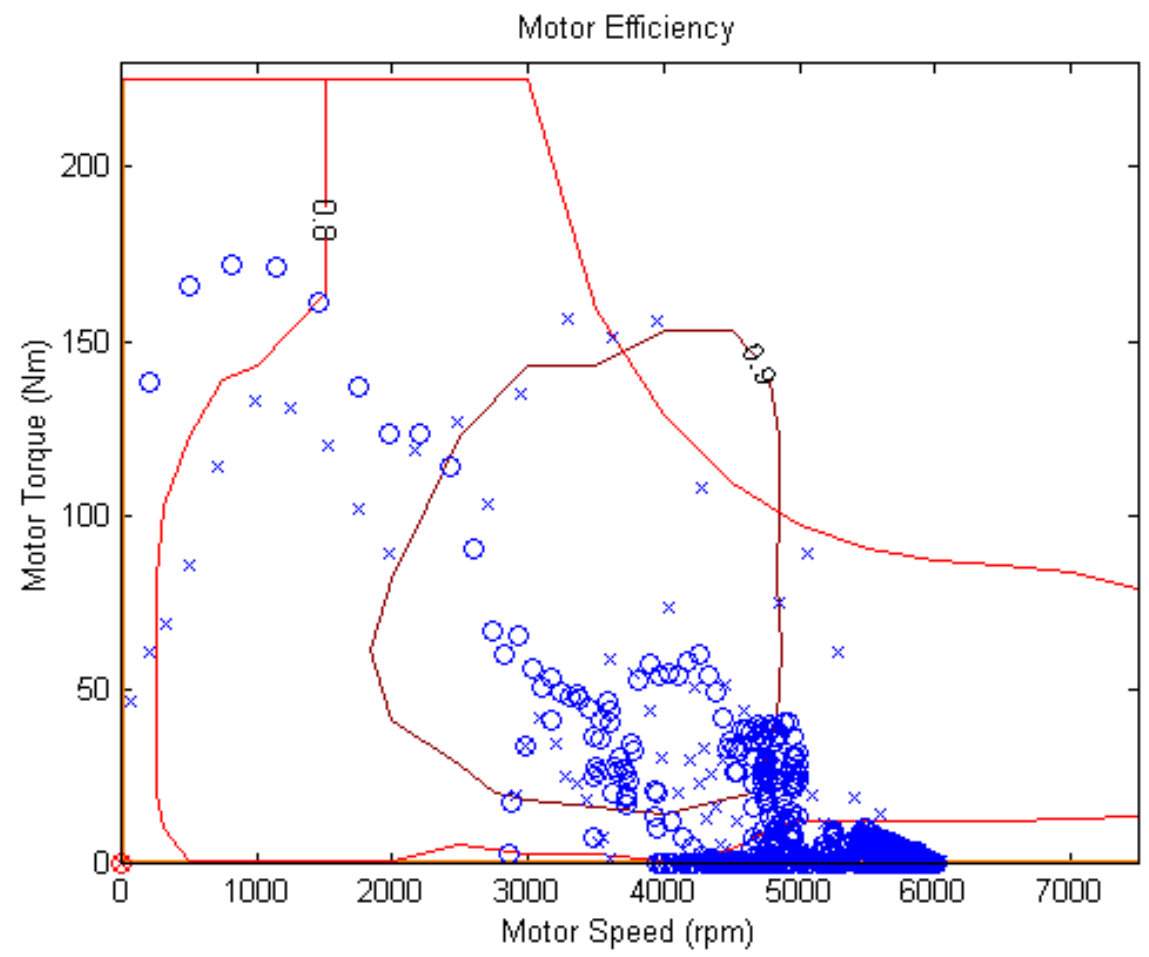

Figure 33. Motor efficiency as the function of motor speed and motor torque. 
Figure 34 shows the alternator efficiency as the function of alternator speed and alternator torque. The points shown with an $\mathrm{x}$ are defining regenerative torque and the red color shows that the rotational direction is opposite to the engine rotational direction. Some blue circles can be seen but only at zero torque. It happens only when the engine is turned off. It means that when the engine is off the alternator is spinning forward with no load on it acting only as a flywheel.

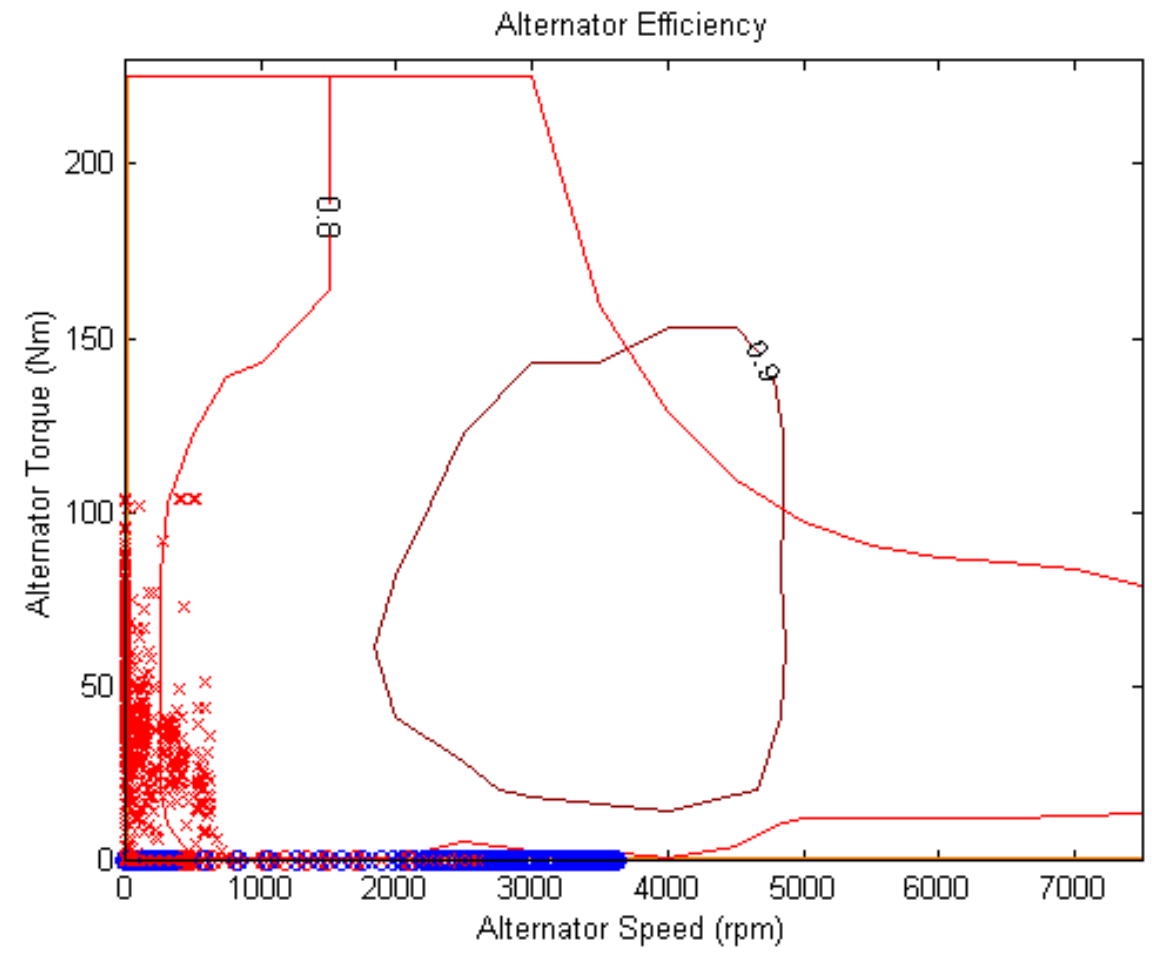

Figure 34. Alternator efficiency as the function of alternator speed and alternator torque. 


\subsection{Configuration \# 4 on the US06 Cycle}

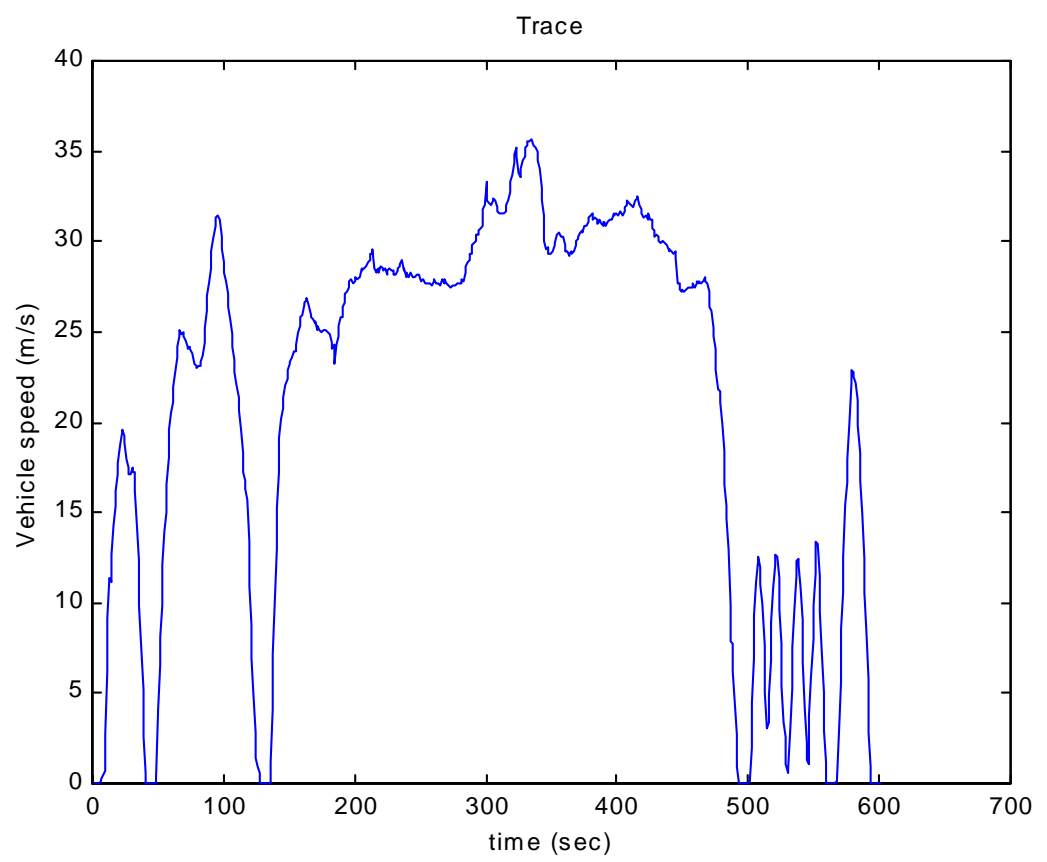

Figure 35. Speed vs. time on the US06 test cycle.

Figure 36 shows the state of charge of the battery during the US06 cycle. The chart shows that the vehicle takes off as an EV causing a rapidly decreasing SOC initially. As soon as the SOC drops to the set minimum the engine turns on and SOC starts increasing. Although the final battery SOC is close to the set upper SOC of the battery, it never reaches it during the US06 cycle. The reason is that the control is optimized and does not charge the battery more than it is ideal and the trace is too short for a complete charge so the engine does not turn off on the US06 cycle. 


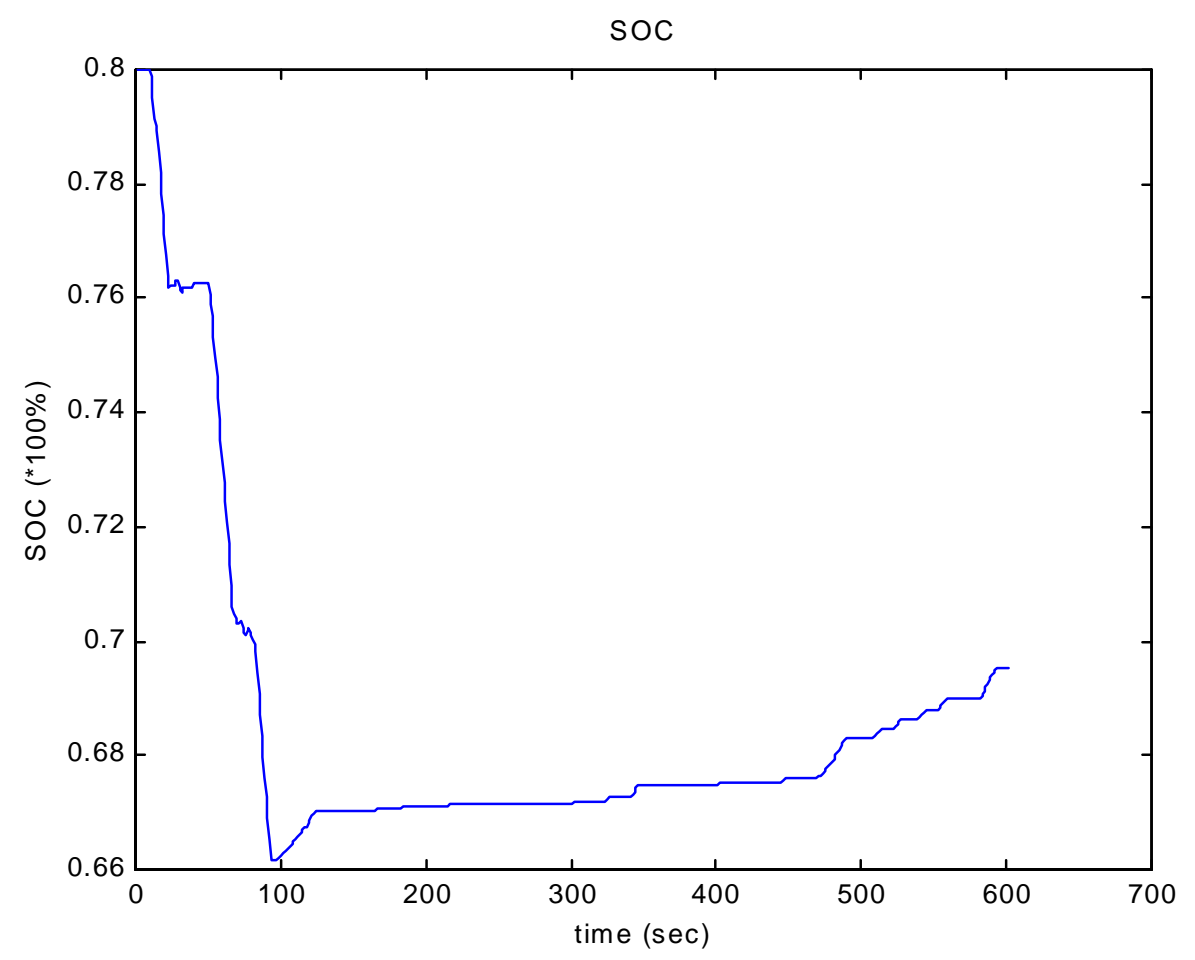

Figure 36. SOC vs. time on the US06 cycle.

It can be seen in Figure 36 that the kinetic energy is captured and stored during the regenerative braking such as on the previous cycles. Basically the engine gives a small rate of charge to the battery pack. The steep rises in SOC are from the regenerative braking.

Figure 37 shows the speed of the engine, the speed of the electric motor and the speed of the alternator. It can be seen that, at the middle section of the trace, the vehicle speed is higher than on the city cycle. The alternator speed is close to zero, so in order to maintain vehicle speed the engine has to speed up. Of course it places the engine out of its most efficient range. Figure 37 also shows that the alternator is spinning backward whenever the engine is on. When the engine is turned off the alternator is spinning forward. The figure also shows that the engine and the alternator both speed up, whenever the power demand is high, making the engine operate at higher speed that gives higher possible power output. 


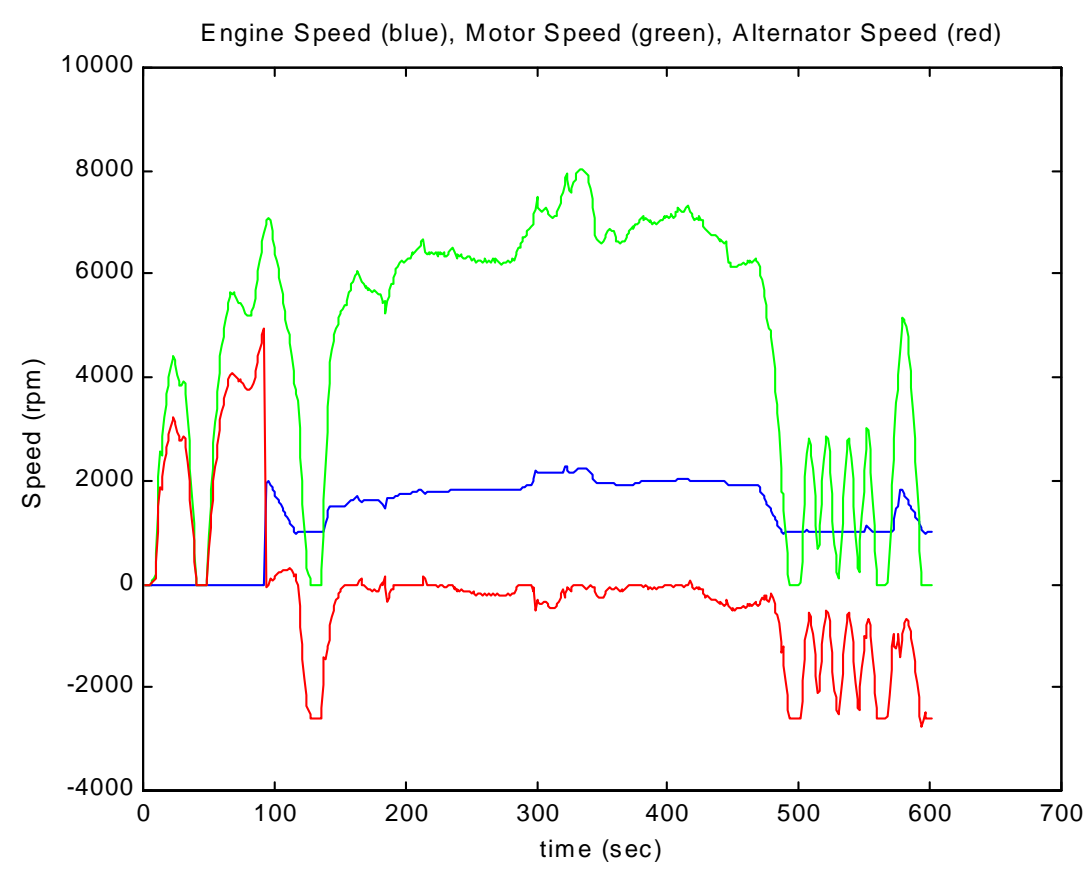

Figure 37. Engine speed, motor speed and alternator speed vs. time on the US06 cycle.

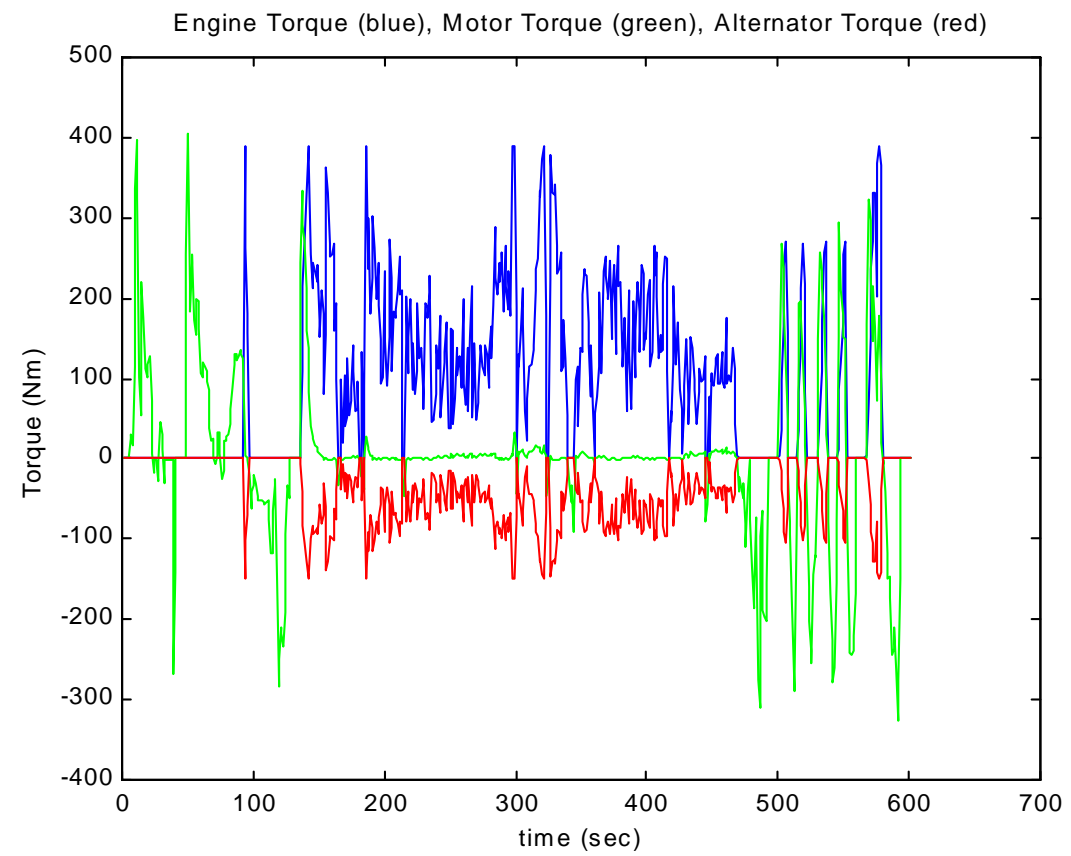

Figure 38. Engine torque, motor torque and alternator torque vs. time on the US06 cycle. 
Figure 38 shows the engine torque, motor torque and the alternator torque vs. time. It can be seen that the engine torque is proportional to the alternator torque and the alternator torque has the opposite direction as engine torque. Both alternator speed and torque have the same direction so the alternator is producing power, it is providing power to the electrical bus.

The negative torque on the motor can be seen only at braking. It shows clearly that the electric motor provides the braking power working as an alternator. It captures the kinetic energy of the vehicle. When the vehicle has reached its cruising speed the electric motor has hardly any torque on it. That shows that the vehicle is uses mainly the engine as a power source such that it operates very close to a conventional vehicle with an above average overdrive ratio (0.6). This means very little battery losses are involved.

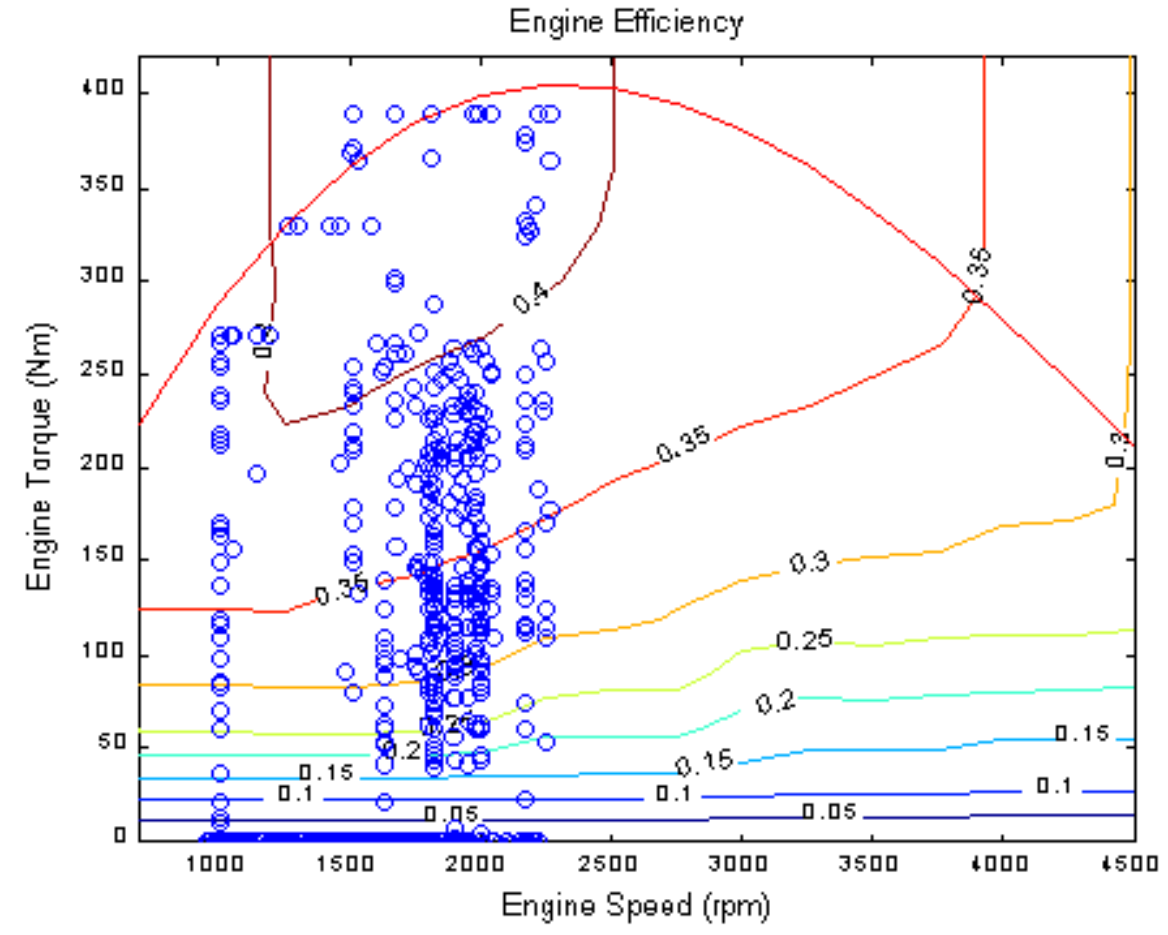

Figure 39. Engine efficiency as the function of engine speed and engine torque. 
Figure 39 shows the engine efficiency as the function of engine speed and engine torque on the FTP highway cycle. It clearly shows that the engine often speeds up to higher rpm to provide enough power to make the vehicle follow the trace. It reaches the maximum torque curve frequently but never reaches its maximum power output. This shows that this is appropriate engine for this application

Figure 40 shows the motor efficiency as a function of motor speed and motor torque. The points shown with an o on the plot are positive torque from motoring, points shown with an $\mathrm{x}$ are negative torque from regenerating and the blue color means that the rotational direction is the same as the engine rotational direction. The motor is providing significant amount of power during the US06 cycle. It reaches maximum its maximum torque a couple of times. Figure 38 also shows that extremely high torque is required from the motor when the engine is off. This means the motor is undersized for this application.

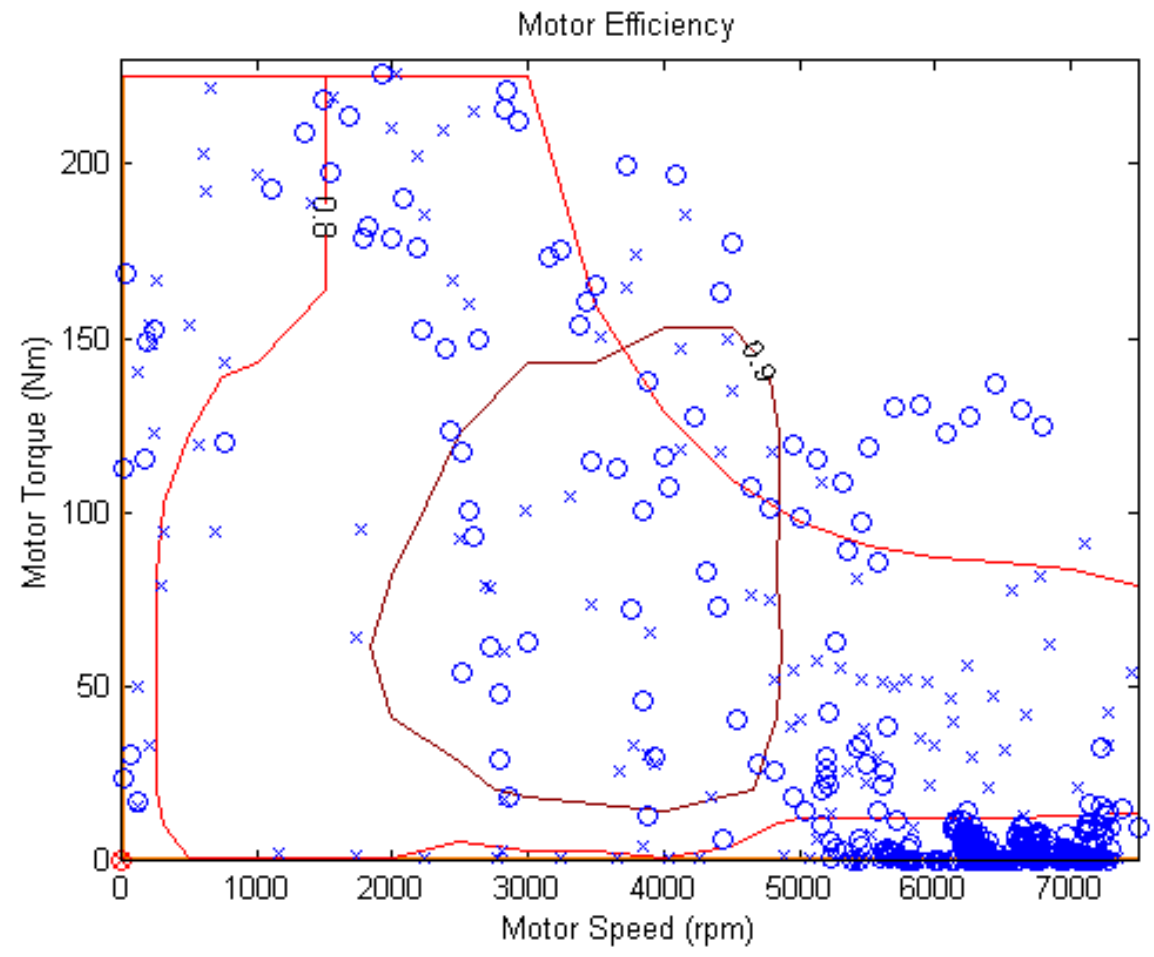

Figure 40. Motor efficiency as the function of motor speed and motor torque. 
Figure 41 shows the alternator efficiency as the function of alternator speed and alternator torque. The points shown with an $\mathrm{x}$ are defining regenerative torque and the red color shows that the rotational direction is opposite to the engine rotational direction. Some blue circles can be seen but only at zero torque. It happens only when the engine is turned off. It means that when the engine is off the alternator is spinning forward with no load on it acting only as a flywheel. The alternator operates only at low speed, low torque range. This shows that the alternator is oversized even for the US06, which is the most severe cycle.

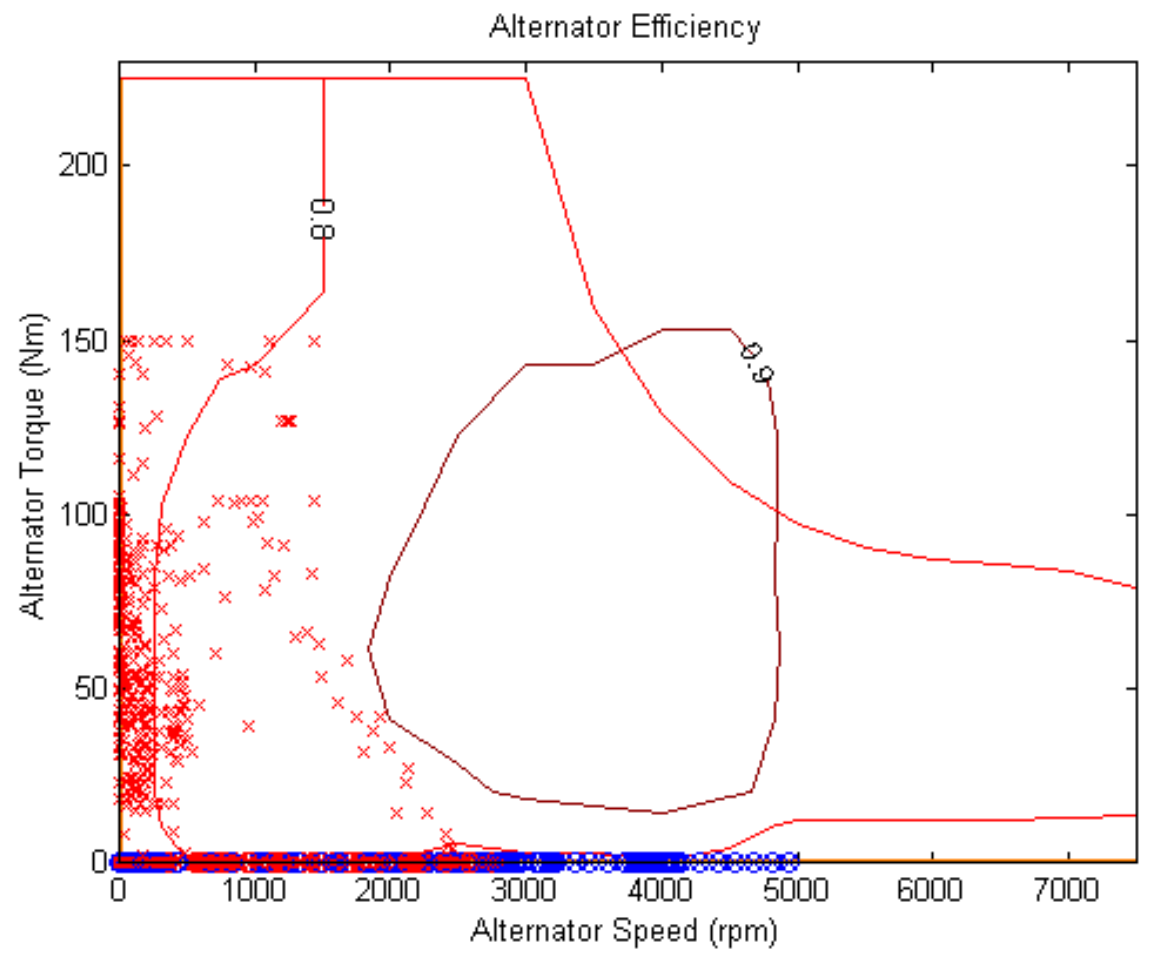

Figure 41. Alternator efficiency as the function of alternator speed and alternator torque. 


\subsubsection{Configuration \# 4 on a $5 \%$ grade at $55 \mathrm{mph}$ steady speed}

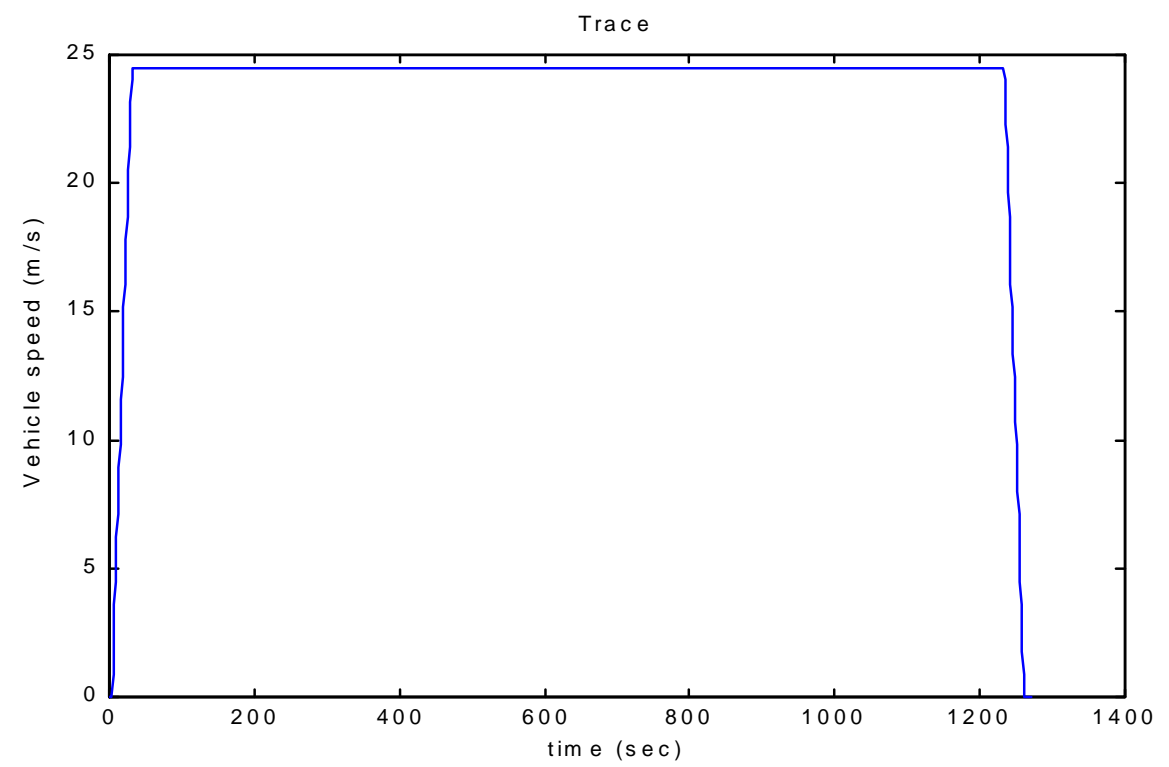

Figure 41.1. Speed vs. time on a $5 \%$ grade at $55 \mathrm{mph}$ steady speed.

Figure 41.2 shows the state of charge of the battery on a $5 \%$ grade at $55 \mathrm{mph}$ steady speed. The chart shows that the vehicle takes off as an EV causing a quickly decreasing SOC initially. As soon as the battery current exceeds 400 amps the engine turns on and SOC stays steady. The difference in SOC throughout the cycle is negative. On the other hand looking only at the section when the engine is on the difference in SOC is positive. This means that the vehicle is charge sustaining even on $5 \%$ grade. The battery SOC never reaches the set upper limit on a $5 \%$ grade at $55 \mathrm{mph}$ steady speed. This is because when the engine is off the battery gets depleted rapidly and the increase of SOC is moderate when the engine is on. The reason for that is the control is optimized and does not charge the battery more than it is ideal and the trace is too short for a complete recharge so the engine does not turn off on the $5 \%$ grade at 55 mph steady speed. 


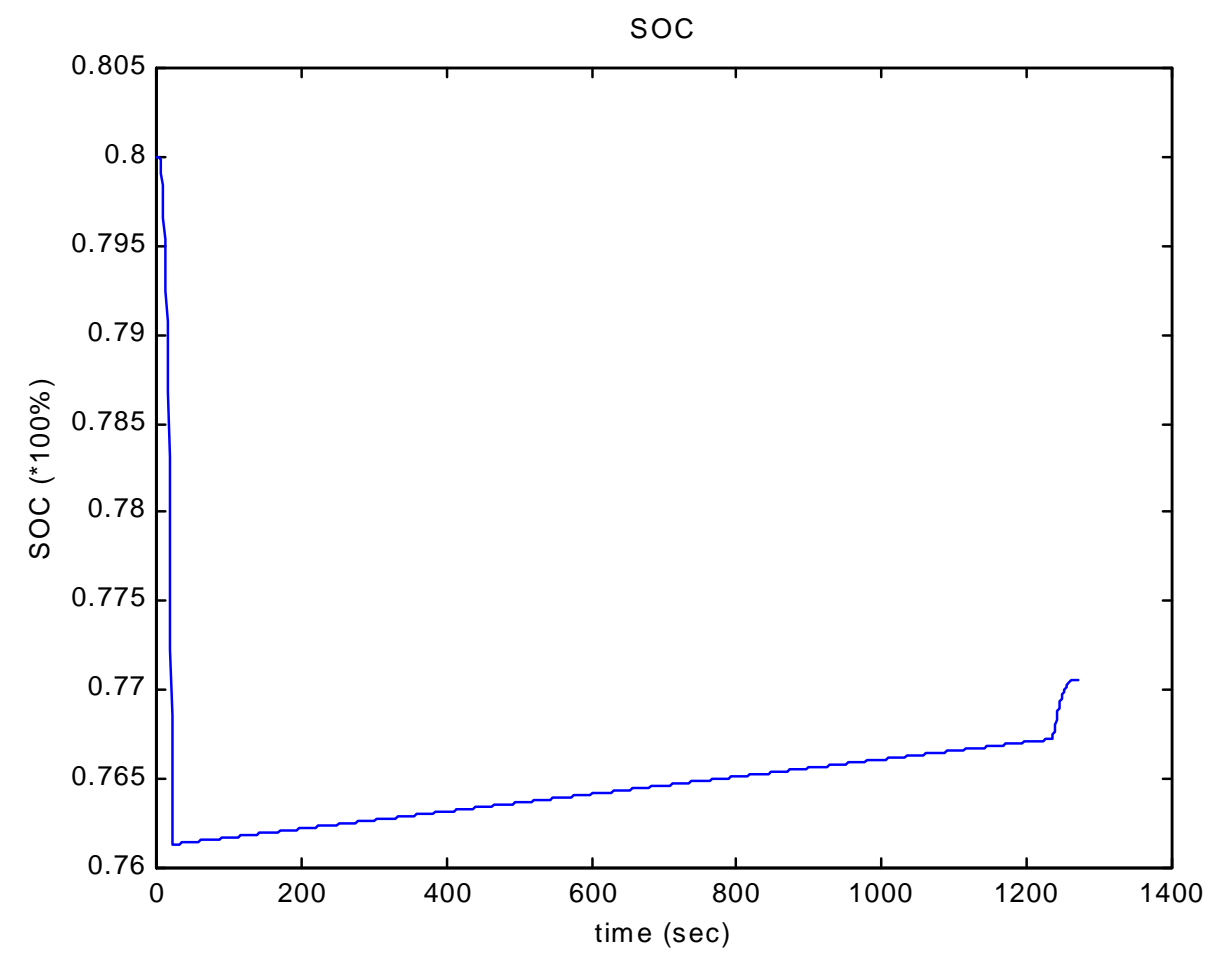

Figure 41.2. SOC vs. time on a $5 \%$ grade at $55 \mathrm{mph}$ steady speed.

It can be seen in Figure 41.2 that the kinetic energy is captured and stored during the regenerative braking. The steep rise in SOC at the end of the trace is from the regenerative braking.

Figure 41.3 shows the speed of the engine, the speed of the electric motor and the speed of the alternator. It can be seen that the vehicle speed is increases until it reaches $55 \mathrm{mph}$ than stays steady. The alternator speed is not zero in this case so it lets the engine operate at a higher power output range. Figure 41.3 also shows that the alternator is spinning forward whenever the engine is off. When the engine is turned on the alternator is spinning backward. 


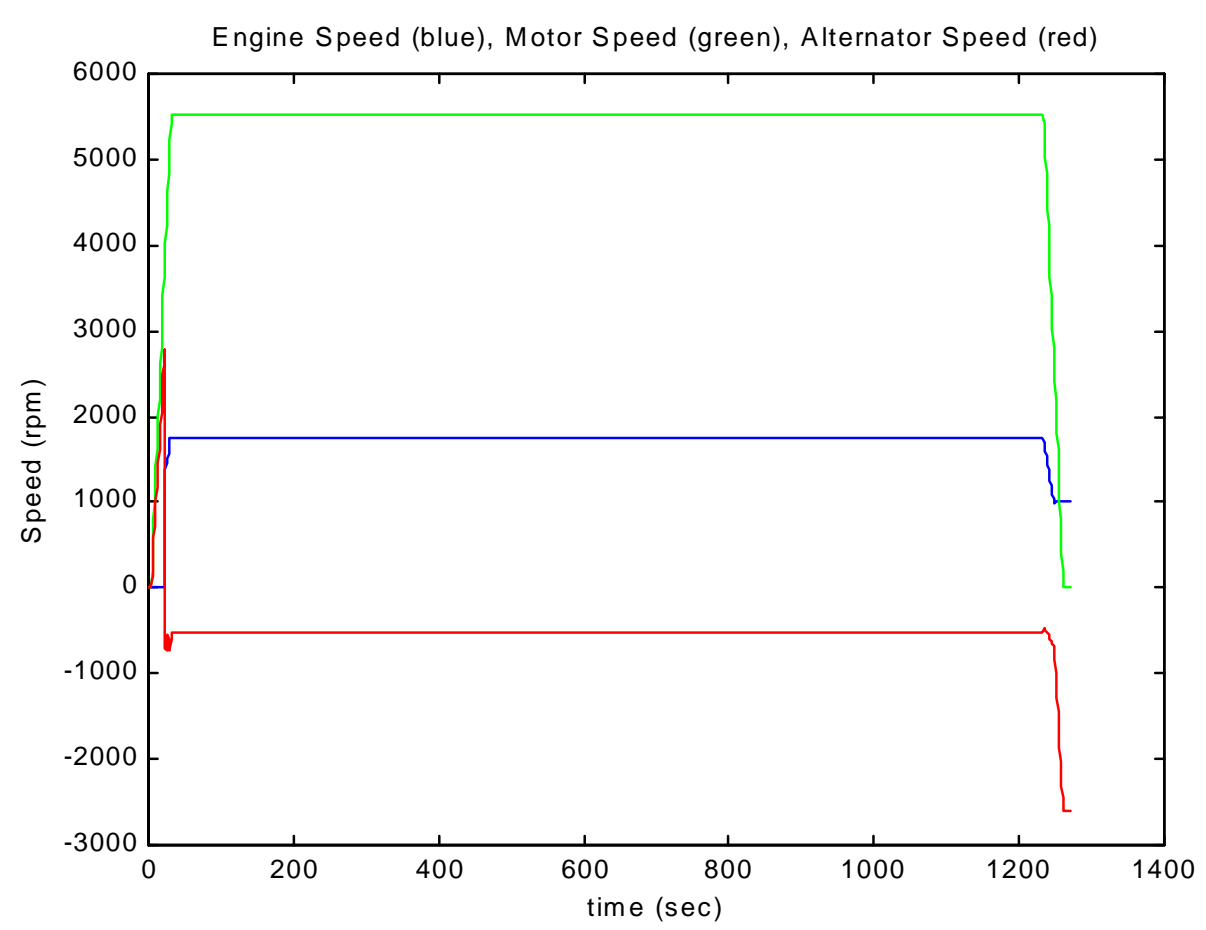

Figure 41.3. Engine speed, motor speed and alternator speed vs. time on a $5 \%$ grade at 55 mph steady speed.

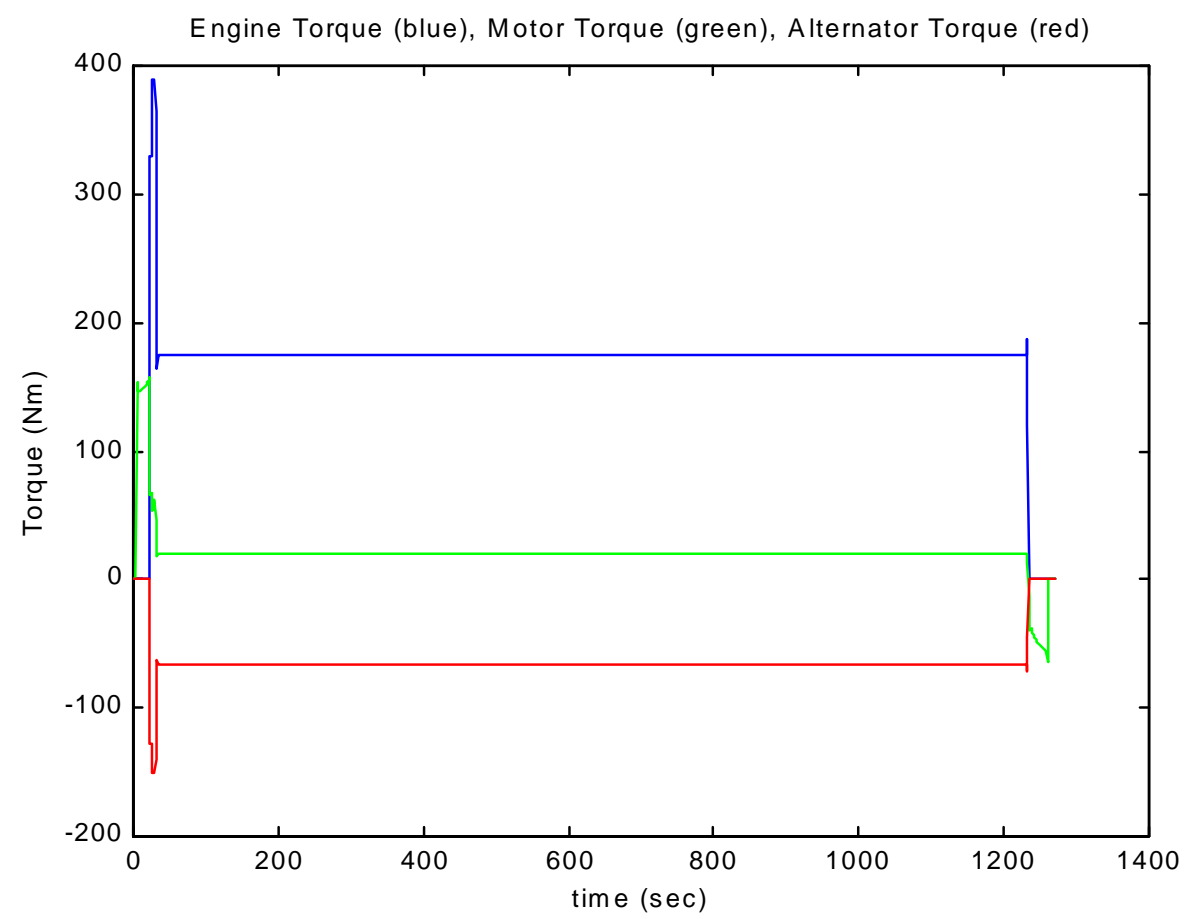

Figure 41.4. Engine torque, motor torque and alternator torque vs. time on a $5 \%$ grade at 55 mph steady speed. 
Figure 41.4 shows the engine torque, motor torque and the alternator torque vs. time. It can be seen that the engine torque is proportional to the alternator torque. At Configuration \# 4 the alternator torque has reversed direction to engine torque. Both alternator speed and torque have the same direction so the alternator is producing power, it is providing power to the electrical bus.

The negative torque on the motor can be seen only at braking. It shows clearly that the electric motor provides the braking power working as an alternator. It captures the kinetic energy of the vehicle. When the vehicle has reached its cruising speed the electric motor provides some torque. That shows that the vehicle uses mainly the engine as a power source but there is a significant amount of energy transmitted electronically through the alternator and the motor. The vehicle is working as a real hybrid.

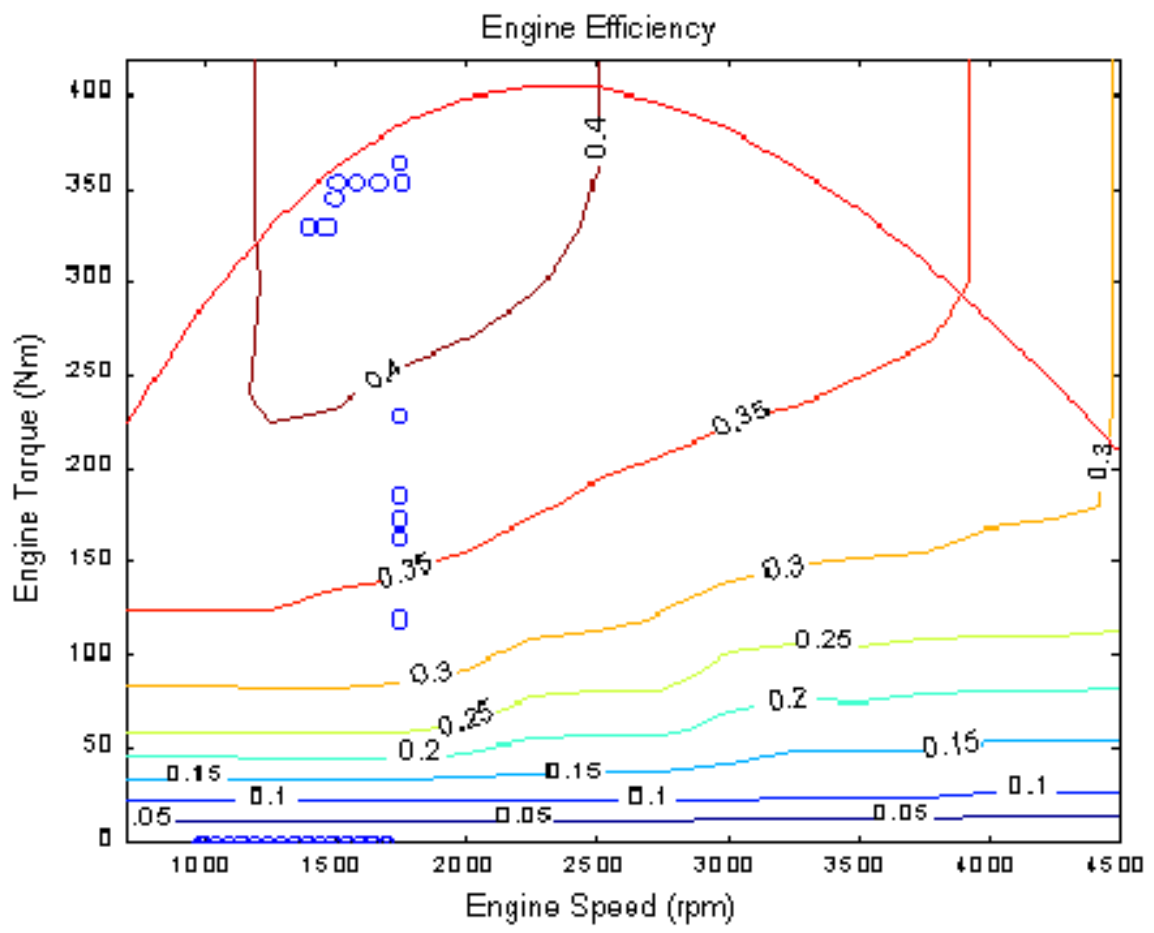

Figure 41.5. Engine efficiency as the function of engine speed and engine torque. 
Figure 41.5 shows the engine efficiency as the function of engine speed and engine torque on a $5 \%$ grade at $55 \mathrm{mph}$ steady speed. It clearly shows that the maximum engine speed is 1800rpm and the torque is the maximum at that speed. The engine operates at a higher power output to provide enough power for propelling the Suburban on a $5 \%$ grade at $55 \mathrm{mph}$ steady speed. The engine is operating at $60 \%$ of its maximum power output so it would be able to handle more severe driving conditions.

Figure 41.6 shows the motor efficiency as a function of motor speed and motor torque. The points shown with an o on the plot are positive torque from motoring, points shown with an $\mathrm{x}$ are negative torque from regenerating and the blue color means that the rotational direction is the same as the engine rotational direction. The motor is providing significant torque. It definitely assists the engine in propelling the vehicle.

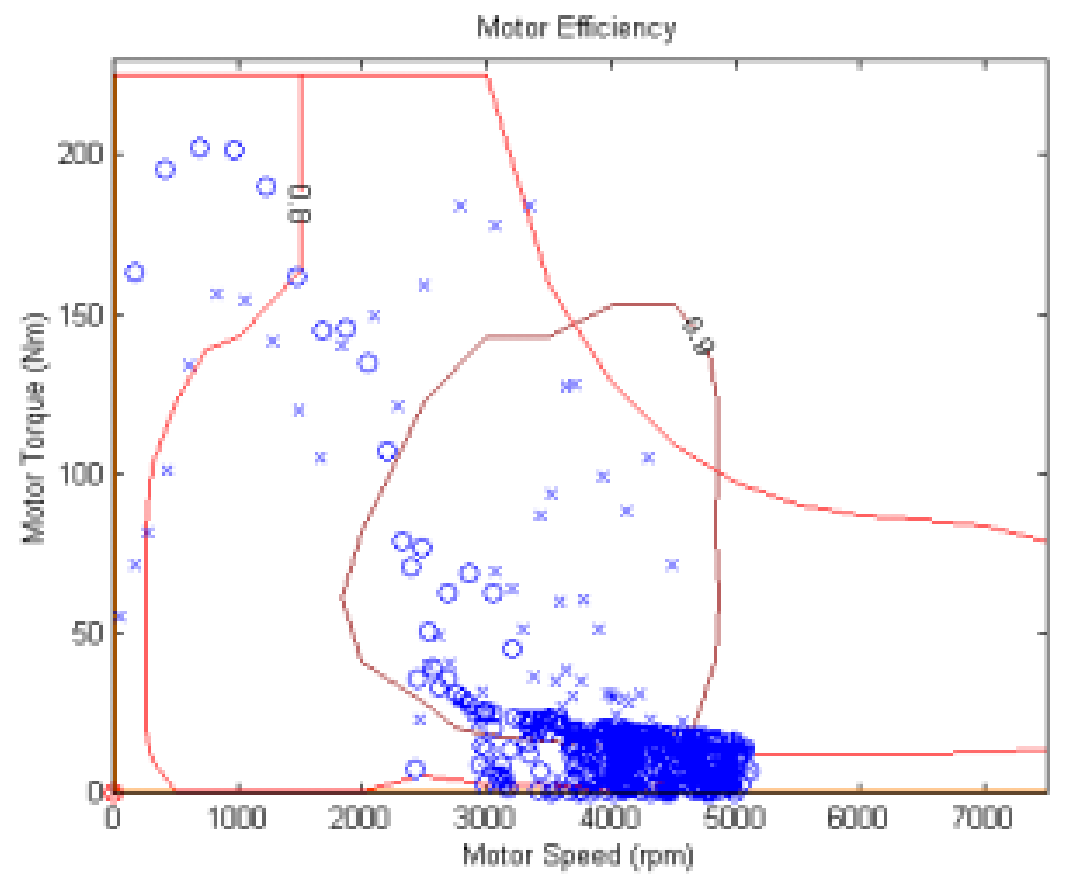

Figure 41.6. Motor efficiency as the function of motor speed and motor torque. 
Figure 41.7 shows the alternator efficiency as the function of alternator speed and alternator torque. The points shown with an $\mathrm{x}$ are defining regenerative torque and the red color indicates that the rotational direction is the opposite to the engine rotational direction. Some blue circles can be seen but only at zero torque. It happens only when the engine is turned off. It means that when the engine is off the alternator is spinning forward with no load on it acting only as a flywheel. The low torque, low speed operation range clearly shows that the alternator is way oversized for this application too. The alternator mostly operates at around $150 \mathrm{Nm}$ and $3000 \mathrm{rpm}$. This provides the electrical energy consumed by the motor. The vehicle does not use energy from the battery. It is charge sustaining.

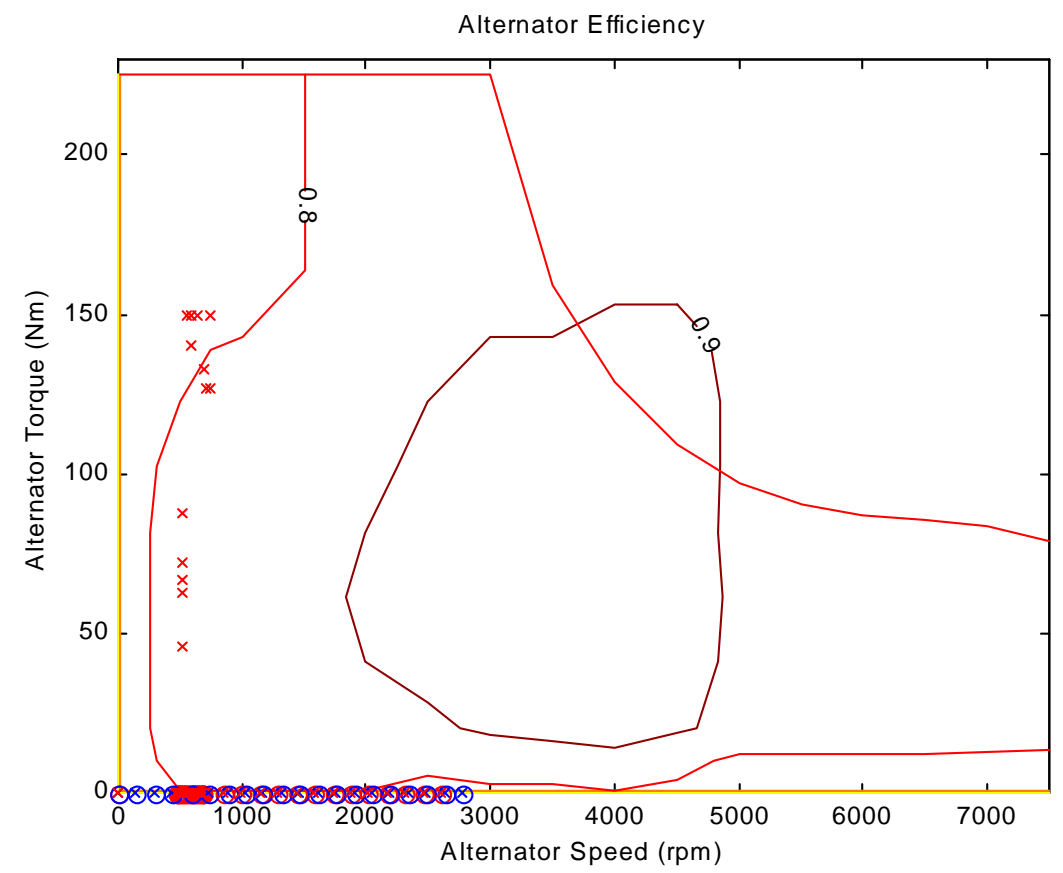

Figure 41.7. Alternator efficiency as the function of alternator speed and alternator torque. 


\subsection{Configuration \# 6 on the FTP City Cycle}

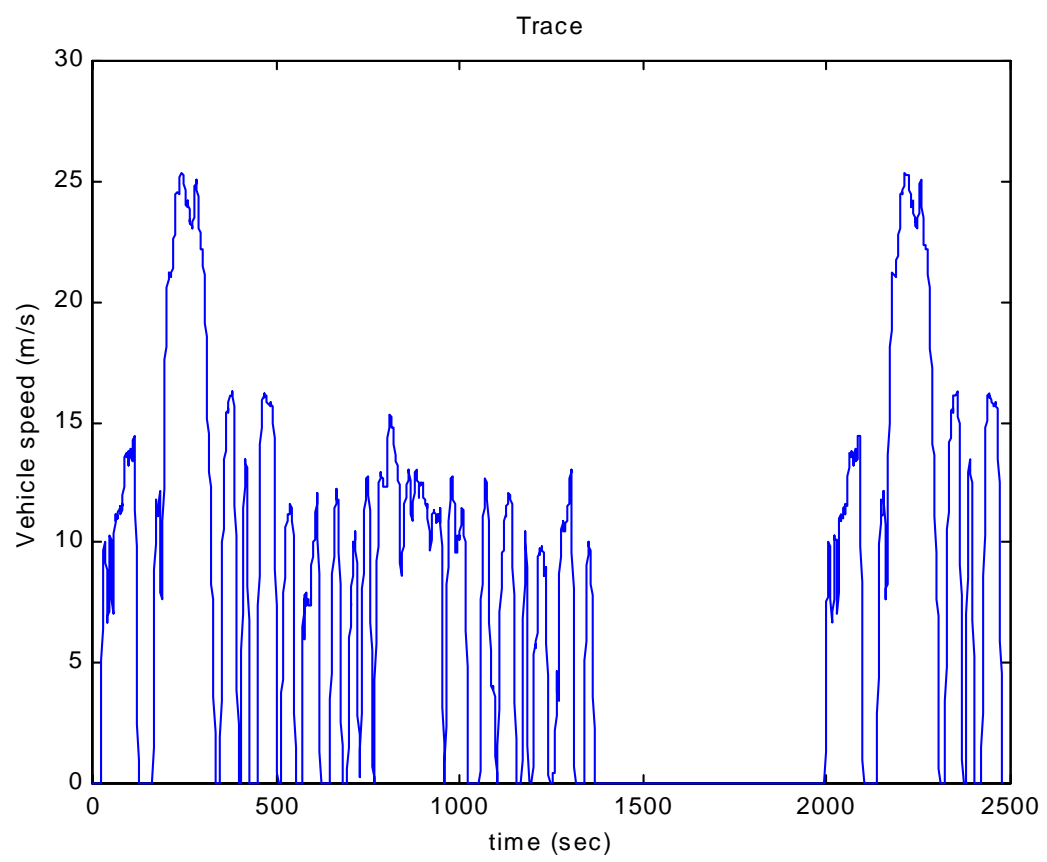

Figure 42. Speed vs. time on the FTP city test cycle.

Figure 43 shows the state of charge of the battery during the FTP city cycle. Basically there is no difference between the SOC plot of the two configurations. The chart shows that the vehicle takes off as an EV causing a quickly decreasing SOC initially. As soon as the SOC drops to the set minimum the engine turns on and SOC starts increasing. The battery SOC never reaches the set upper limit during the FTP city cycle. The reason is that the control system turns the engine off after 5 seconds of idling after the vehicle came to a full stop and stayed stationary for 5 seconds no matter what the SOC is. The engine turns back on again as soon as current out of batteries exceeds the set limit of 400 amps. 


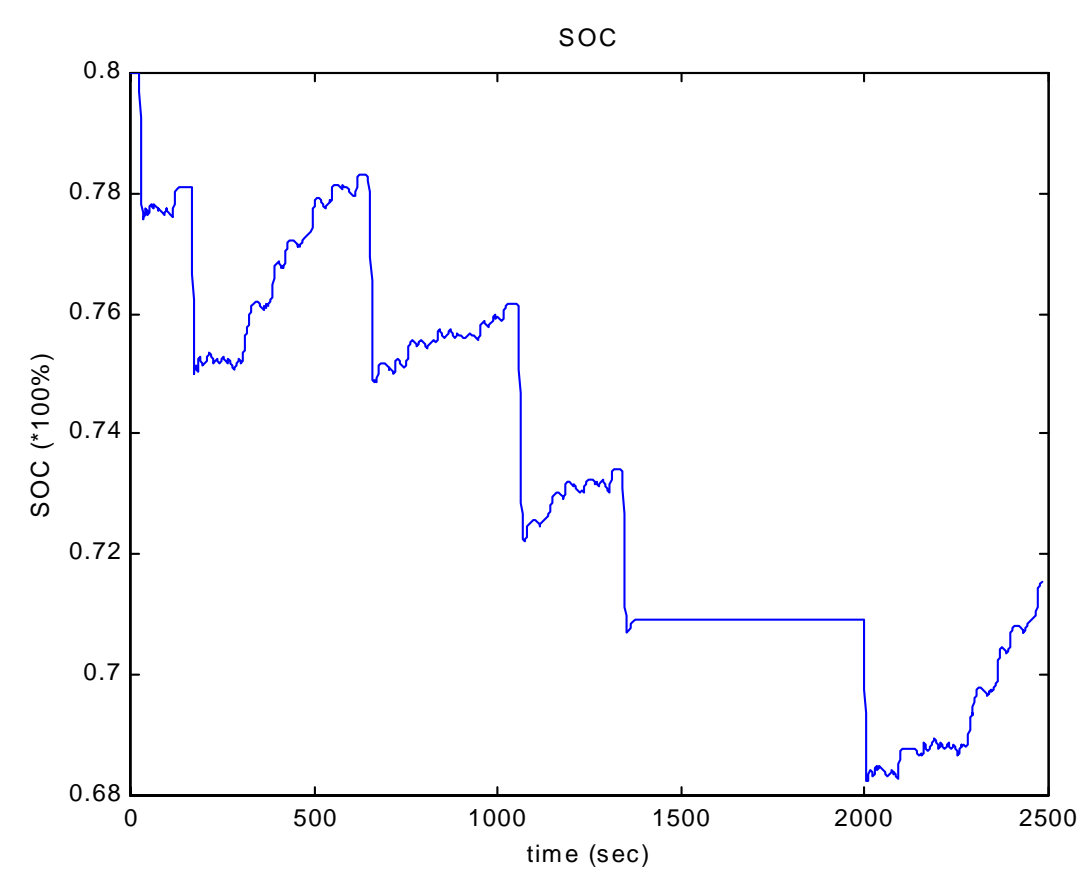

Figure 43. SOC vs. time on the FTP city cycle.

It can be seen in Figure 43 that the kinetic energy is captured and stored during the regenerative braking. The main difference is that the alternator is spinning at much higher speed. This gives a higher basic charge rate to the batteries and can be seen on the SOC. The steep rises in SOC are, again, from the regenerative braking.

Figure 44 shows the speed of the engine, the speed of the electric motor and the speed of the alternator. It is obvious that the engine is oversized for the FTP city cycle at Configuration \# 6 as well. Most of the time it is spinning at 1000rpm, which is hardly above idling speed. The engine speeds up only to increase vehicle speed whenever the alternator reached close to zero rpm so the unit has reached its maximum overdrive capability. The alternator speed gets close to zero, in order to maintain vehicle speed the engine has to speed up. Figure 44 also shows that the alternator is spinning in the same direction as the engine does whenever the engine is on. When the engine is off the alternator is spinning backward. 


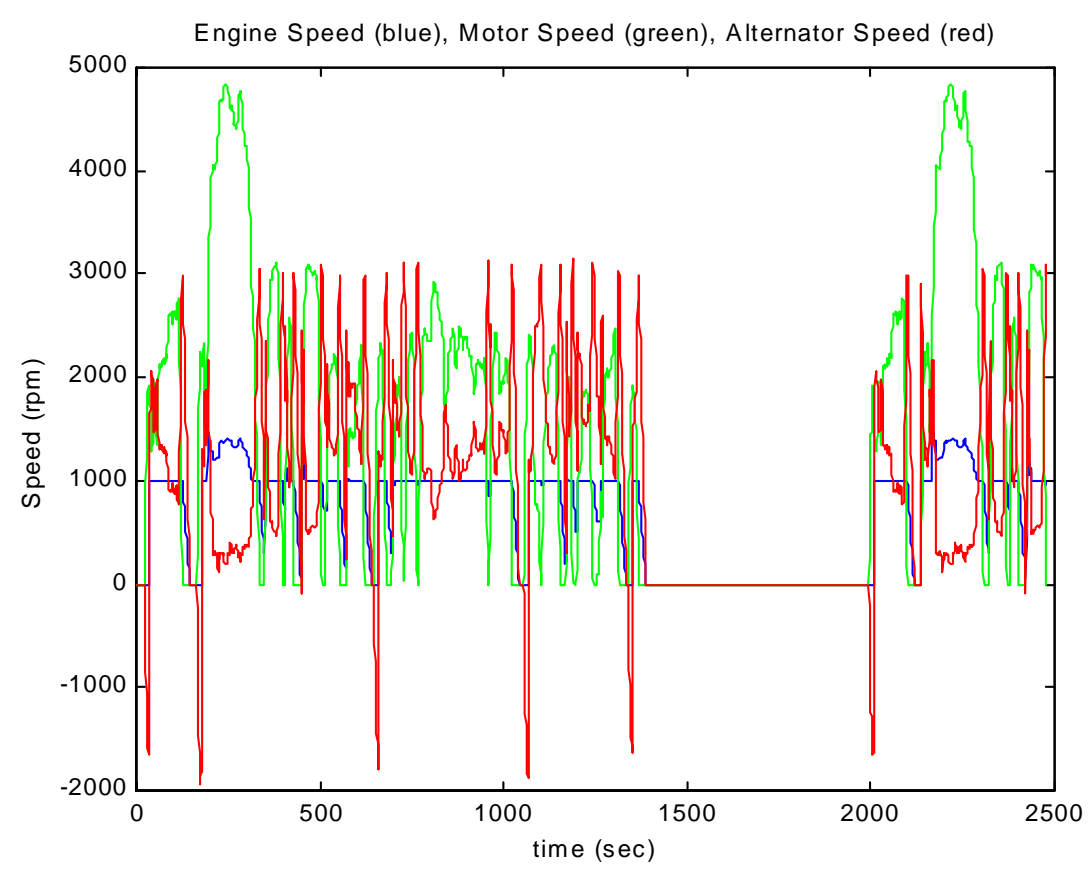

Figure 44. Engine speed, motor velocity and alternator speed vs. time on the FTP city cycle.

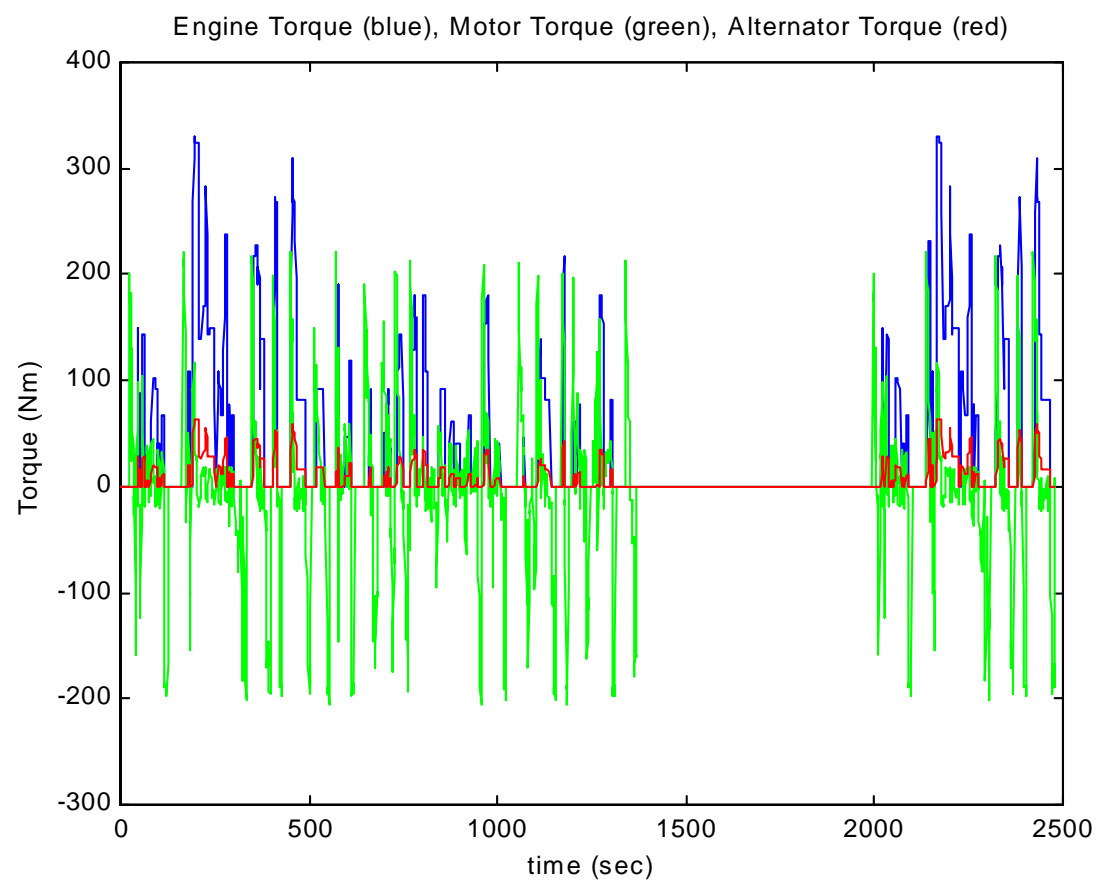

Figure 45. Engine torque, motor torque and alternator torque vs. time on the FTP city cycle. 
Figure 45 shows the engine torque, motor torque and the alternator torque vs. time. It can be seen that the engine torque is proportional to the alternator torque. Alternator torque is in the same direction as the engine torque. Both alternator speed and torque have the same direction so the alternator is producing power, it is providing power to the electrical bus.

The negative torque on the motor can be seen only at braking. It shows clearly that the electric motor provides the braking power working as an alternator. It captures the kinetic energy of the vehicle.

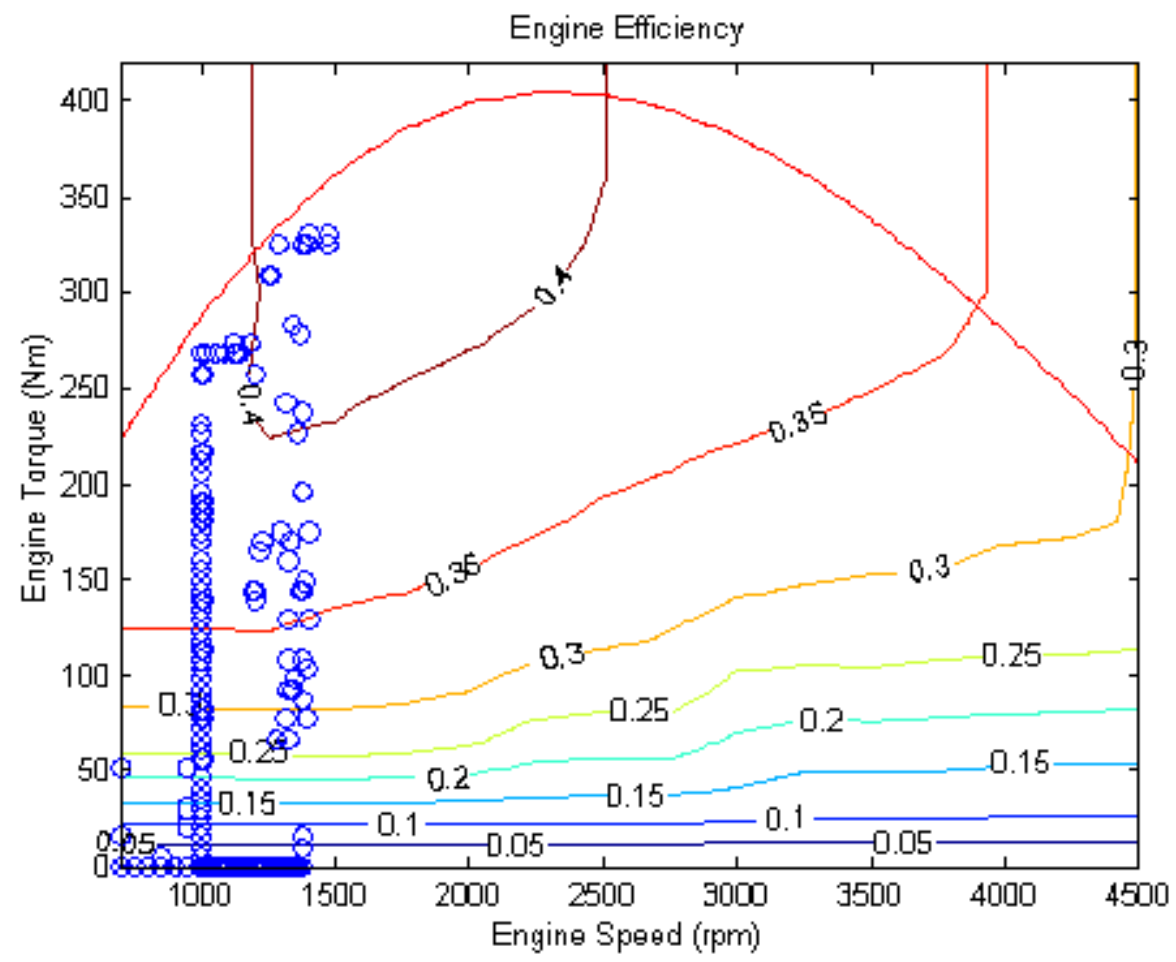

Figure 46. Engine efficiency as the function of engine speed and engine torque.

Figure 46 shows the engine efficiency as the function of engine speed and engine torque. It clearly shows that the engine mostly works at a speed of $1000 \mathrm{rpm}$. Although it does not need to operate at a high power output to provide enough power in order to make the vehicle meet the trace, it goes up to half of the maximum engine power capability to propel the Suburban on the FTP city cycle. 
Figure 47 shows the motor efficiency as a function of motor speed and motor torque. The points shown with an o on the plot are positive torque from motoring, points shown with an $\mathrm{x}$ are negative torque from regenerating and the blue color means that the rotational direction is the same as the engine rotational direction. The motor operates at low torque most of the time. Figure 45 shows that high torque is required from the motor only when the engine is off or during regenerative braking.

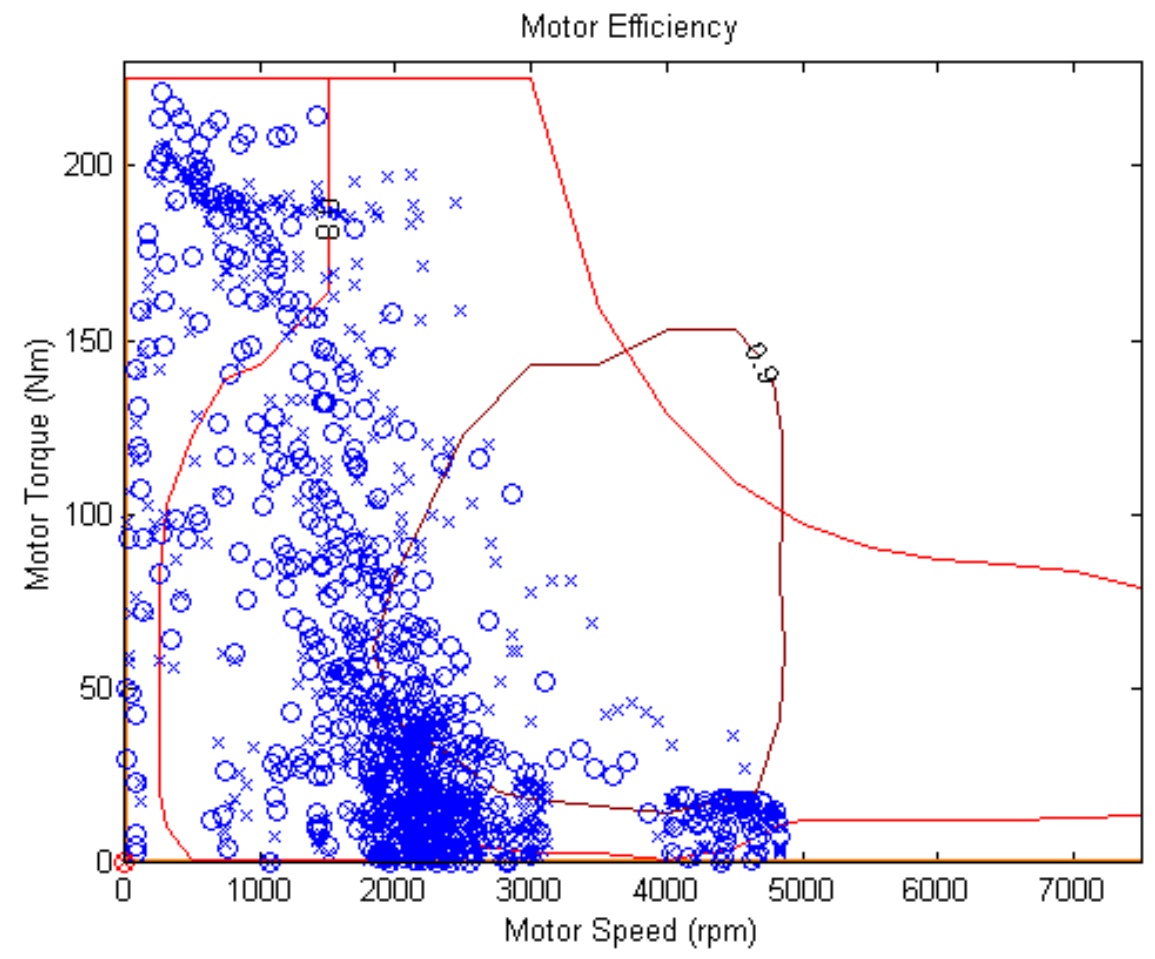

Figure 47. Motor efficiency as the function of motor speed and motor torque.

Figure 48 shows the alternator efficiency as the function of alternator speed and alternator torque. The points shown with an $\mathrm{x}$ are defining regenerative torque and the blue color indicates that the rotational direction is the same as the engine rotational direction. Some red circles can be seen in the graph but only at zero torque and when the engine is turned off. It means that when the engine is off the alternator is spinning forward with no load on it acting only as a flywheel. 


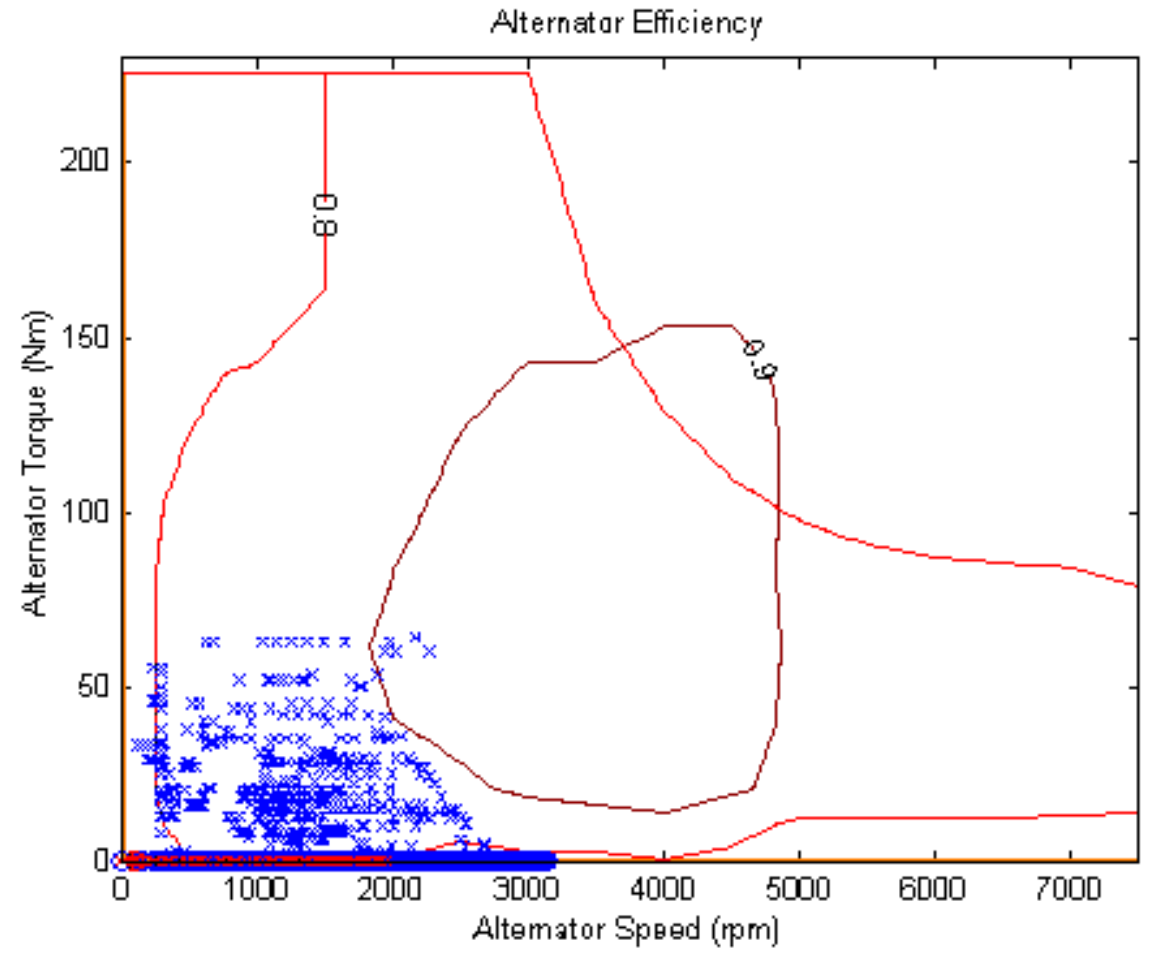

Figure 48. Alternator efficiency as the function of alternator speed and alternator torque. 


\subsection{Configuration \# 6 on the HWFET Cycle}

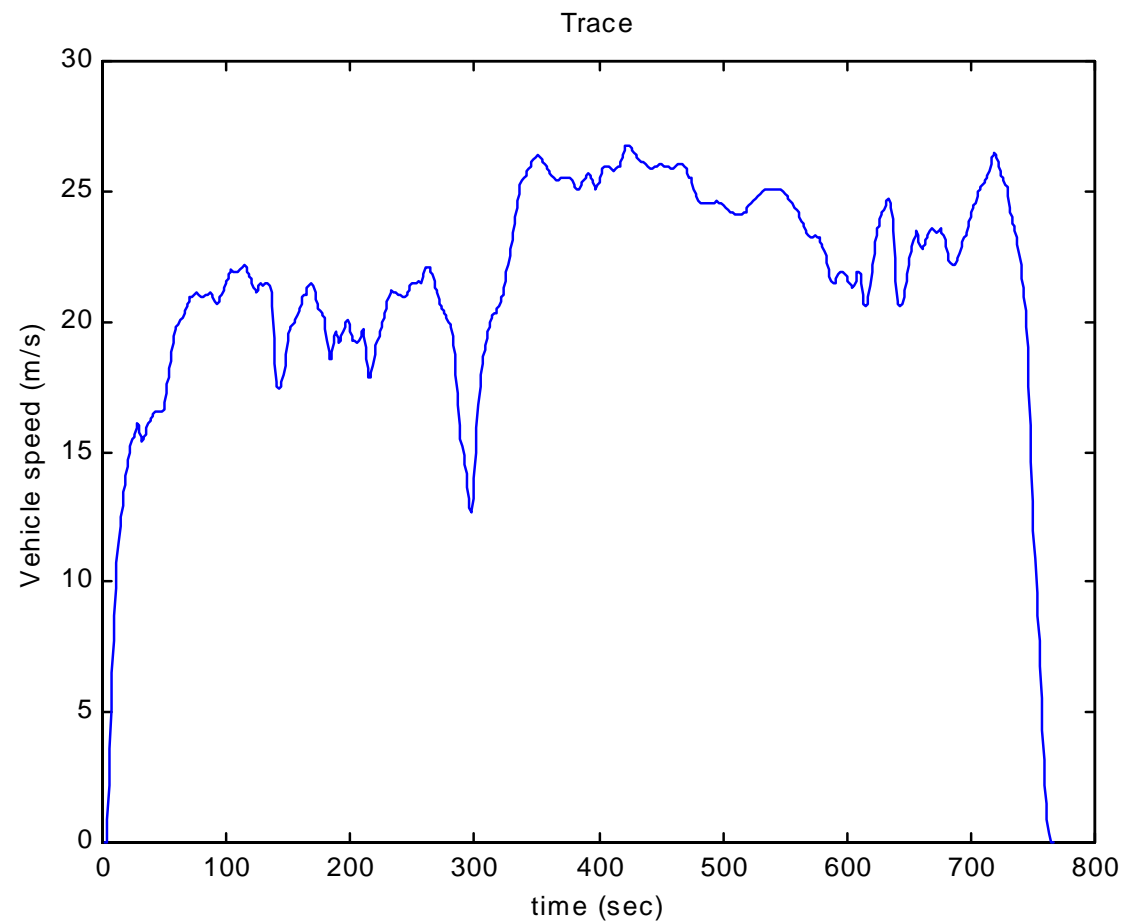

Figure 49. Speed vs. time on the HWFET test cycle.

Figure 50 shows the state of charge of the battery during the HWFET cycle. The chart shows that the vehicle takes off as an EV causing a quickly decreasing SOC initially. As soon as the SOC drops to the set minimum the engine turns on and SOC stays steady. The difference in SOC throughout the cycle is negative. On the other hand looking only at the section when the engine is on the difference in SOC is positive. The battery SOC never reaches the set upper limit during the HWFET cycle. This is because when the engine is off the battery gets depleted rapidly and the increase of SOC is moderate when the engine is on. The reason is that the control is optimized and does not charge the battery more than it is ideal and the trace is too short for a complete charge so the engine does not turn off on the highway cycle. This is off course to eliminate battery losses 


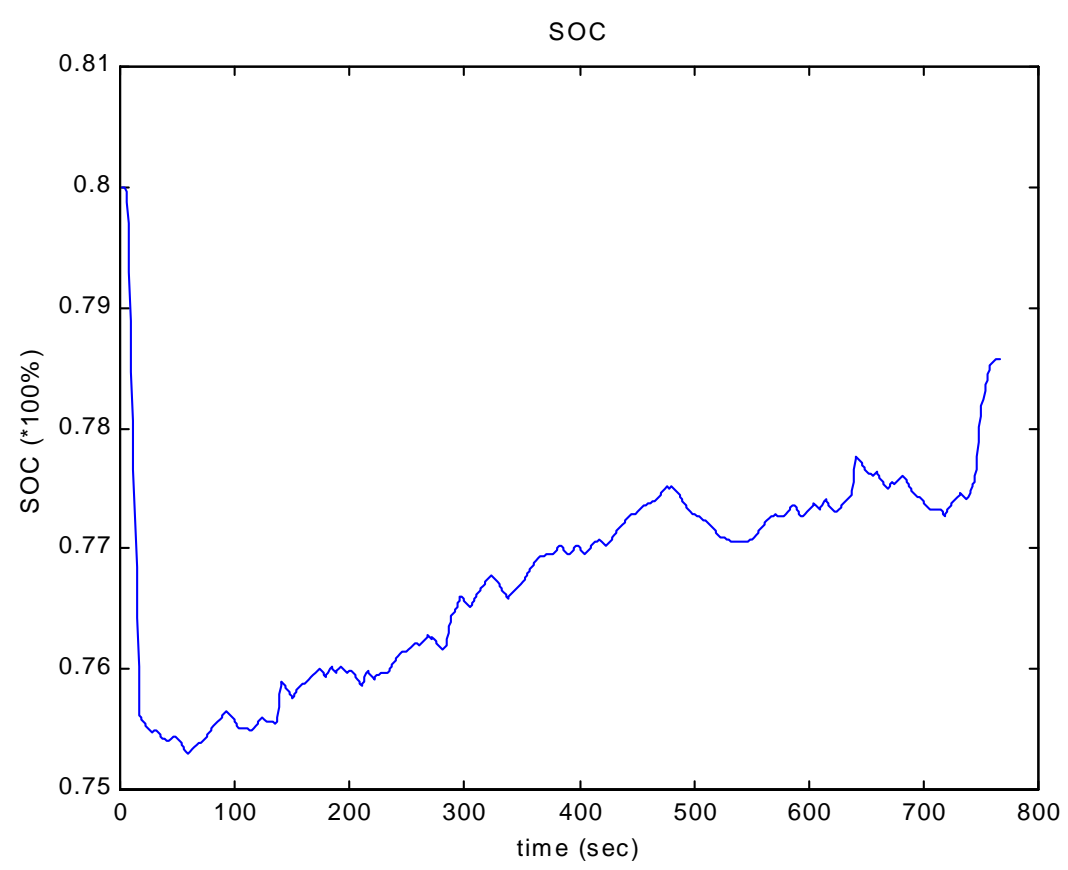

Figure 50. SOC vs. time on the HWFET cycle.

It can be seen in Figure 50 that the kinetic energy is captured and stored during the regenerative braking The steep rises in SOC are from the regenerative braking.

Figure 51 shows the speed of the engine, the speed of the electric motor and the speed of the alternator. It can be seen that the vehicle speed is higher than on the city cycle. The alternator speed is close to zero, so in order to maintain vehicle speed the engine has to speed up. This places the engine out of its most efficient range. Figure 51 also shows that the alternator is spinning forward whenever the engine is on. When the engine is turned off the alternator is spinning backward. 


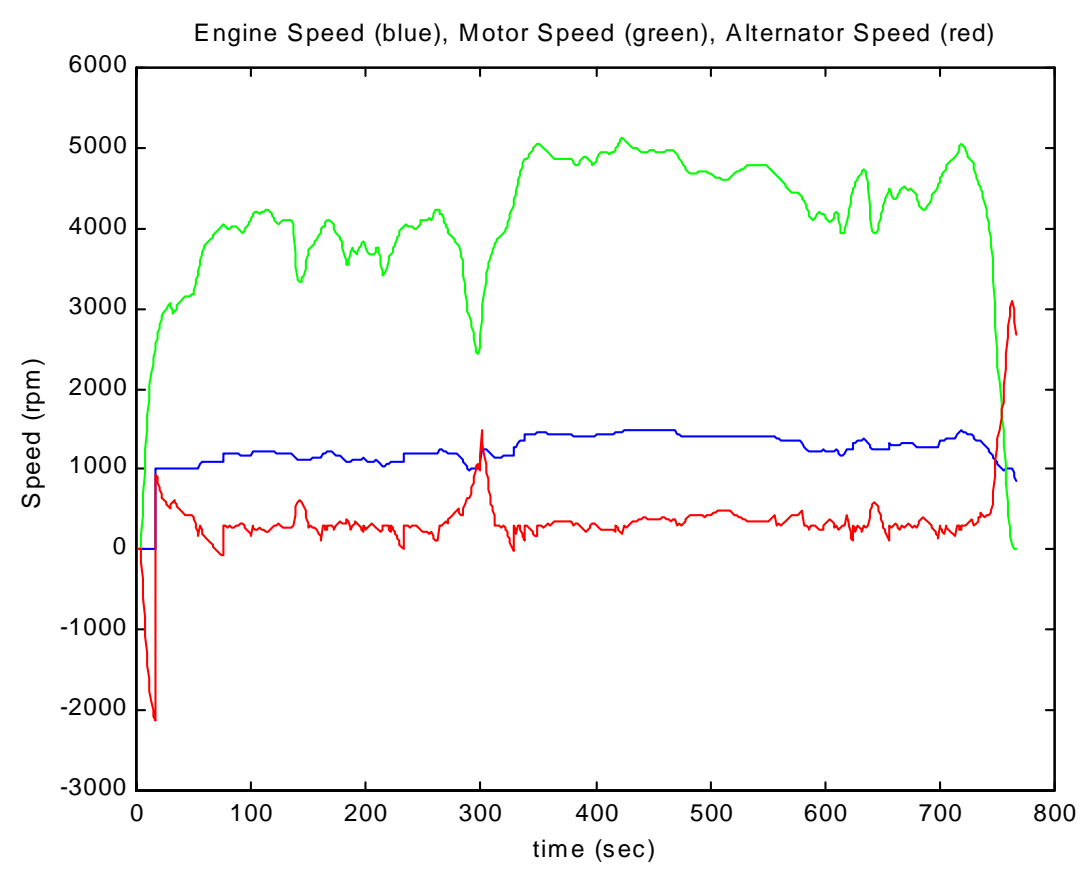

Figure 51. Engine speed, motor speed and alternator speed vs. time on the HWFET cycle.

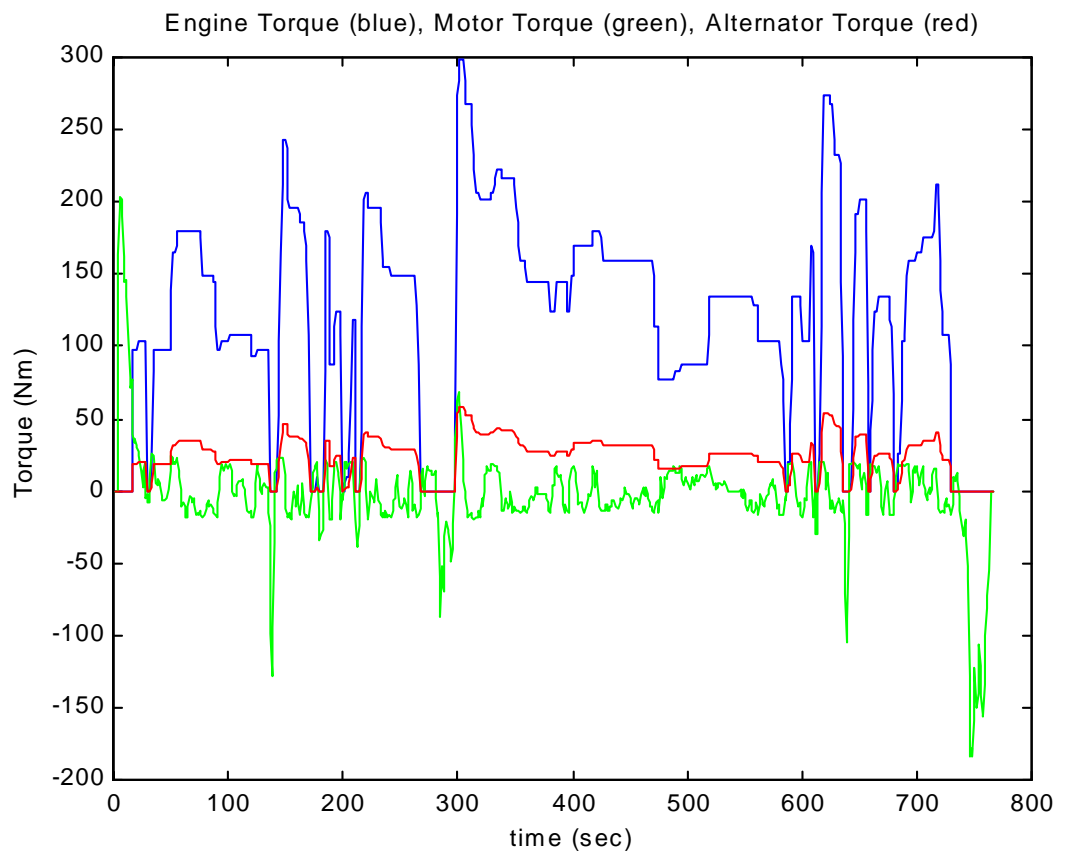

Figure 52. Engine torque, motor torque and alternator torque vs. time on the HWFET cycle. 
Figure 52 shows the engine torque, motor torque and the alternator torque vs. time. It can be seen that the engine torque is proportional to the alternator torque. At Configuration \# 6 the alternator torque has the same direction to engine torque. Both alternator speed and torque have the same direction so the alternator is producing power, it is providing power to the electrical bus.

The negative torque on the motor can be seen only at braking. It shows clearly that the electric motor provides the braking power working as an alternator. It captures the kinetic energy of the vehicle. When the vehicle has reached its cruising speed the electric motor produces very little torque. That shows that the vehicle uses mainly the engine as a power source so it operates very close to a conventional vehicle with an above average overdrive ratio (0.6).

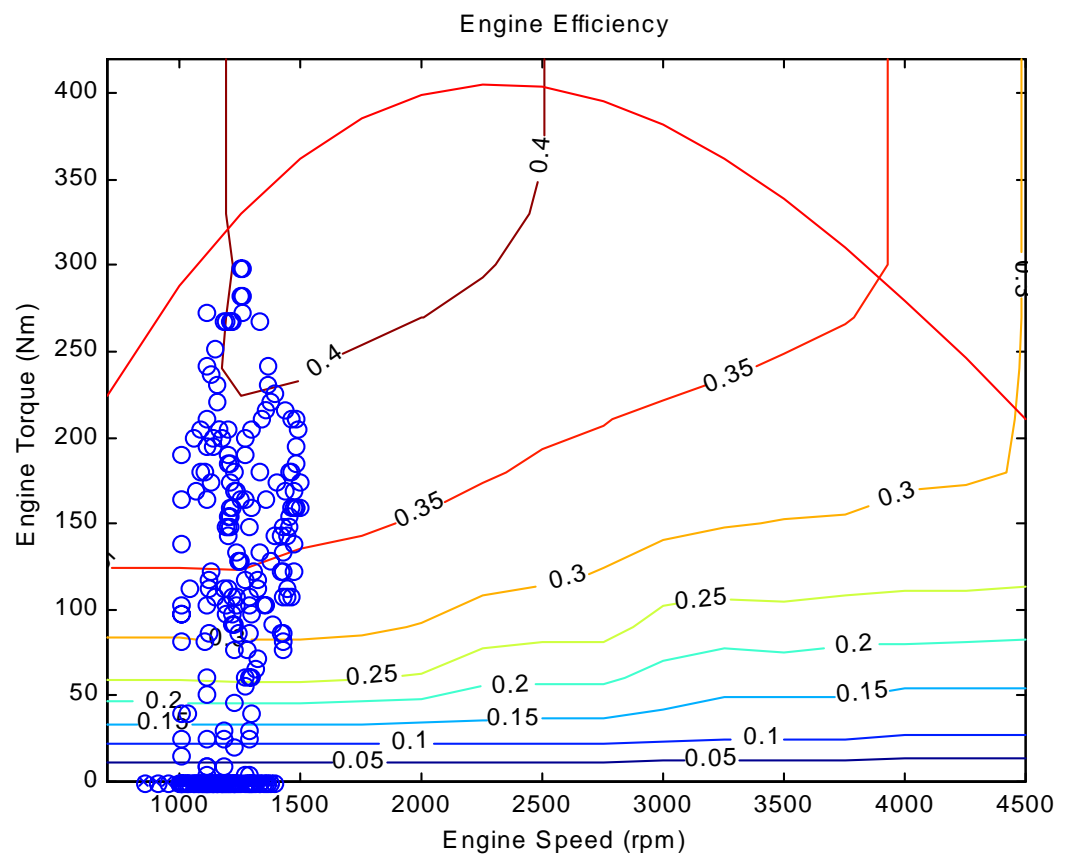

Figure 53. Engine efficiency as the function of engine speed and engine torque. 
Figure 53 shows the engine efficiency as the function of engine speed and engine torque on the HWFET cycle. It clearly shows that the maximum engine speed is $1800 \mathrm{rpm}$. It does not need to operate at a high power output to provide enough power for propelling the Suburban on the HWFET cycle. It does not need to operate at a high speed either due to high overdrive. The fact that the engine never operates at the maximum available torque, shows that the engine is oversized for this application too.

Figure 54 shows the motor efficiency as a function of motor speed and motor torque. The points shown with an o on the plot are positive torque from motoring, points shown with an $\mathrm{x}$ are negative torque from regenerating and the blue color means that the rotational direction is the same as the engine rotational direction. The motor operates at close to zero torque most of the time. Figure 52 shows that high torque is required from the motor only when the engine is off or during regenerative braking.

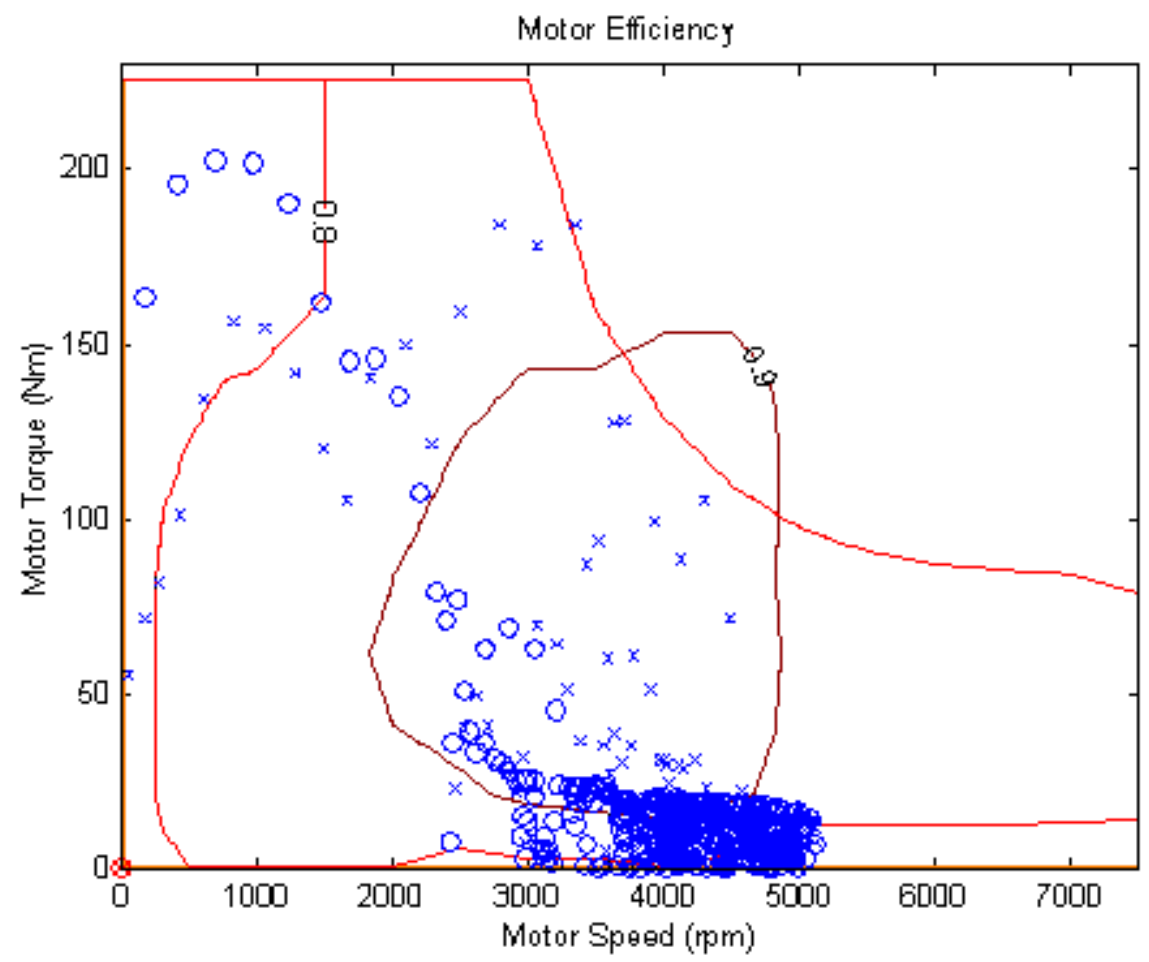

Figure 54. Motor efficiency as the function of motor speed and motor torque. 
Figure 55 shows the alternator efficiency as the function of alternator speed and alternator torque. The points shown with an $\mathrm{x}$ are defining regenerative torque and the blue color shows that the rotational direction is the same as the engine rotational direction. Some red circles can be seen but only at zero torque. It happens only when the engine is turned off. It means that when the engine is off the alternator is spinning forward with no load on it acting only as a flywheel. The low torque, low speed operation range clearly shows that the alternator is way oversized for this application.

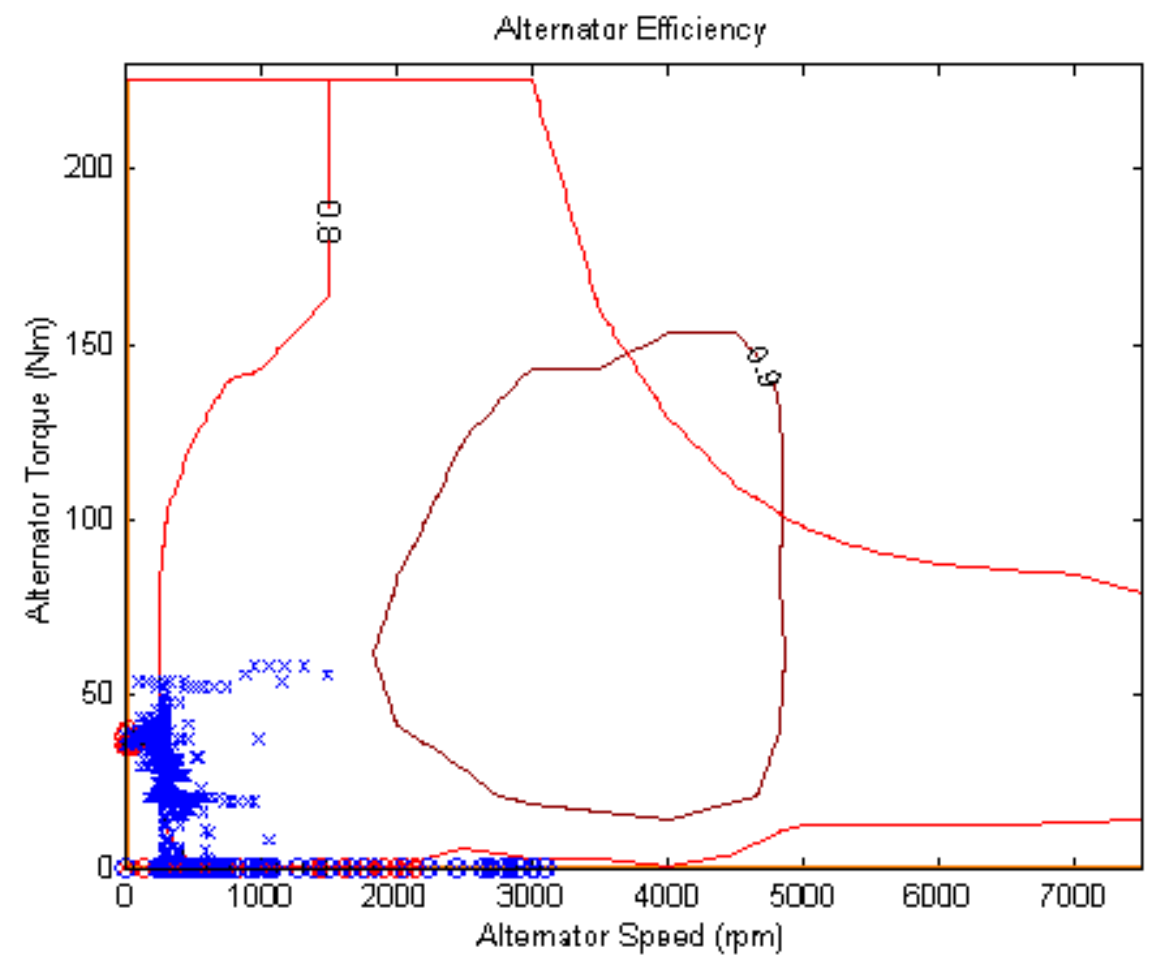

Figure 55. Alternator efficiency as the function of alternator speed and alternator torque. 


\subsection{Configuration \# 6 on the US06 Cycle}

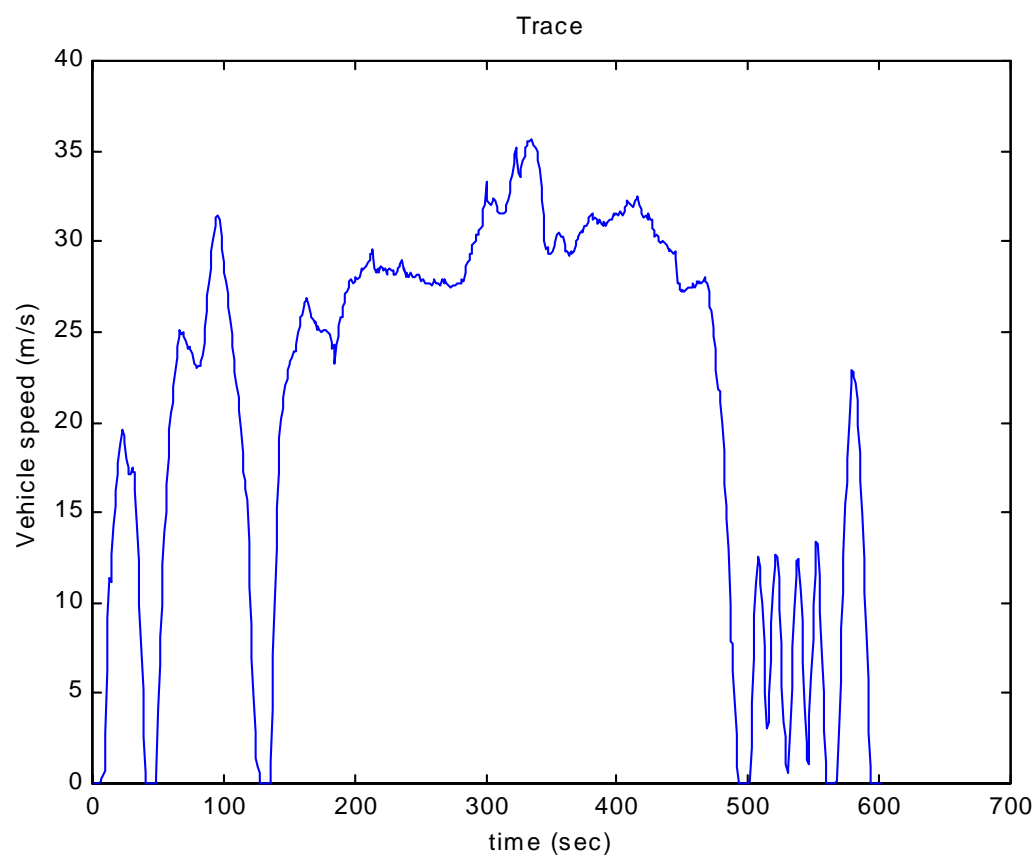

Figure 56. Speed vs. time on the US06 test cycle.

Figure 57 shows the state of charge of the battery during the US06 cycle. The chart shows that the vehicle takes off as an EV causing a rapidly decreasing SOC initially. As soon as the SOC drops to the set minimum the engine turns on and SOC starts increasing. The battery reaches $80 \%$ SOC, which was the set threshold where computer turns the engine off, and vehicle starts operate as an electric vehicle. The engine turnson again when current flowing out of the batteries exceeds 400 amps. The reason is that the control is optimized and it does not charge the battery more than it is ideal and the trace is too short for a complete charge so engine does not turn off on the US06 cycle. The control tries to eliminate the losses related to the battery as much as possible. 


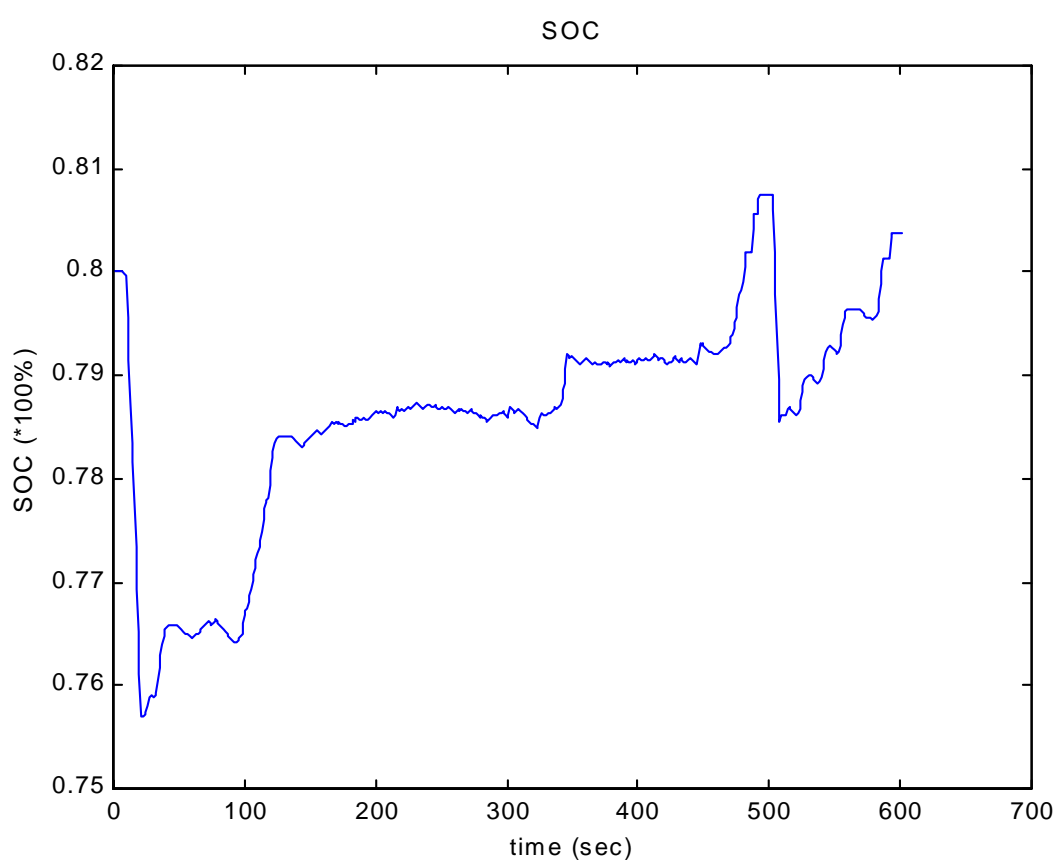

Figure 57. SOC vs. time on the US06 cycle.

It can be seen in Figure 57 that the kinetic energy is captured and stored during the regenerative braking such as on the previous cycles. Basically the engine gives a small rate of charge to the battery pack. The steep rises in SOC are from the regenerative braking

Figure 58 shows the speed of the engine, the speed of the electric motor and the speed of the alternator. It can be seen that, at the middle section of the trace, the vehicle speed is higher than on the city cycle. The alternator speed is close to zero, so in order to maintain vehicle speed the engine has to speed up. Of course it places the engine out of its most efficient range. Figure 58 also shows that the alternator is spinning forward whenever the engine is on. When the engine is turned off the alternator is spinning backward. The figure also shows that the engine and the alternator both speed up, whenever the power demand is high, making the engine operate at higher speed that gives higher possible power output. 


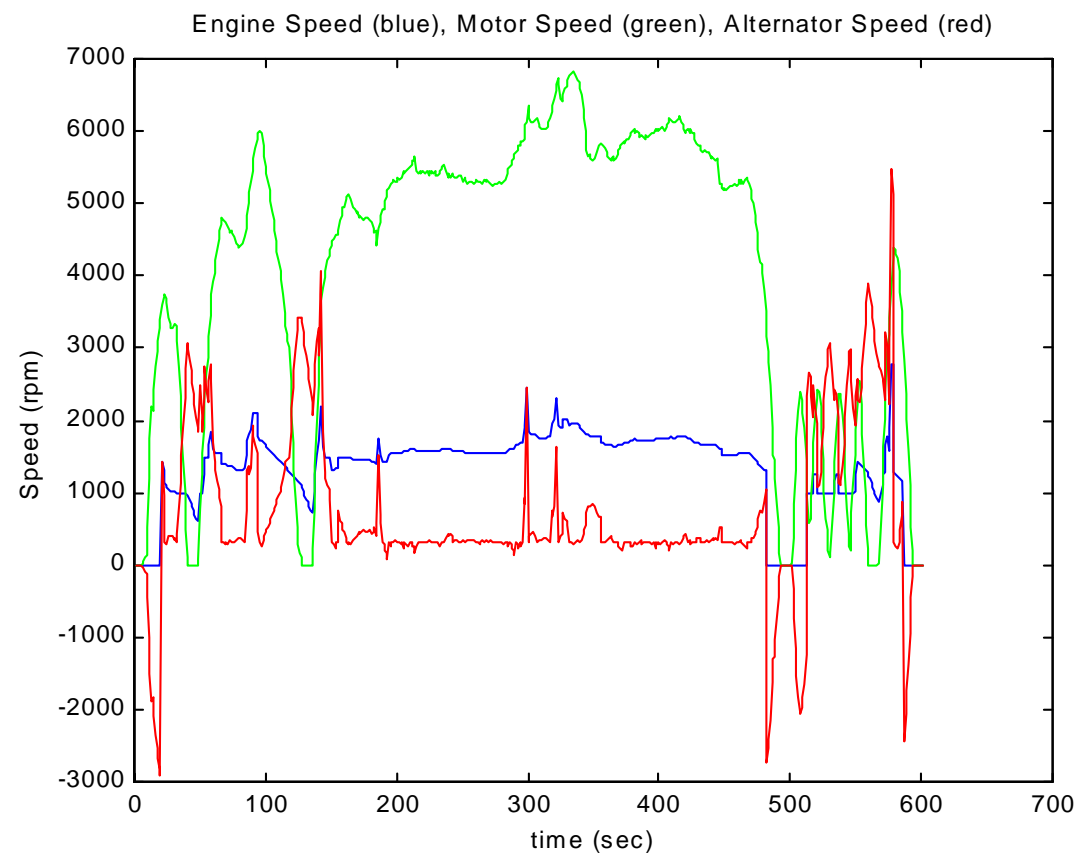

Figure 58. Engine speed, motor speed and alternator speed vs. time on the US06 cycle.

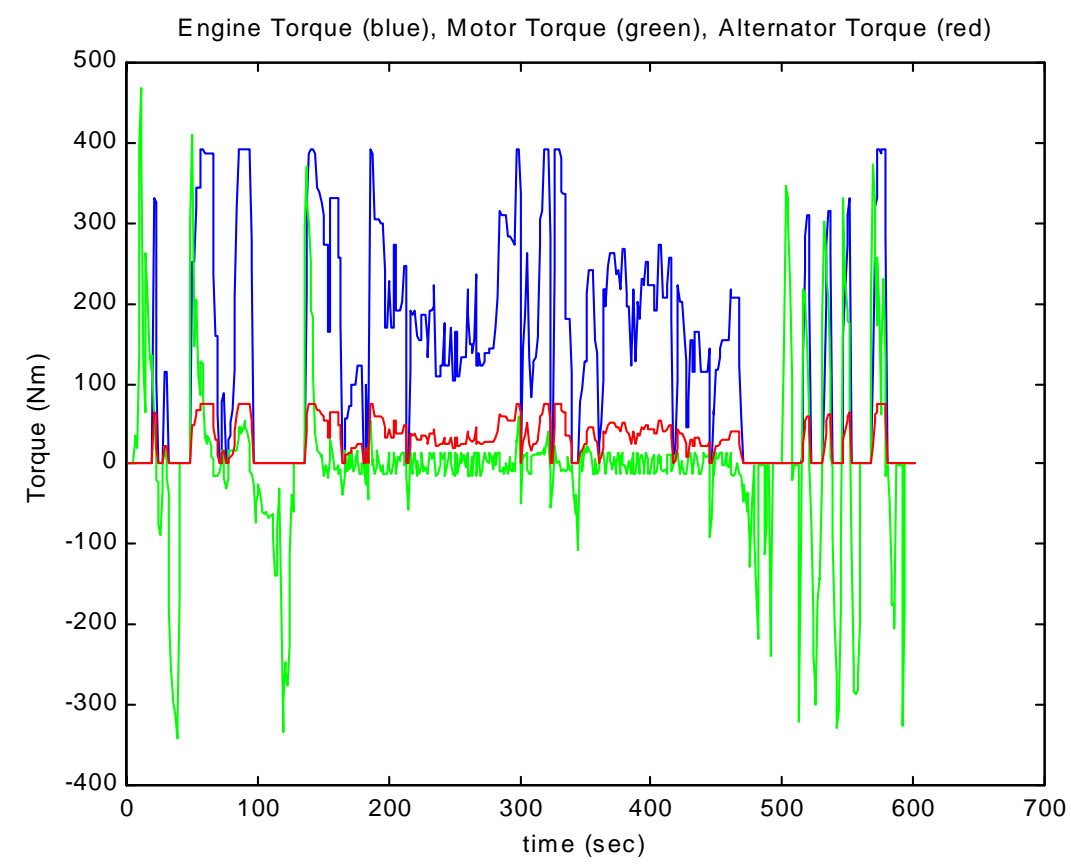

Figure 59. Engine torque, motor torque and alternator torque vs. time on the US06 cycle. 
Figure 59 shows the engine torque, motor torque and the alternator torque vs. time. It can be seen that the engine torque is proportional to the alternator torque and the alternator torque has the opposite direction as engine torque. Both alternator speed and torque have the same direction so the alternator is producing power, it is providing power to the electrical bus.

The negative torque on the motor can be seen only at braking. It shows clearly that the electric motor provides the braking power working as an alternator. It captures the kinetic energy of the vehicle. When the vehicle has reached its cruising speed the electric motor has hardly any torque on it. That shows that the vehicle is uses mainly the engine as a power source so it operates very close to a conventional vehicle with an above average overdrive ratio (0.6). It means again that battery losses are very low.

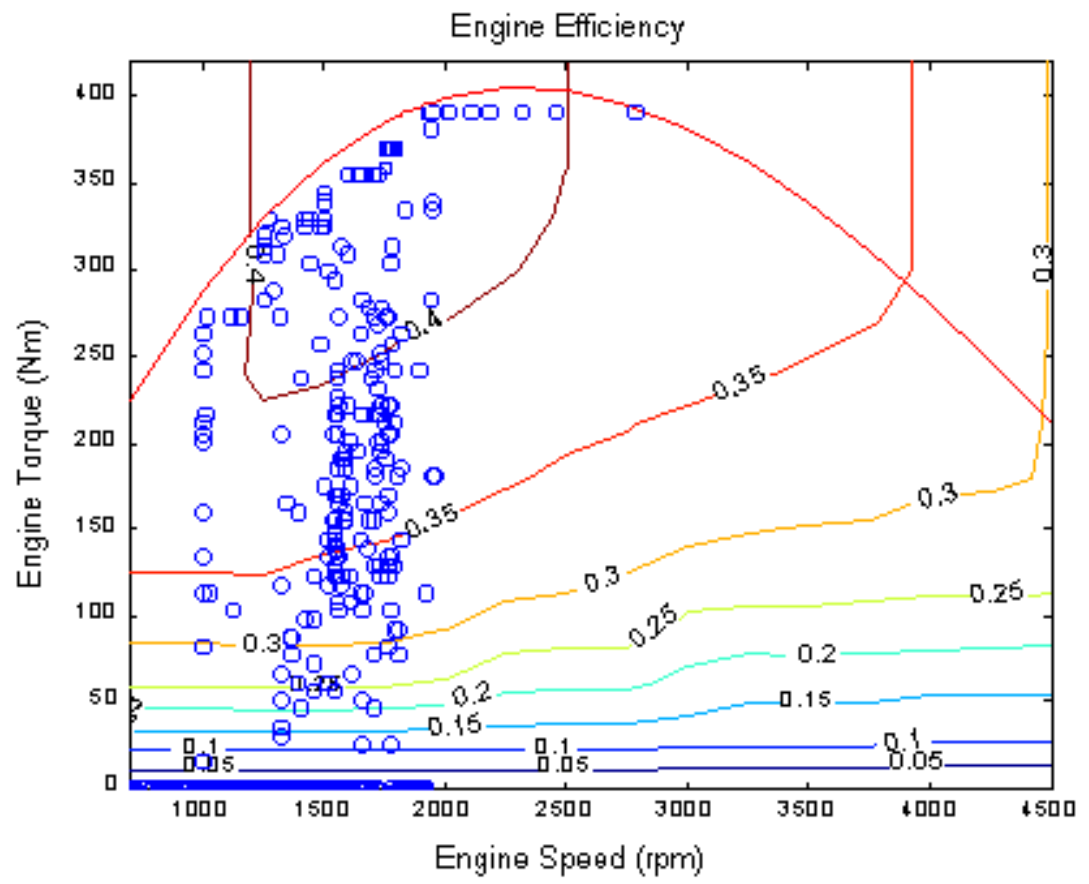

Figure 60. Engine efficiency as the function of engine speed and engine torque. 
Figure 60 shows the engine efficiency as the function of engine speed and engine torque on the FTP highway cycle. It clearly shows that the engine often speeds up to higher rpm to provide enough power to make the vehicle follow the trace. It reaches the maximum torque curve frequently but never reaches its maximum power output. This shows that this is appropriate engine for this application

Figure 61 shows the motor efficiency as a function of motor speed and motor torque. The points shown with an o on the plot are positive torque from motoring, points shown with an $\mathrm{x}$ are negative torque from regenerating and the blue color means that the rotational direction is the same as the engine rotational direction. The motor is providing significant amount of power during the US06 cycle. It reaches maximum its maximum torque a couple of times. Figure 59 also shows that extremely high torque is required from the motor when the engine is off. This means the motor is undersized for this application.

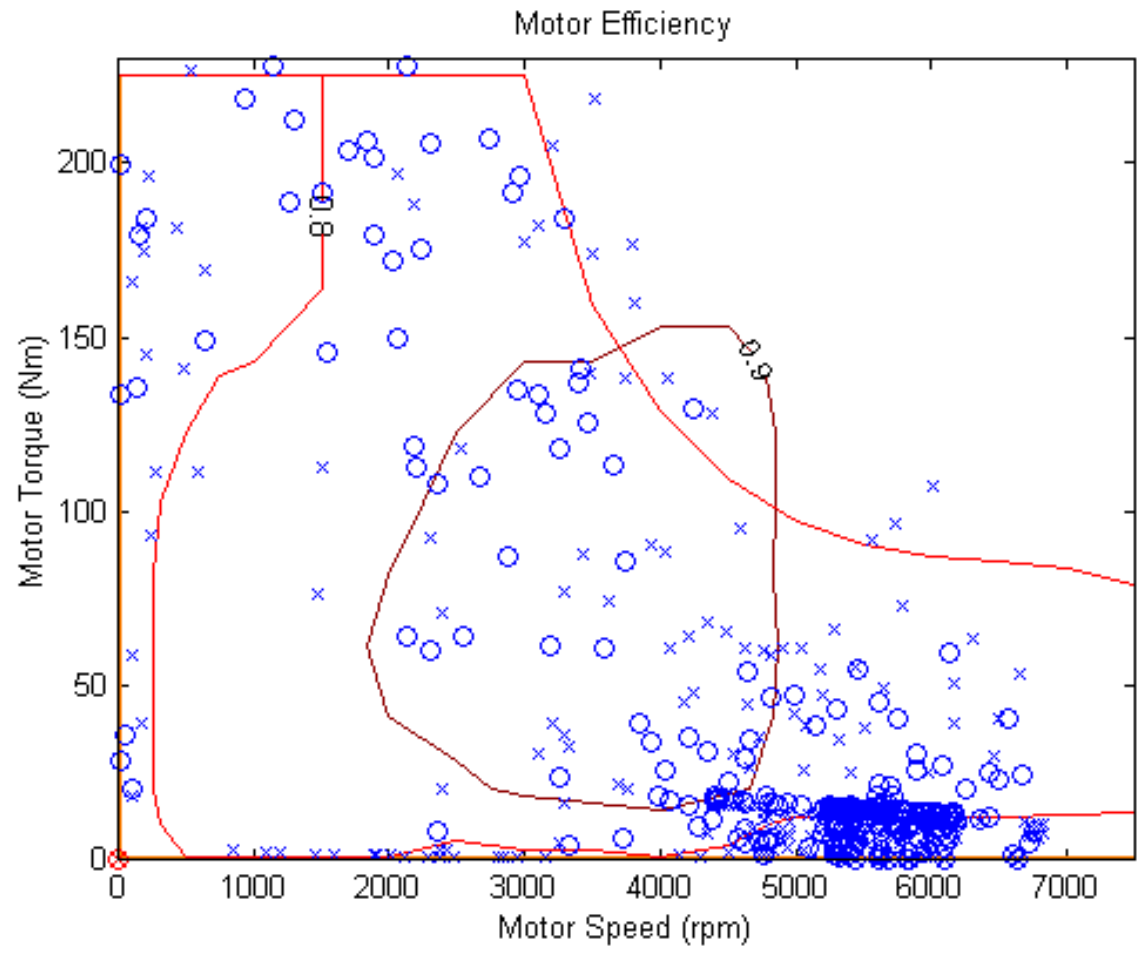

Figure 61. Motor efficiency as the function of motor speed and motor torque. 
Figure 62 shows the alternator efficiency as the function of alternator speed and alternator torque. The points shown with an $\mathrm{x}$ are defining regenerative torque and the blue color shows that the rotational direction is the same as the engine rotational direction. Some red circles can be seen but only at zero torque. It happens only when the engine is turned off. It means that when the engine is off the alternator is spinning backward with no load on it acting only as a flywheel. The alternator operates only at low speed, low torque range. This shows that the alternator is oversized even for the US06, which is the most severe cycle.

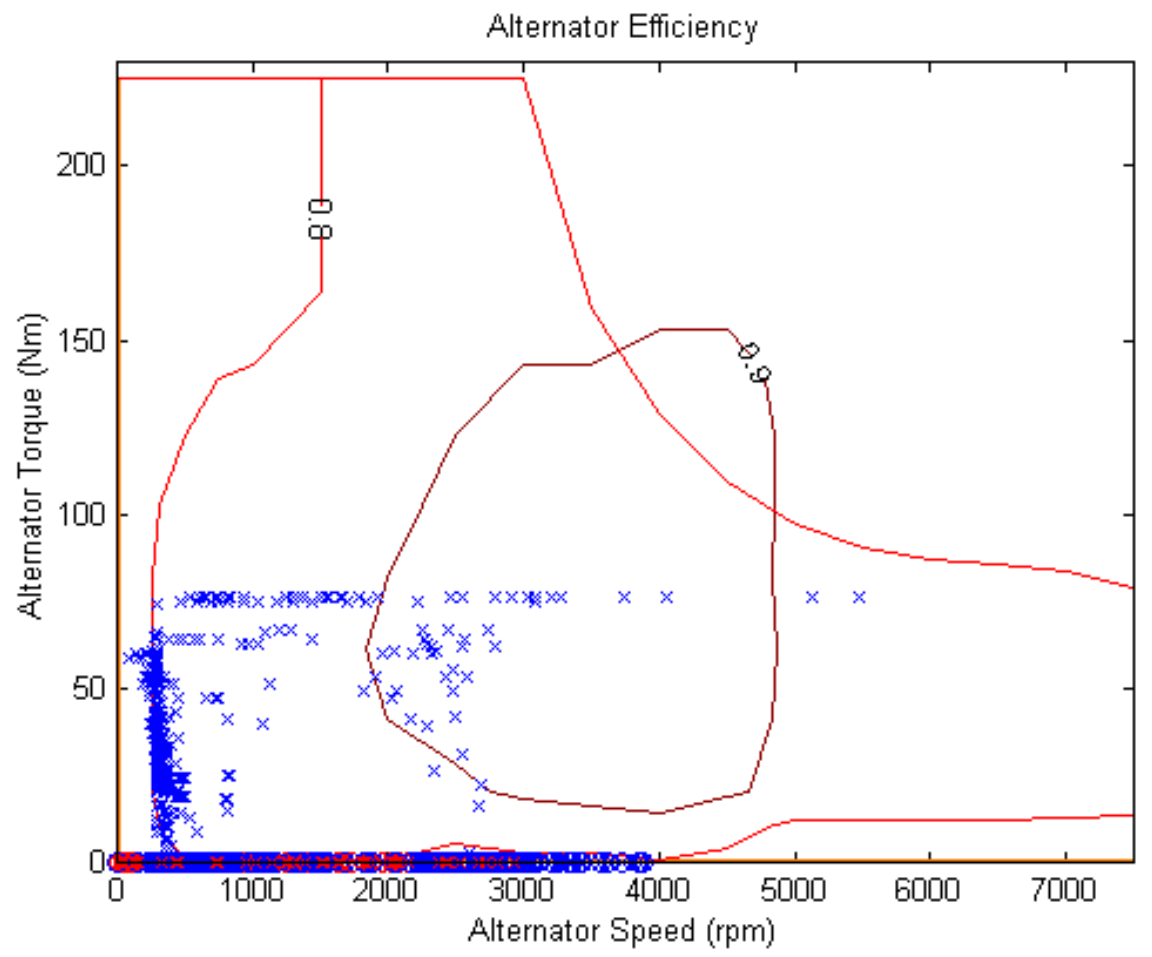

Figure 62. Alternator efficiency as the function of alternator speed and alternator torque. 


\subsection{Configuration \# 6 on a $5 \%$ grade at 55 mph steady speed}

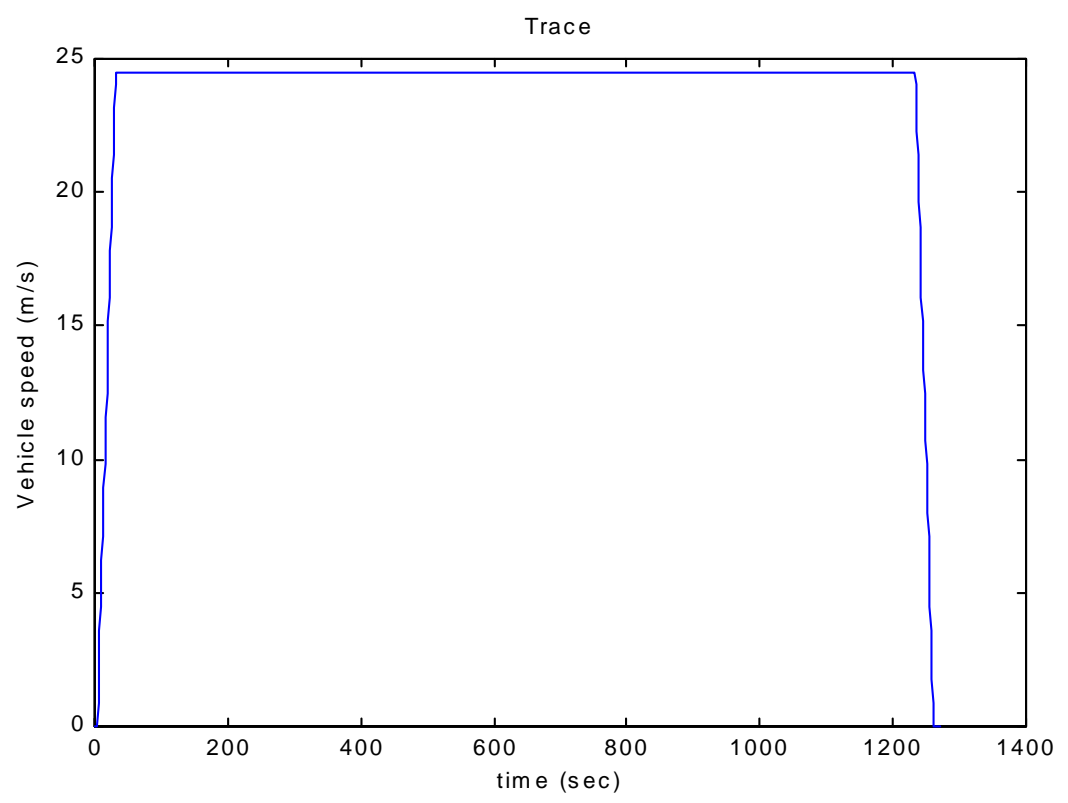

Figure 62.1. Speed vs. time on a $5 \%$ grade at $55 \mathrm{mph}$ steady speed.

Figure 62.2 shows the state of charge of the battery on a $5 \%$ grade at $55 \mathrm{mph}$ steady speed. The chart shows that the vehicle takes off as an EV causing a quickly decreasing SOC initially. As soon as the battery current exceeds 400 amps the engine turns on and SOC stays steady. The difference in SOC throughout the cycle is negative. On the other hand looking only at the section when the engine is on the difference in SOC is positive. This means that the vehicle is charge sustaining even on $5 \%$ grade. The battery SOC never reaches the set upper limit on a $5 \%$ grade at $55 \mathrm{mph}$ steady speed. This is because when the engine is off the battery gets depleted rapidly and the increase of SOC is moderate when the engine is on. The reason for that is the control is optimized and does not charge the battery more than it is ideal and the trace is too short for a complete recharge so the engine does not turn off on this cycle. 


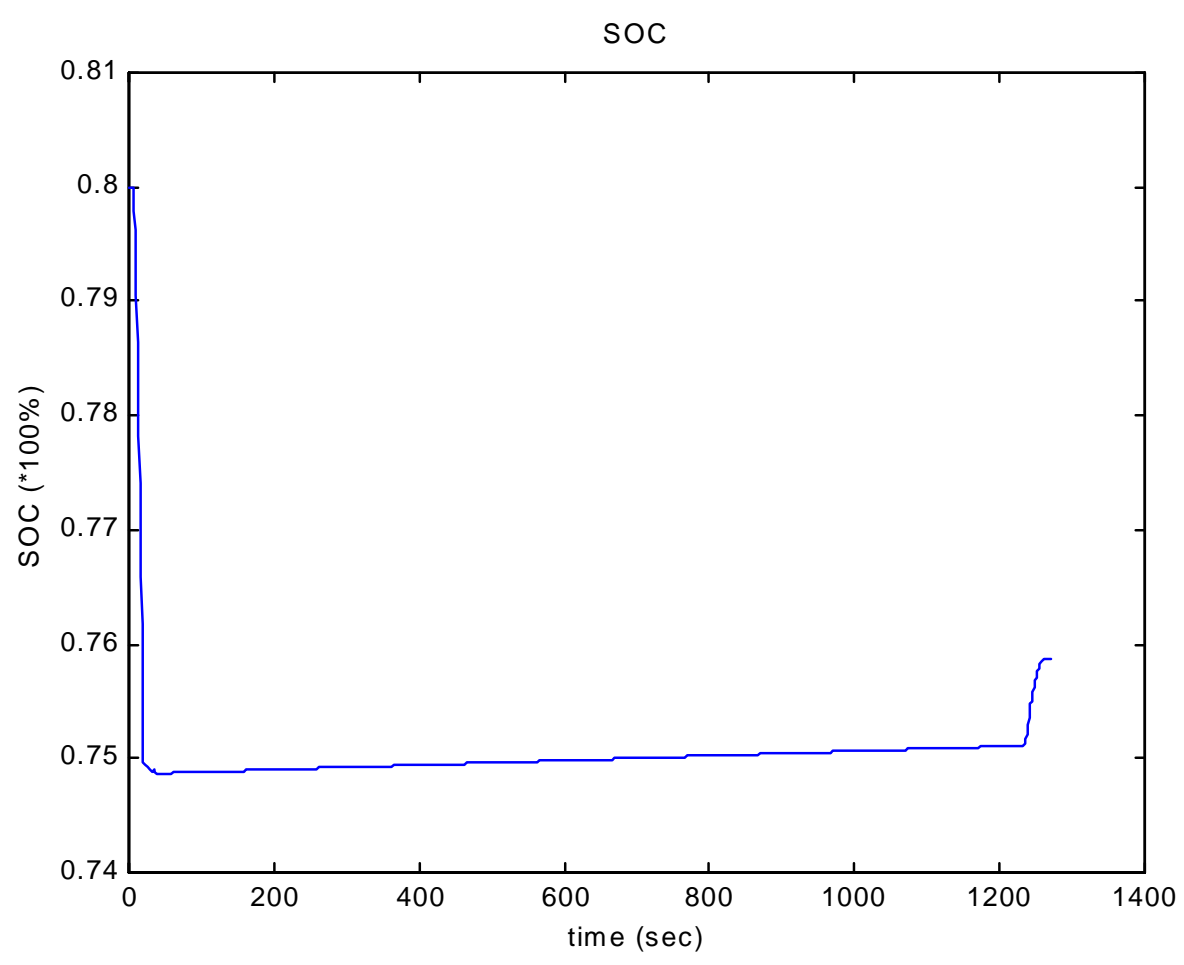

Figure 62.2. SOC vs. time on a $5 \%$ grade at $55 \mathrm{mph}$ steady speed.

It can be seen in Figure 62.2 that the kinetic energy is captured and stored during the regenerative braking. The steep rise in SOC at the end of the trace is from the regenerative braking.

Figure 62.3 shows the speed of the engine, the speed of the electric motor and the speed of the alternator. It can be seen that the vehicle speed is increases until it reaches 55 mph than stays steady. The alternator speed is not zero in this case so it lets the engine operate at a higher power output range. Figure 62.3 also shows that the alternator is spinning backward whenever the engine is off. When the engine is turned on the alternator is spinning forward. 


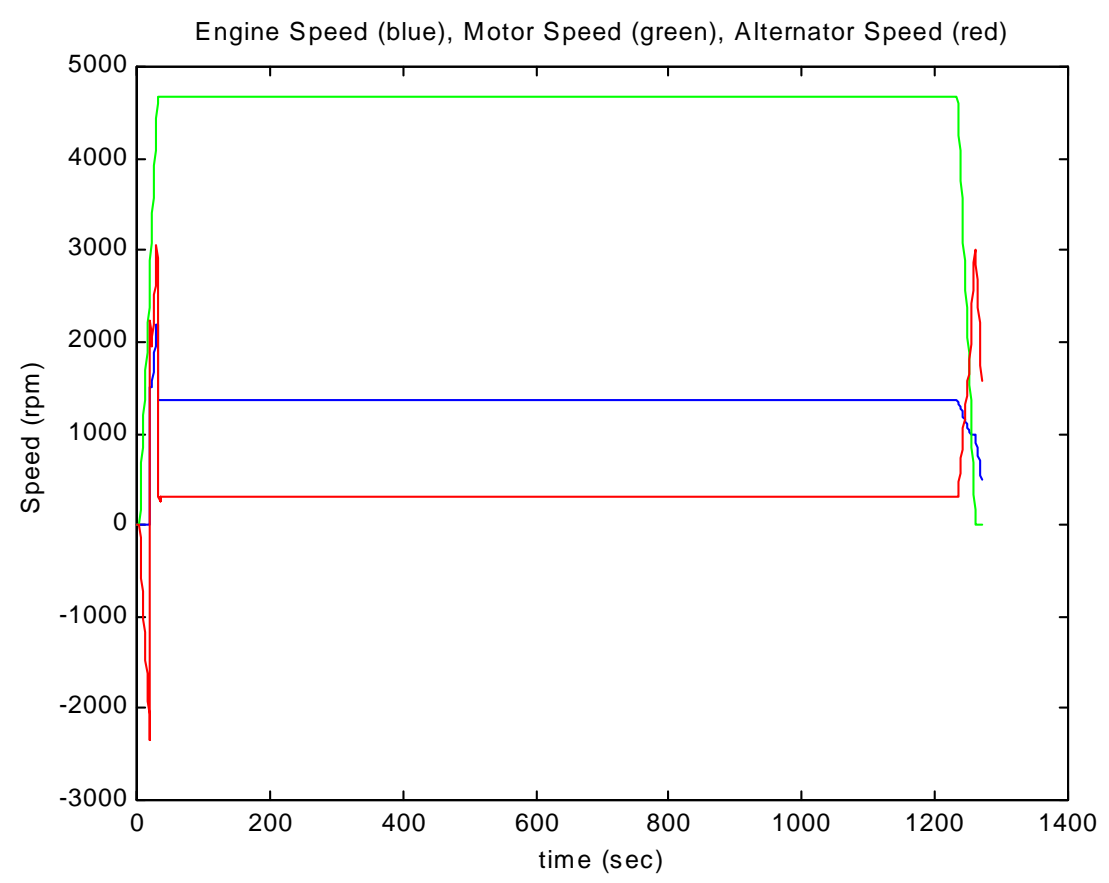

Figure 62.3. Engine speed, motor speed and alternator speed vs. time on a $5 \%$ grade at 55 mph steady speed.

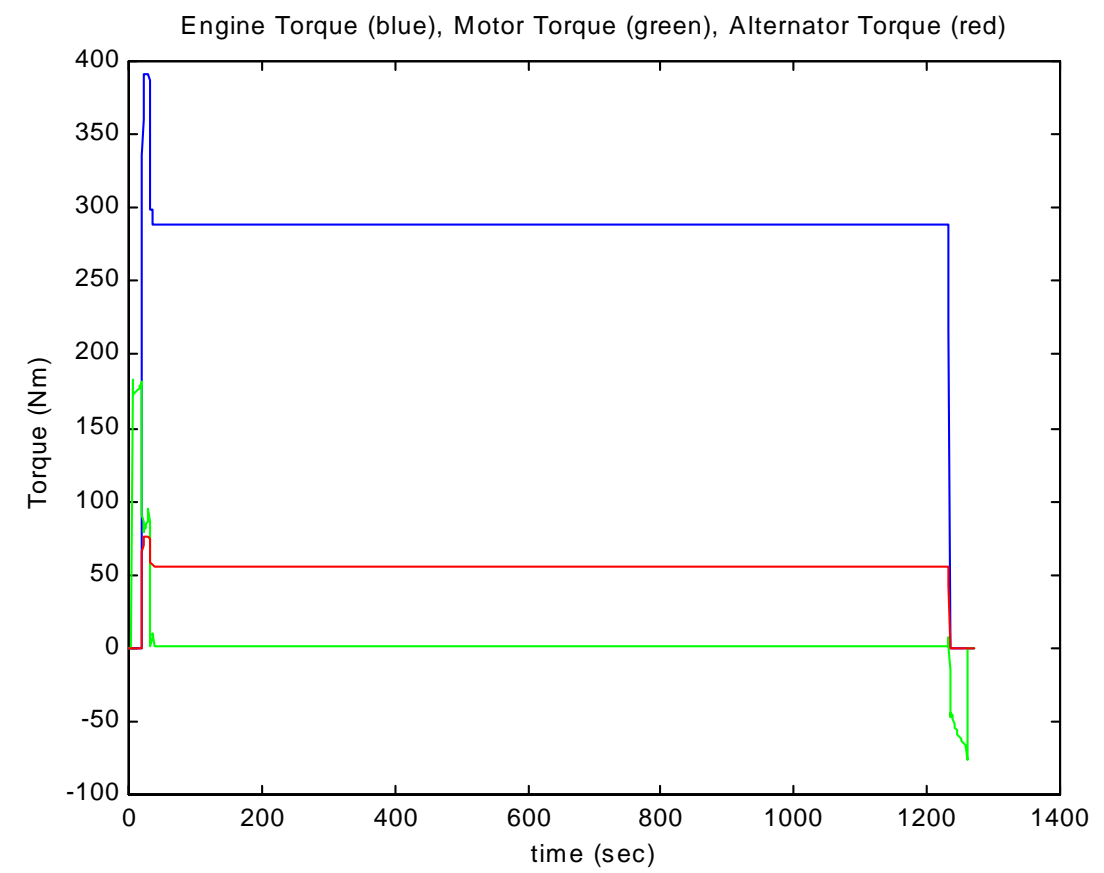

Figure 62.4. Engine torque, motor torque and alternator torque vs. time on a $5 \%$ grade at 55 mph steady speed. 
Figure 62.4 shows the engine torque, motor torque and the alternator torque vs. time. It can be seen that the engine torque is proportional to the alternator torque. At Configuration \# 6 the alternator torque has the same direction as engine torque. Both alternator speed and torque have the same direction so the alternator is producing power, it is providing power to the electrical bus.

Negative torque on the electric motor can be seen only at braking. It shows clearly that the electric motor provides the braking power working as an alternator. It captures the kinetic energy of the vehicle. When the vehicle has reached its cruising speed the electric motor provides very littie torque. That shows that the vehicle uses mainly the engine as a power source but there is some energy transmitted electronically through the alternator and the motor.

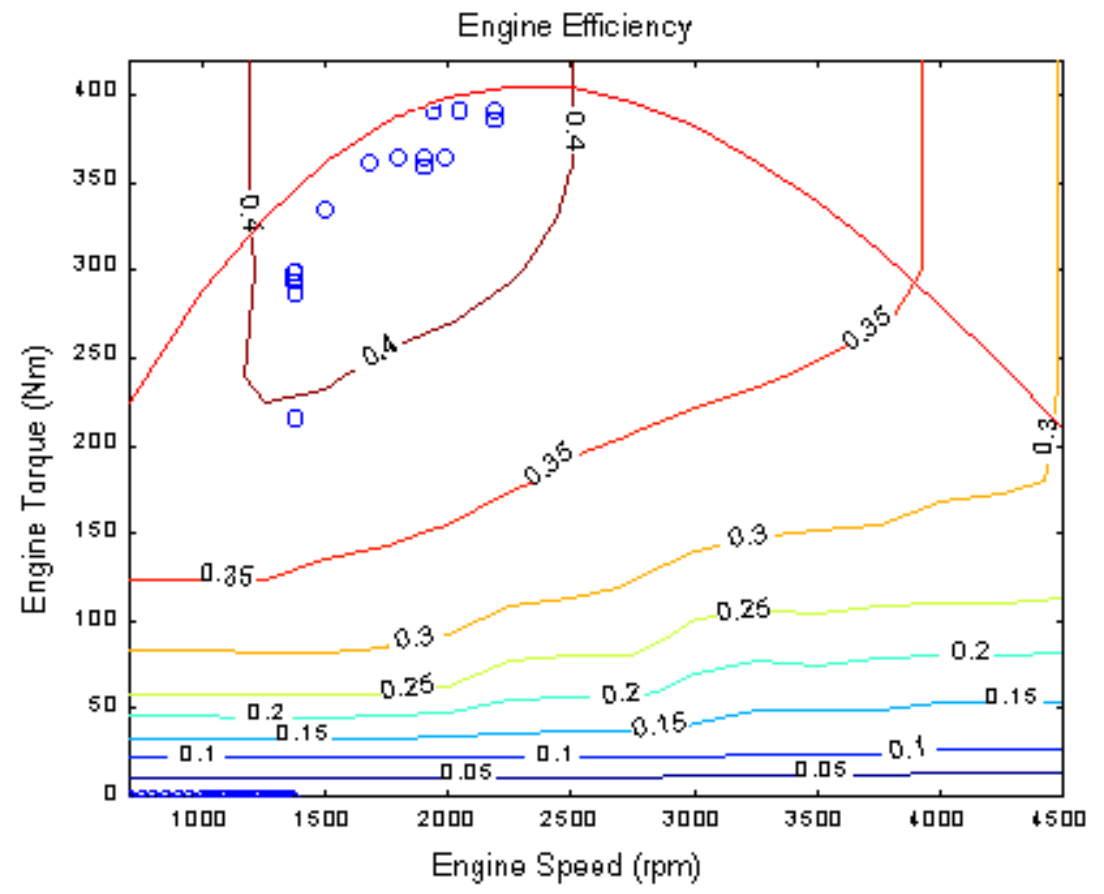

Figure 62.5. Engine efficiency as the function of engine speed and engine torque. 
Figure 62.5 shows the engine efficiency as the function of engine speed and engine torque on a $5 \%$ grade at $55 \mathrm{mph}$ steady speed. It clearly shows that the maximum engine speed is about 1800rpm and the torque is the maximum at that speed. The engine operates at a higher power output to provide enough power for propelling the Suburban on a $5 \%$ grade at $55 \mathrm{mph}$ steady speed. The engine is operating at about $60 \%$ of its maximum power output so it would be able to handle more severe driving conditions.

Figure 62.6 shows the motor efficiency as a function of motor speed and motor torque. The points shown with an o on the plot are positive torque from motoring, points shown with an $\mathrm{x}$ are negative torque from regenerating and the blue color means that the rotational direction is the same as the engine rotational direction. The motor is providing significant torque. It definitely assists the engine in propelling the vehicle.

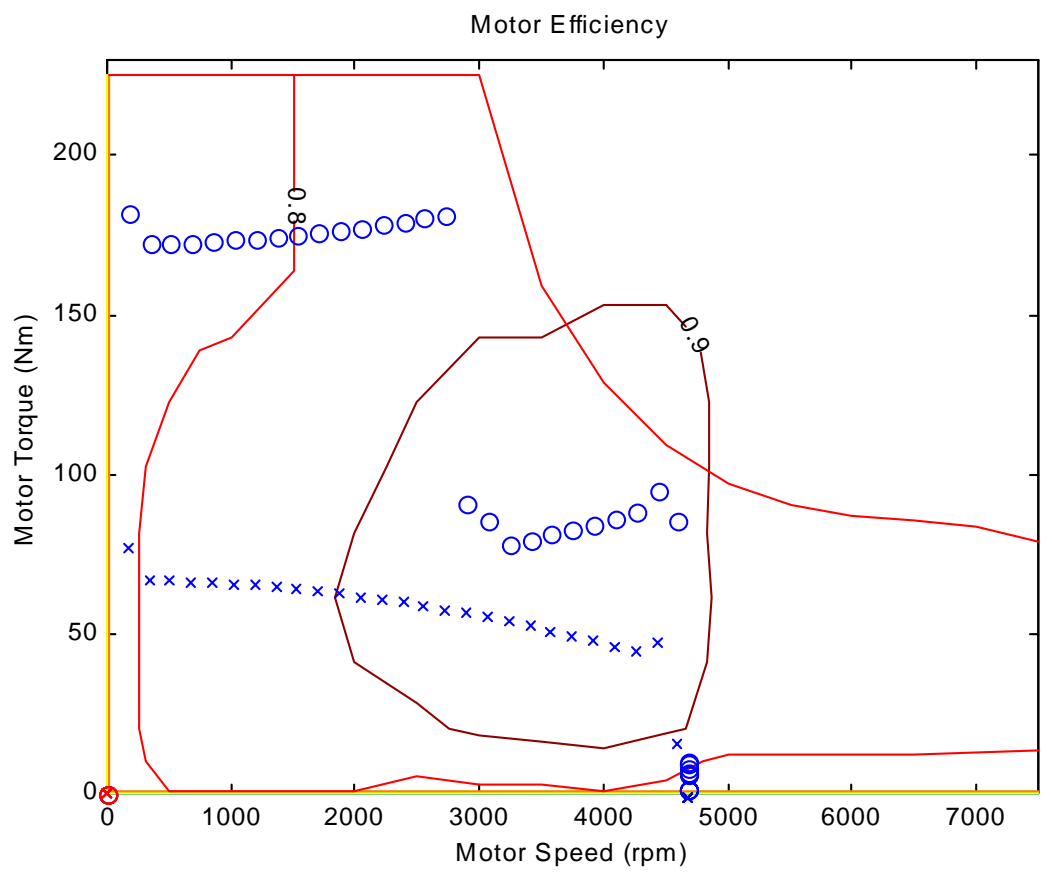

Figure 62.6. Motor efficiency as the function of motor speed and motor torque. 
Figure 62.7 shows the alternator efficiency as the function of alternator speed and alternator torque. The points shown with an $\mathrm{x}$ are defining regenerative torque and the blue color indicates that the rotational direction is the same as the engine rotational direction. Some red circles can be seen but only at zero torque. It happens only when the engine is turned off. It means that when the engine is off the alternator is spinning backward with no load on it acting only as a flywheel. The low torque, low speed operation range clearly shows that the alternator is way oversized for this application too. The alternator mostly operates at around $150 \mathrm{Nm}$ and 3000rpm. This provides the electrical energy consumed by the motor. The vehicle does not use energy from the battery. It is charge sustaining.

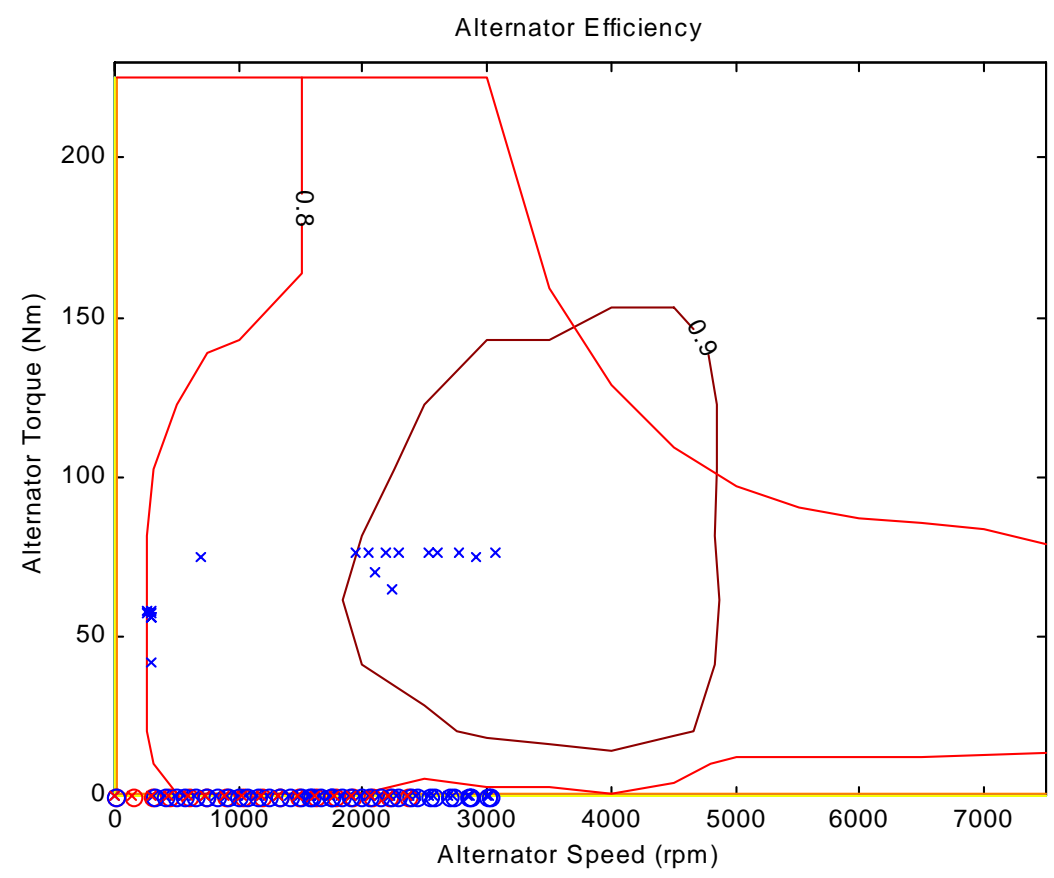

Figure 62.7. Alternator efficiency as the function of alternator speed and alternator torque. 


\section{Discussion of Results}

Computer simulation has been performed on different vehicles. Table 6 summarizes the vehicles simulated with HVSim.

\begin{tabular}{|l|l|l|l|l|l|}
\hline & Conventional & Series HEV & Parallel HEV & PC-Hybrid \#4 & PC-Hybrid \#6 \\
\hline Engine & GM 5.3 V8, & Detroit Diesel & Detroit Diesel & Detroit Diesel & Detroit Diesel \\
gasoline & Corporation 642 & Corporation 642 & Corporation 642 & Corporation 642 \\
\hline Transmission & 5-speed manual & 5-speed manual & 5-speed manual & N/A & N/A \\
& transmission & transmission & transmission & & \\
\hline Gearing ratios & $3.059,1.625,1$, & 3.0831 .833 & 3.0831 .833 & N/A & N/A \\
& 0.696 & 1.2170 .950 .741 & 1.2170 .950 .741 & & \\
\hline Motor & NO & SR218 Unique & SR218 Unique & SR218 Unique & SR218 Unique \\
& & Mobility & Mobility & Mobility & Mobility \\
\hline Alternator & NO & SR218 Unique & NO & SR218 Unique & SR218 Unique \\
& & Mobility & & Mobility & Mobility \\
\hline Diff. ratio & 3.72 & 3.72 & 3.72 & 1.5 & 2.92 \\
\hline
\end{tabular}

\section{Table 6. Vehicle configuration simulated with HVSim.}

The ultimate base of comparison is the fuel economy of the different vehicles. Table 7 shows the fuel economy results for the different setups. 


\begin{tabular}{|l|l|l|l|l|l|}
\hline $\begin{array}{l}\text { Fuel Economy } \\
(\mathrm{mpg})\end{array}$ & Conventional & Series HEV & Parallel HEV & $\begin{array}{l}\text { PC-Hybrid } \\
\# 4\end{array}$ & $\begin{array}{l}\text { PC-Hybrid } \\
\# 6\end{array}$ \\
\hline FTP City & 16.6 & 24.6 & 22.4 & 39.6 & 37.5 \\
\hline Highway FET & 21.8 & 23.7 & 27.6 & 36.2 & 33.52 \\
\hline US06 & 15.1 & 14.7 & 16.1 & 26.4 & 26.2 \\
\hline $\begin{array}{l}\text { \%5 grade } \\
\text { at 55mph }\end{array}$ & 14.1 & $\begin{array}{l}\text { Not capable of } \\
\text { making the } \\
\text { trace }\end{array}$ & 15.52 & 19.1 & 18.7 \\
\hline
\end{tabular}

Table 7. Fuel economy of the different configurations on the FTP city, on the FTP highway and on the US06 cycles. These fuel economy results are not corrected by any EPA factors. 


\section{Conclusion}

The purpose of this study was the detailed examination of the Planetary Combination Hybrid Electric Vehicle design (PC-Hybrid). Different possible design layouts were investigated as possible setups of the PC-Hybrid and the two most promising ones have been chosen for further investigation and simulation. A control strategy has been developed for the optimal operation PC-Hybrid configurations. A computer program was made to simulate the fuel economy of the PC-Hybrid.

The simulated fuel economy results of the PC-Hybrid configurations were compared to the simulated fuel economy results of a conventional vehicle, a series hybrid, and a parallel hybrid. The simulation was performed on the FTP City cycle, on the FTP Highway cycle and on the US06 cycle.

From table 6 it is obvious that the PC-Hybrid Configuration \#4 and PC-Hybrid Configuration \#6 have the best fuel economy of all. The average fuel economy of the configurations is almost equivalent. Both of them are excellent candidates for hybrid electric vehicle application. The only difference between the two configurations is that Configuration \# 4 has high-torque low-speed output while Configuration \#6 has a low-torque high-speed output. Obviously the require different final drive ratio. The one that fits better to present days differentials is Configuration \#6. A power source and transaxle unit like Configuration \#6 could replace the engine and transmission unit in an existing vehicle right away. That is

probably the reason why Toyota has put Configuration \#6 in the Prius. [10] Configuration \# 4 requires lower gearing ratio in the differential. However, in a SUV like the Suburban the combination of the two configurations would eliminate the range shifter providing an almost infinitely variable transmission. 


\section{References}

[1] http://www.arb.ca.gov/homepage.htm (02/16/2000)

[2] http://search.britannica.com $(8 / 8 / 2000)$

[3] http://www.bergen.org/AAST/Projects/Engineering_Graphics/Drill/motor.html $(8 / 8 / 2000)$

[4] http://www.mtwp.k12.pa.us/schools/mtms/7white/524750.html (8/8/2000)

[5] http://www.cybercomm.net/\%7Ejaguarca/students/B11/history.html (8/9/2000)

[6] http://www.hpo.hu/Magyar/ipsz/bendzsel.html\#33 (8/9/2000)

[7] http://www.iea.org/pubs/studies/files/autofue/autofue.htm\#table (8/22/2000)

[8] http://www.nrcan.gc.ca/es/etf/summaries/ghgmana.htm (8/22/2000)

[9] http://www.dieselnet.com (8/22/2000)

[10] Abe, S.; Tojima, K.; Kotani, T.; Shamoto, S.; Ibanaki, R.; Sakai, A. "Development of Toyota Hybrid System”, Toyota Technical Review, 1998

[11] Takaoka, T.; Hirose, K.; Ueda, T.; Nouno, Y.; Tada, H.; Kanai, H. "High-ExpansionRatio Gasoline Engine for the TOYOTA Hybrid System”, Toyota Technical Review, 1998

[12] Hellman, K. H.; Peralta, M. R.; Piotrowski, G. K.; "Evaluation of a Toyota Prius Hybrid System” EPA 420-R-98-006, 1998.

[13] Duoba, M. “Toyota Prius HEV Operation and In-situ Engine Mapping Results”, report at Argonne National Laboratoty, 1998

[14] Duoba, M. “Prius Data Exchange Workshop”, USCAR October 281999

[15] Kellermeyer, W. F. "Development and Validation of a Modular Hybrid Electric Vehicle Simulation Model”, Thesis, West Virginia University, 1998

[16] http://www.futuretruck.org/technical/index.html (08/23/2000) 
[17] http://www.ecomall.com/greenshopping/gm.htm (9/22/2000)

[18] http://www.engin.umd.umich.edu/ ece274nn/ece546/win1999/bstop096/techreport4.html

[19] Mark's Standard Handbook for Mechanical Engineers $9^{\text {th }}$ edition

[20] Consultation with Dr. C. M. Atkinson,

[21] Fleming, F. A.; Shumard, P.; Dickinson, B. "Rapid recharge capability of valve regulated lead acid batteries for EV \& HEV applications" http://hepi.com/papers.htm 9/27/2000.

[22] Schmidt, M. R.; Klemen, D. “One-mode, input-split, parallel, hybrid transmission” United States Patent 5,558,595 September 24, 1996

[23] Schmidt, M. R. "Two-mode, input-split, parallel, hybrid transmission” United States Patent 5,558,588 September 24, 1996

[24] Schmidt, M. R. “Two-mode, compound-split, electro-mechanical vehicular transmission” United States Patent 5,558,589 September 24, 1996

[25] Schmidt, M. R. "Two-mode, split power, electro-mechanical transmission" United States Patent 5,577,973 November 26, 1996

[26] Mabie, H. H.; Reinholtz, C.F. "Mechanisms and dynamics of machinery", John Willey \& Sons, USA, 1987 